\title{
Customer value creation in a natural resource-scarce enviroment: the role of market knowledge in adaptation and sustainability
}

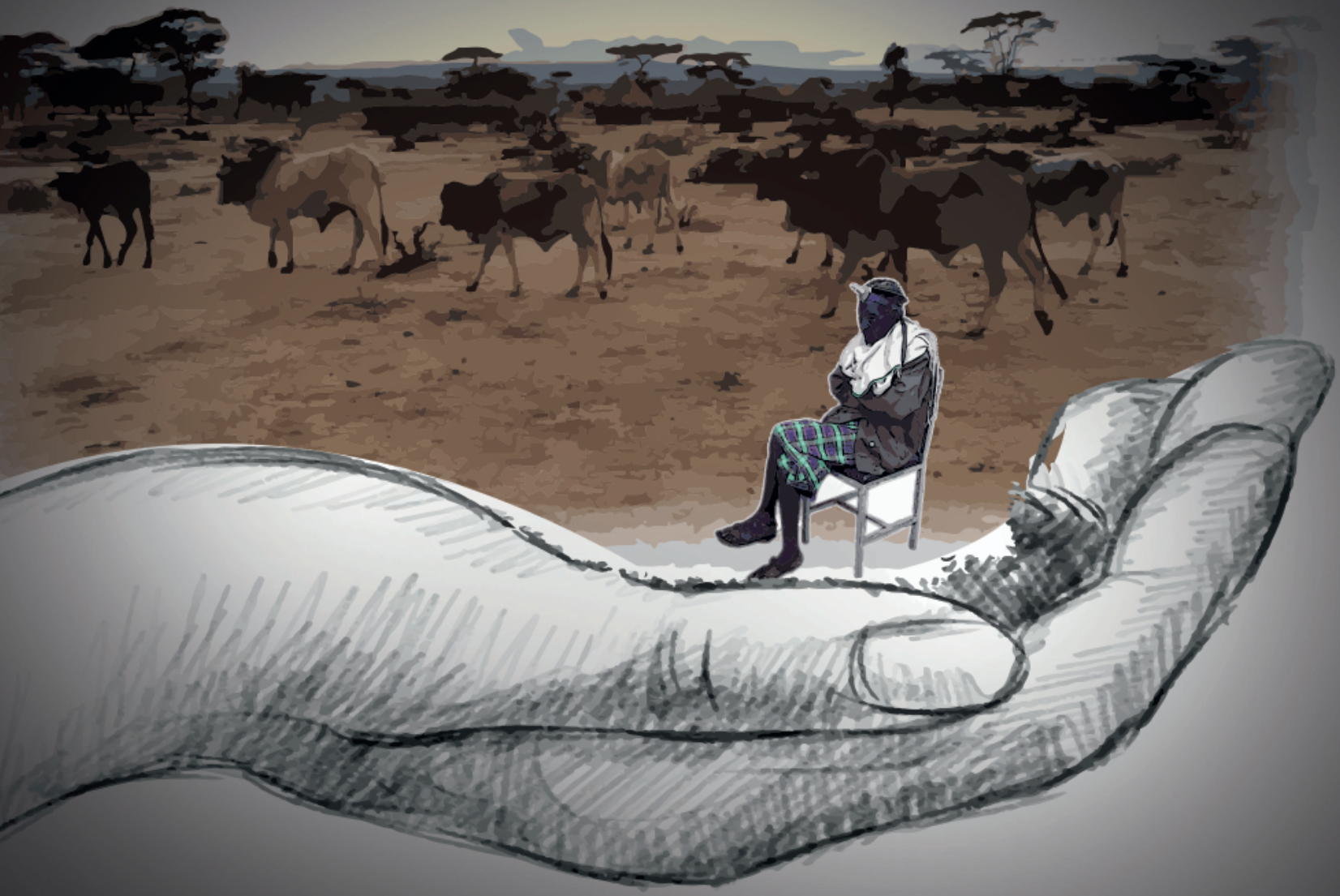




\section{Propositions}

1. Pastoralism is a living lab to learn how to deal with natural resource scarcity.

(this thesis)

2. Inequality in market knowledge drives the unsustainable use of communal resources. (this thesis)

3. Evolutionary theory is an underutilized perspective in the social sciences.

4. Quantitative models are more relevant if they are grounded in qualitative insights.

5. The free market is the biggest enemy to tribal politics.

6. Access to high-quality education is the shortest way to stop discrimination.

Propositions belonging to the thesis, entitled

'Customer value creation in a natural resource-scarce environment: the role of market knowledge in adaptation and sustainability'

Desalegn Amlaku Gugissa

Wageningen, 11 November 2020 

Customer value creation in a natural resource-scarce environment: the role of market knowledge in adaptation and sustainability 


\section{Thesis committee}

\section{Promotors}

Dr P.T.M. Ingenbleek

Associate professor, Marketing and Consumer Behaviour Group

Wageningen University \& Research

Prof. Dr J.C.M. van Trijp

Professor of Marketing and Consumer Behaviour

Wageningen University \& Research

\section{Other members}

Prof. Dr WA Dolfsma, Wageningen University \& Research

Prof. Dr H Van Herk, Vrije Universiteit Amsterdam

Prof. Dr S Burgess, Tshwane University of Technology, Pretoria, South Africa

Dr MM van den Berg, Wageningen University \& Research

This research was conducted under the auspices of the Wageningen School of Social Sciences (WASS). 


\section{Customer value creation in a natural resource-scarce environment:}

\section{the role of market knowledge in adaptation and sustainability}

Desalegn Amlaku Gugissa

\section{Thesis}

submitted in fulfilment of the requirements for the degree of doctor

at Wageningen University

by the authority of the Rector Magnificus,

Prof. Dr A.P.J. Mol, in the presence of the

Thesis Committee appointed by the Academic Board to be defended in public

on Wednesday 11 November 2020

at 11:00 a.m. in the Aula. 


\section{Desalegn Amlaku Gugissa}

Customer value creation in a natural resource-scarce environment: the role of market knowledge in adaptation and sustainability, 230 pages.

PhD thesis, Wageningen University, Wageningen, the Netherlands (2020)

With references, with summary in English

ISBN: 978-94-6395-484-6

DOI: https://doi.org/10.18174/528233 
In memory of

Amlaku Gugissa Mandefero 




\section{Table of Content}

Chapter 1 General introduction 9

Chapter 2 When resource scarcity threatens customer value: Conceptualizing adaptation capabilities from a resource-scarce emerging market context

Chapter 3 Market knowledge as a driver of adaptation capabilities in managing 81 scarcity of natural resources

Chapter 4 When natural resources break down, market knowledge steps in: A panel study in the extreme context of Ethiopian pastoralists

Chapter 5 Market knowledge as a driver of sustainable use of common-pool resources in communities that are integrated with the global market system

Chapter 6 General discussion

References

Summary

Samenvatting

Acknowledgements

About the author 



\section{Chapter 1}

General Introduction 


\subsection{Pressure from natural resource scarcity}

Sustainability is one of the greatest challenges humanity faces in the $21^{\text {st }}$ century (Fay, 2012; UN, 2010). The demand for raw material continues to grow because of unsustainable consumption patterns by high-income countries and the rapid rise of middle-class consumers in developing and emerging economies (Dolan, 2002). At the same time, global climate change is further constraining the supply of natural resources (Dolan, 2002). Natural resources such as minerals, pasture, farming lands, forests, groundwaters, rivers, and fish-stocks are increasingly depleted and becoming scarcer (Hart \& Dowell, 2011; Ostrom, 2008, 2009). Marketing as a science studying the means to satisfy human needs and wants has acquired a notorious reputation for its impacts on natural resources (Achrol \& Kotler, 2012; Kotler, 2011). Marketing is often seen as part of the sustainability problem since it mostly focuses on enlarging consumers' demands and on satisfying those demands, which may lead to the overuse of natural resources (e.g., Kjellberg, 2008; Witkowski, 2005). Marketing has, for example, been accused of stimulating over-consumption, offering assortments in which more items are wasted than used, and triggering competition among firms to offer products at the lowest price even if that doesn't cover the costs related to the renewal of natural resources at the bases of the marketing system (Witkowski, 2005; Wooliscroft \& Ganglmair-Wooliscroft, 2018). Such competition will ultimately increase the overuse of natural resources.

Common-pool natural resources are particularly prone to overuse and potential destruction since nobody owns these resources. Common-pool resource refers to natural or human-made resources whose size or characteristics make it difficult and costly, but not impossible, to exclude potential beneficiaries from obtaining benefits (Ostrom, 2008). Common-pool natural resources include among others shared irrigation systems, river systems, fishing grounds, pastures, or groundwater natural resources that are scarce and to which individuals in a group have no specific claim except 
the right to use them (Kimbrough \& Vostroknutov, 2015; Ostrom, 2008). Each person's use of such resources subtracts benefits that others might enjoy, creating competition over the resources (Ostrom, 2008). Common-pool natural resources are thus both non-excludable and rivalrous, which renders them prone to overuse and potential destruction.

With the increasing scarcity of natural resources, firms need to make drastic changes in their value creation process if sustainability is to be achieved (Kotler, 2011). Firms and their marketers have been operating under the assumption of an endless supply of resources which further worsens the impact of marketing on natural resources (Kotler, 2011). With the increasing pressure for sustainability, there is now a growing recognition that marketing processes and practices have consequences for the environment and particularly when natural resources are used to the point of scarcity, leading to resource depletion (Hart \& Dowell, 2011; Kotler, 2011). The causes of natural resource depletion are mostly attributed to industrial users driven by market demand (e.g., Duffy, Layton, \& Dwyer, 2017; Witkowski, 2005). As a result, marketers are increasingly facing pressure from consumers' awareness and government regulations to be environmentally friendly (Duffy et al., 2017; Fuller, 1999). The growing imbalance of the supply and demand for resources will also inevitably threaten the performance of firms. To position themselves competitively in the resourcescarce world, firms should develop capabilities that help them to deal with the growing threat of resource scarcity (Hult, 2011; Kotler, 2011).

While the marketing literature acknowledges the strategic importance of embracing natural environment imperatives into marketing theories and practices (Hult, 2011; Kotler, 2011), the question of 'how' the issue of natural resource scarcity can be incorporated into firms' value creation processes has not yet been well addressed. The marketing literature on corporate environmentalism (e.g., Banerjee, Iyer, \& Kashyap, 2003; McKenzie-Mohr, Lee, Kotler, \& 
Schultz, 2011) and environmental consumer behavior (e.g., Banerjee et al., 2003; Farmer, Breazeale, Stevens, \& Waites, 2017; Garvey \& Bolton, 2017) has studied how the impacts of value creation on the natural resource can be minimized. These studies, however, primarily focused on addressing 'what went wrong' in resource affluent contexts such as North American and Western European markets. These works thus leave a gap for empirical studies that target contexts where the depletion of natural resources is already directly being experienced. Studying this context is important because businesses in such contexts more likely already apply solutions for natural resource scarcity in their value creation process.

Existing literature provides insights into how firms in resource-affluent contexts can innovate to offer products that are more environmentally friendly and encourage consumers' behavior to be more sustainable (e.g., Banerjee et al., 2003; Garvey \& Bolton, 2017). Much less is known about how businesses in resource-scarce contexts adapt their value creation process to the resource scarcities. This thesis therefore looks at the issue of resource scarcity from the perspective of businesses that operate in resource-scarce contexts. Specifically, it examines how businesses operating in a natural resource-scarce environment adapt their primary business function, which is to create customer value (Slater, 1997; Woodruff, 1997), to actual and predicted natural resource scarcities. The approach allows taking natural resource scarcity issues as a matter of both sustaining natural resources and maintaining business performance, instead of looking at it exclusively from the perspective of businesses' environmentalism. So, the approach provides essential insight that enriches our understanding of the role of marketing in natural resource-scarce settings. 


\subsection{Studying the adaptation of the customer value creation process to natural resource scarcity}

Customer value creation is central to all marketing activities by firms, and meeting or exceeding customer expectations is the main road to a profitable business according to marketing theory (Slater, 1997; Woodruff, 1997). Customer value is generally seen as experiential (Eggert, Ulaga, Frow, \& Payne, 2018; Vargo \& Lusch, 2008), and defined as 'an interactive, relativistic preference and experience of consumers' (Holbrook, 2005, pp. 46). From the perspective of customers, it is what customers want from buying and using a supplier's products and services (J. B. Smith \& Colgate, 2007). In creating customer value, firms decide what products to offer and how to deliver them to customers (J. B. Smith \& Colgate, 2007). These decisions determine what resources to take for making and delivering those products. Both the making and delivering processes have sideeffect environmental costs in the form of resource depletion (Claudy, Peterson, \& Pagell, 2016; Fuller, 1999).

To address such side-effect environmental costs, firms should recognize and internalize the scarcity of resources in their value creation processes (Kotler, 2011). This leads firms to adapt their value creation processes to the changes in the natural environment (Kotler, 2011). Adaptation is 'the decision-making process and the set of actions undertaken to maintain the capacity to deal with current or future predicted changes' (Nelson, Adger, \& Brown, 2007, pp. 396). The adaptation of the customer value creation process to constrained availability of resources is most likely to occur in environments where firms directly experience the pressure from natural resource scarcity. Firms that operate in natural resource-scarce environments may therefore already have adapted their value creation processes and activities to create the capacity to deal with actual and predicted resource scarcities. 
The present thesis aims to draw lessons from pastoralists who raise livestock in arid and semi-arid drylands (Koocheki \& Gliessman, 2005) on how to adapt the customer value creation processes to natural resource scarcity. Pastoralists constitute a very appropriate context to study this since they inhabit a complex ecological system that demands a continuous balance between livestock population and natural resources (Koocheki \& Gliessman, 2005; Tessema, Ingenbleek, \& Van Trijp, 2014). Their context is prone to natural resource scarcity due to arid and semi-arid climatic conditions (FAO, 2001). Research has, however, shown that pastoralists have resilient ways of utilizing natural resources in a fragile environment (e.g., Fratkin \& Mearns, 2003; Tessema et al., 2014). The thesis uses the natural resource-scarce context of pastoralists in Ethiopia to examine how the customer value creation processes can be adapted to the scarcity of natural resources.

\subsection{Ethiopian pastoralists}

Ethiopia has a pastoral population of over 12 million, which is the highest pastoral population in East Africa (World Bank, 2013). This thesis primarily focuses on Borana pastoralists in southern Ethiopia. Borana pastoralists have strong traditional institutions that enable them to sustainably manage common-pool natural resources (e.g., Homann, Rischkowsky, Steinbach, Kirk, \& Mathias, 2008). They are also increasingly integrating into local and international live animal and meat supply chains (Catley, Lind, \& Scoones, 2013). The Borana pastoralist community represents an important source of livestock to the live animal traders and meat value chain actors that operate in both local and export markets in the country (Barrett, 2008; Catley et al., 2013). Yet, because of the arid climatic condition of the region, natural resource scarcity remains the main challenge for the pastoralists to produce livestock that satisfies the needs of the market (Gomes, 2006; Luseno, McPeak, Barrett, Little, \& Gebru, 2003). 
For many generations, Borana pastoralists have been leading a traditional lifestyle and way of livestock production (Coppock, Desta, Gebru, \& Tezera, 2005). The traditional pastoralism is mostly a subsistence-oriented livestock herding system. Natural resources, primarily pasture and water, are fundamental to the livelihood system (Gomes, 2006; Luseno et al., 2003). These resources are, however, seasonally variable and often scarce (Gebremeskel, Desta, \& Kassa, 2019; Luseno et al., 2003). In effect, the traditional pastoralism primarily focused on sustaining the livestock-based livelihood by maintaining the local ecological balance between the availability of natural resources and livestock population. The pastoralists rely on their traditional natural resource adaptation practices that are deeply ingrained in their cultural fabrics: traditional institutions, values, and norms (Gomes, 2006; Nyong, Adesina, \& Osman Elasha, 2007). Studies show that traditional pastoralism is adaptive to a natural resource-scarce environment (e.g., FernándezGiménez \& Fillat Estaque, 2012; Tessema et al., 2014).

During the last few decades, however, a fundamental change has been taking place in the traditional pastoral system; the pastoralists are increasingly integrating into local and international supply chains (Catley et al., 2013; Tessema, Ingenbleek, \& van Trijp, 2019). As a result, the pastoralists start to breed and fatten livestock for markets such that they meet the needs of live animal traders and their own needs for food. However, producing livestock for markets might require them to pursue a fundamentally different way of using natural resources, namely, to create value for customers and make profits, which is completely different from what they used to in the traditional pastoralism. Recent studies (e.g., Tessema et al., 2019) show that pastoralism is increasingly becoming and seen as livestock breeding and fattening business. Like any other business, knowledge about the needs of customers and competing offerings is strategically important for the pastoralists to competitively create and deliver market offerings that satisfy the requirements of 
their target customers (Ingenbleek, Tessema, \& van Trijp, 2013; Teklehaimanot, Ingenbleek, Tessema, \& van Trijp, 2017). With increasing market integration, the pastoralists are also accumulating knowledge about the needs of customers and competing offerings (Teklehaimanot et al., 2017; Tessema et al., 2019). Hence, with market integration, they most likely combine two types of knowledge: the traditional ecological knowledge about adaptation to natural resource scarcity and the market knowledge about the needs and requirements of markets.

This thesis aims to draw lessons from pastoralists on how they adapt their customer value creation process to natural resource scarcities. When pastoralists are confronted with natural resource scarcity for breeding and fattening livestock in ways to meet the needs of their buyers, they might use their traditional ecological knowledge to adapt their market-based livestock breeding and fattening practices. This will provide insights into how they leverage their traditional natural resource adaptations in their customer value creation process, namely breeding and fattening livestock to satisfy the requirements of markets.

\subsection{Approach, aim and research questions}

The thesis takes a strategic marketing approach to investigate how businesses adapt their customer value creation process to natural resource scarcity (Varadarajan, 2010). Adaptation to natural resource scarcity requires businesses, among others, to make changes on their value propositions to customers, production methods and processes for resource efficiency, and engagement of stakeholders to find solutions to resource scarcity. By undertaking the adaptation actions, businesses have decided to align their processes of satisfying the needs of customers with that of the changes in the natural environments, which enables them to maintain and build new competitive advantages in a changing environment. Decisions that influence businesses' competitive advantages in a changing environment are central to strategic marketing (Varadarajan, 2010). The 
strategic marketing approach will thus contribute by guiding the focus on adaptation actions that enable businesses to maintain competitive advantages in natural resource-scarce conditions.

The overall aim of this thesis is to draw lessons from pastoralists on how they manage to adapt their customer value creation process to a natural resource-scarce environment. To achieve this aim, the thesis is designed around four research questions. First, how do pastoralists adapt the customer value creation process to the scarcity of natural resources? To answer the question, the thesis builds on the literatures on customer value creation, which considers market knowledge as a strategically important resource for the integration of resources to create customer value (Marinova, 2004; Slater, Olson, \& Eibe Sørensen, 2012), and on strategic marketing, which argues that maintaining competitive advantage in changing environment is essential for businesses' success (Varadarajan, 2010). By taking the context of the pastoralists, the thesis examines how the pastoralists combine their traditional knowledge about the natural environment with their market knowledge in order to maintain their customer value creation during natural resource-scarce times. The thesis then identifies and conceptualizes natural resource adaptation capabilities that help to adapt the customer value creation process to the scarcity of natural resources.

Second, the thesis answers the question how do natural resource adaptation capabilities of pastoralists influence customer value creation in a resource-scarce environment? The thesis empirically tests the role of natural resource adaptation capabilities in maintaining product quality for customers using a cross-sectional dataset collected from pastoralists during a natural resourcescarce time. The thesis draws insights into the role of market knowledge in leveraging adaptation capabilities in the customer value creation processes and into the mediation effects of the capabilities on the effect of market knowledge on product quality and quality of life. 
Third, the thesis answers the question of how does the level of natural resource scarcity, that pastoralists experience, influence the contributions of adaptation capabilities and market knowledge to maintain the customer value creation during resource-scarce times? In a resource dynamic environment, the role of natural resource adaptation capabilities might depend on the resource availability conditions (Sirmon, Hitt, \& Ireland, 2007). To test this, the thesis builds on our unique access to three movements panel data collected across relatively distinct natural resource availability conditions of pastoralists. The thesis then provides insights into the moderation effect of natural resource scarcity on the performance contributions of natural resource deployment capability that directly relates to the ability to make efficient and effective use of available natural resources.

Fourth, the thesis answers the question of whether market knowledge contributes to the sustainable use of natural resources? In doing so, the thesis uses a common-pool resource dilemma experiment (Prediger, Vollan, \& Frolich, 2011) to examine how market knowledge influences cooperation to the sustainable use of common-pool natural resources in the context of pastoralists. Answering the question tests whether market knowledge and natural environmental knowledge complement each other, indicating whether market knowledge also enables the pastoralists to sustainably use natural resources (as the case with the natural environmental knowledge). The answer also provides insight into the consequences of a customer-focused value creation process on the sustainable use of natural resources.

\subsection{Structure of the thesis}

The thesis consists of six chapters (see Figure 1.1) that are organized around the four research questions. Chapter 2 entitled "When resource scarcity threatens customer value: Conceptualizing adaptation capabilities from a resource-scarce emerging market context" conceptualizes natural 
resource adaptation capabilities that enable firms to adapt the customer value creation process to natural resource scarcity. Based on in-depth qualitative interviews, observations, and focus-group discussions about how the pastoralists adapt their livestock breeding and fattening practices to the scarcity of natural resources, the chapter conceptualizes three general capabilities that help to adapt the customer value creation to natural resource scarcity. The three natural resource adaptation capabilities are matching value propositions, natural resource deployment, and managing customer expectation capabilities that intervene sequentially at the value defining, developing, and delivering stages of the customer value creation process, respectively. The chapter also illustrates that knowledge on the natural environment helps the pastoralists to develop the adaptation capabilities and that the deployment of the capabilities in the customer value creation process is fostered by market knowledge. Then, the learning is integrated and synergized into a conceptual framework that will guide the subsequent quantitative chapters, which aim to empirically test propositions on the antecedents and consequences of natural resource adaptation capabilities.

Chapter 3 entitled "Market knowledge as a driver of adaptation capabilities in managing scarcity of natural resources" builds on the results from the previous chapter by empirically testing the propositions drawn from the conceptual framework. Based on the insights provided in Chapter 2, the chapter proposes and tests the mediating effects of natural resource adaptation capabilities on the relation between market knowledge and two outcomes of the customer value creation process in the context of pastoralists, namely, product quality and quality of life. Chapter 3 provides insights into the mediating role of natural resource adaptation capabilities in the impact of market knowledge on the outcomes of the customer value creation process.

Chapter 4 entitled "When natural resources break down, market knowledge steps in: A panel study in the extreme context of Ethiopian pastoralists" tests how the level of scarcity for natural resources 
influences the effect of natural resource adaptation capability on performance. Using three- waves of longitudinal data from 120 pastoralists, the chapter demonstrates that the pastoralists' ability to minimize the decrease in product quality during resource-scarce times through natural resource deployment depends on their level of market knowledge. It shows that market knowledge enables them to add more value to customers when resources are relatively more constrained rather than abundant. The results in Chapter 3 and Chapter 4 show that the pastoralists created higher customer value during natural resource-scarce time by leveraging natural resource adaptation capabilities. However, the higher customer value creation during resource-scarce time might come at the cost of natural resources, through overexploiting the available natural resources. This thus paves the way for further research in Chapter 5.

Chapter 5 entitled "Market knowledge as a driver of sustainable use of common-pool resources in communities that are integrated with the global market system" examines the effect of market knowledge on decisions concerning cooperation to the sustainable use of common-pool natural resources. It addresses both the positive and negative aspects of market knowledge on the sustainable management of common-pool natural resources. It shows that higher market knowledge among common-pool natural resource users is important to protect the natural resource from depletion, whereas within-group variance in market knowledge harms the sustainability of the resources.

Chapter 6 entitled "General conclusion and implications" draws conclusions and implications from the main findings and the implication of the previous chapters for the literature, businesses and policymakers. The chapter ends with discussing the limitations of the thesis and directions for future research. Figure 1.1. provides an outline of the chapters and their interrelationships. 


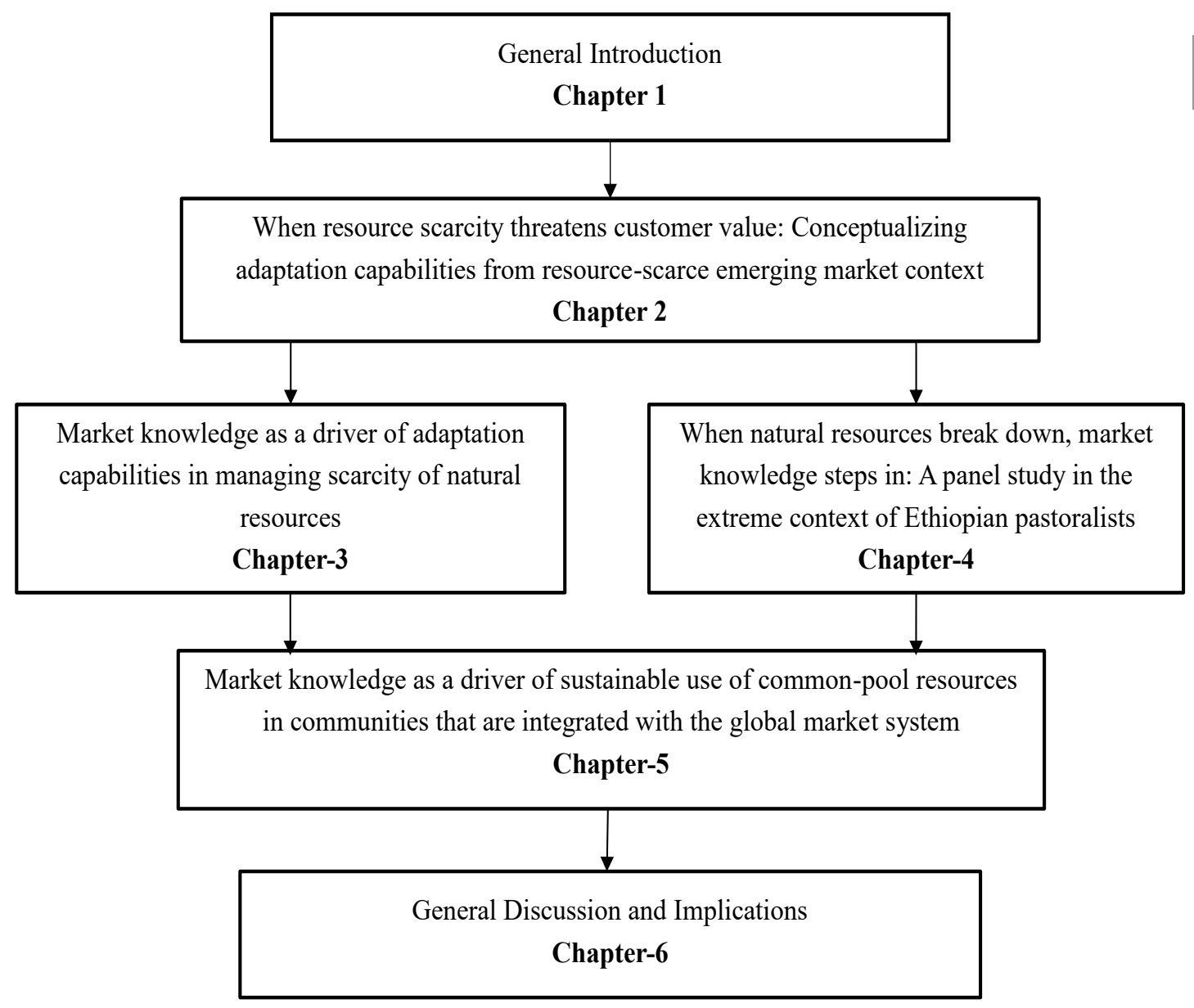

Figure 1.1: Thesis outline 



\section{Chapter 2}

\section{When resource scarcity threatens customer value: Conceptualizing adaptation capabilities from a resource-scarce emerging market context}

This chapter is to be submitted for publication as Desalegn A. Gugissa, Paul T.M. Ingenbleek \& Hans van Trijp. When resource scarcity threatens customer value: conceptualization adaptation capabilities from a resource-scarce emerging market context 


\begin{abstract}
The increasing scarcity of natural resources is transforming marketing into a balancing act between customer expectations and the low availability of crucial resources. The inevitable adaptation of value-creation processes in such situations has yet to be the subject of academic inquiry. This study conceptualizes adaptation capabilities through which businesses adjust their processes of creating customer value to account for the scarcity of natural resources. Our insights are developed based on informed grounded theory methods within the context of an emerging market characterized by a high level of resource scarcity: family-based pastoral businesses in southern Ethiopia. The study identifies three general adaptation capabilities that intervene at subsequent stages in the process of creating customer value: matching value propositions (adjusting the value propositions based on the risk of resource scarcity), deploying natural resources (making efficient and effective use of available resources) and managing customer expectations (interacting with customers to change value expectations). The findings offer concrete guidance for redesigning marketing into a balanced process in which businesses learn not only from markets but also from the natural environment about actual and anticipated resource scarcities.
\end{abstract}

Keywords: Market knowledge, adaptation capabilities, matching value propositions, natural resource deployment, managing customer expectations, customer value creation 


\subsection{Introduction}

Natural resources (e.g., minerals, groundwater, farming land, forests, and fish stocks) are becoming increasingly scarce (Hart \& Dowell, 2011; Ostrom, 2009). For example, in the United States, the scarcity of rare earth elements needed for high-tech defense systems is a key concern for the industry, and the US Congress regards it as a threat to national security (Grasso, 2013). The increasing scarcity of natural resources also affects companies, which are suddenly being confronted with the need to arrive at a balance between the demands of customers and the scarce resources needed to satisfy their demands (Beermann, 2011; Field, Barros, Stocker, \& Dahe, 2012). To maintain performance, these companies should strategically develop the ability to adapt their operations (cf., Kotler, 2011). Some companies (e.g., GE) try to avoid the use of scarce natural resources, such as rhenium (Bell, Mollenkopf, \& Stolze, 2013). Others have started to secure access to scarce resources by strengthening stakeholder relations (Moyo, 2012) or by building closed-loop supply chains (Bell et al., 2013).

The existing marketing literature tends to see resource availability as a matter of long-term sustainability (Kotler, 2011; Little, Lee, \& Nair, 2019; Varadarajan, 2014), rather than as an immediate or potential threat to operations. This is logical, given that resource scarcity-and actions aimed at adapting to it — do not become visible (and are therefore not easily studied) in the resource-affluent environments that have traditionally characterized the marketing literature. Because adaptation to resource scarcity requires creative solutions, studies on innovation have indeed argued that resource scarcity triggers product innovation (e.g., Cunha, Rego, Oliveira, Rosado, \& Habib, 2014; Troilo, De Luca, \& Atuahene-Gima, 2014). Extending this line of thinking further, Radjou, Prabhu, and Ahuja (2012) examine resource-scarce contexts in emerging markets to derive valuable lessons for innovation, which can also be implemented in contexts that are still 
resource-rich. Taken together, these studies have addressed the "positive" side of resource scarcity, while largely ignoring the more pressing issue of how businesses can adapt their processes of creating customer value in order to minimize the impact of scarcity on value creation for customers.

In light of the issues outlined above, the purpose of this article is to explore how businesses confronted with resource scarcity adapt their processes of customer value creation in order to maintain value standards for customers, thereby attempting to secure their market performance. More specifically, this study uses informed grounded theory (Thornberg, 2012) to conceptualize adaptation capabilities for adjusting the process of creating customer value to conditions of resource scarcity. Because such adaptation actions are difficult (if not impossible) to recognize within the resource-affluent context in which the strategic marketing literature is rooted (cf. Burgess \& Steenkamp, 2006; Sheth, 2011), this study focuses on the context of pastoralists in Ethiopia. Pastoralists earn their living by raising livestock in an arid environment, which is often characterized by scarcity of natural resources, pasture and water-all of which are necessary to sustain their livestock production (Lee, Neves, Wiebe, Lipper, \& Zurek, 2009). Ethiopian pastoralists have developed a wide variety of adaptation actions in order to cope with this perpetual scarcity of resources, (Homann et al., 2008). Although these adaptation actions have been studied for decades in various disciplines, including ecology (e.g., Davies, 2008), anthropology (e.g., Galvin, 2009), and economics (e.g., Barrett \& Carter, 2010), they have yet to be investigated by marketing researchers.

With this study, we make at least two contributions to the existing literature. First, we use the context to identify three generic adaptation capabilities that apply to the value-defining, developing, and delivering stages of the customer-value creation process. These capabilities provide insight into the options that are available to companies for adapting to resource scarcity. 
Second, our study draws on qualitative evidence to propose a conceptual framework with empirically testable propositions concerning the antecedents and consequences of the adaptation capabilities. We demonstrate that businesses develop adaptation capabilities by integrating the risks of resource scarcity into the process of creating customer value. We then provide evidence to suggest that marketing must be seen as a learning process, not only about markets (Cayla \& Arnould, 2013; Day, 2002), but also about the environment of natural resources (Kotler, 2011).

The remainder of this article begins with a conceptual background on the process of creating customer value and on adaptation actions for addressing resource scarcity. This is followed by a description of the case-study context of Ethiopian Borana pastoralists, along with a presentation of the methods used in the study. After presenting the results and conceptualization of the adaptation capabilities that pastoralists use to adapt the process of creating customer value to conditions of resource scarcity, we state our conclusions and make concrete suggestions for future research.

\subsection{Customer-value creation}

The strategic marketing literature is primarily concerned with the ways in which companies create value for customers and subsequently appropriate that value (cf., Mizik \& Jacobson, 2003; Varadarajan, 2010). Customer value is generally seen as experiential (Eggert et al., 2018; Vargo \& Lusch, 2008), and it has been defined as "an interactive, relativistic, preference and experience" of consumers (Holbrook, 2005, pp. 46). From the perspective of customers, value consists of what customers seek to gain by buying and using a supplier's products and services (J. B. Smith \& Colgate, 2007).

Drawing on the resource-based view of the firm, the marketing literature regards the process of creating customer value broadly, in terms of capabilities (e.g., Day, 1994; A. Morgan, Feng, \& 
Whitler, 2018; Nenonen, Storbacka, \& Windahl, 2019). Capabilities are complex bundles of skills and knowledge, which are exercised through organizational processes that ensure the superior coordination of functional activities (Day, 1994; Sanchez \& Heene, 1997). They create value by acting upon other resources, including natural resources (Madhavaram \& Hunt, 2008; Vargo \& Lusch, 2008).

One popular conceptualization of the process of creating customer value is developed by Webster (2002), who envisions value creation as three sequential sub-processes: value-defining, valuedeveloping, and value-delivering (Kotler \& Keller, 2012; Webster, 2002) (see Figure 2.1.). The value-defining process guides businesses to develop an outside-in perspective: sensing and scanning the market to define target markets and their value needs (Day, 2011; Kotler \& Keller, 2012). In the next process, value-developing, the value needs of the target customers are translated into offerings by procuring and assembling inputs. In the final process, offerings are delivered to the target customers, which leads customers to experience the value in their own contexts, where it is integrated with other resources (Payne, Storbacka, \& Frow, 2008). This could subsequently lead to customer satisfaction and loyalty (Kotler \& Keller, 2012; Webster, 2002). The three-stage process of creating customer value reflects generic marketing functions that describe how companies pursue competitive advantage through superior customer-value creation (Kotler \& Keller, 2012). The present contribution builds on this model to explain and analyze adaptation actions that companies undertake in order to adapt their marketing processes and practices to the scarcity of natural resources. 


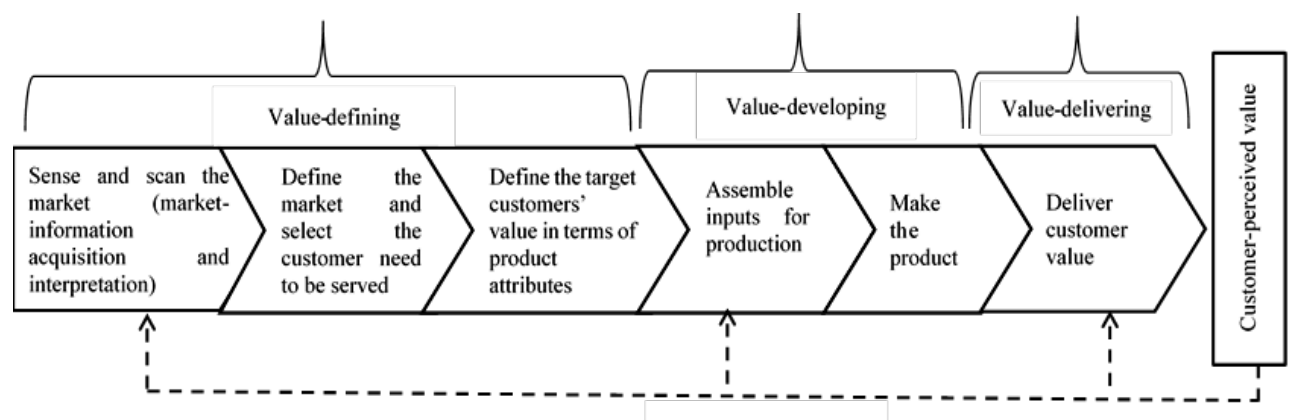

Feedback

Figure 2.1. The process of creating customer value (based on Kotler \& Keller, 2012; Webster, 2002)

\subsection{Adapting the process of customer value to conditions of natural-resource scarcity}

To create customer value, companies integrate resources of various types. The literature generally holds that companies make use of both tangible and intangible resources in the process of creating customer value (Kotler \& Keller, 2012; Vargo \& Lusch, 2004, 2008). Intangible resources (e.g., skills and knowledge) are difficult to imitate, and they therefore provide a stronger basis for obtaining competitive advantages (Vargo \& Lusch, 2004, 2008). For this reason, the literature places considerable emphasis on intangible resources. Physical resources, and particularly natural resources, have received far less scholarly attention. Natural resources are the biophysical foundations for all forms of value creation by companies. According to Kotler (2011), companies and marketing scholars have been operating under the assumption of an infinite availability of natural resources. The current wave of attention to sustainable development, however, has been accompanied by a growing recognition that many of the natural resources that are currently available are likely to become scarce (Hult, 2011; Kotler, 2011). The causes of natural-resource depletion are largely attributed to industrial users driven by market demand (e.g., Duffy et al., 2017; Witkowski, 2005). As a result, the depletion of natural resources is often regarded as an ancillary environmental cost of marketing that, in practice, largely focuses on enlarging and satisfying the 
needs and wants of customers, rather than on reducing environmental effects (Kjellberg, 2008; Kotler, 2011; Witkowski, 2005).

Because raw materials, water, clean air, and other natural resources play a fundamental (but often unrecognized) role in the creation of customer value, the scarcity of such resources has far-reaching consequences for the value-creation process (Kjellberg, 2008; Kotler, 2011; Witkowski, 2005) and, accordingly, for consumption and the affluent lifestyle to which consumers have become accustomed. Natural-resource scarcity can arise either because resource holders are no longer willing to provide access to the resources that they control (Maignan \& Ferrell, 2004), or because the resources have become depleted (Hart \& Dowell, 2011). Such depletion can be either permanent or temporary, as in the case of seasonality in renewable resources or cyclical ecosystems (Bell et al., 2013).

Given the consequences of resource scarcity for value creation, companies are likely to feel pressure to respond. Resource-dependency theory suggests that, in such situations, managers tend to strengthen the relationships with the stakeholders who control the resources (Maignan \& Ferrell, 2004; Pfeffer \& Salancik, 2003). This approach ignores the possibility that natural resources can become depleted, thereby becoming scarce for all users. In such situations, such advice could be expected to lead to a race for control over the final resources that are left (Bell et al., 2013; Ostrom, 2009). At a more fundamental level, the evolutionary approach suggests that companies should adapt to actual or potential changes in environmental circumstances (Smit, Burton, Klein, \& Wandel, 2000). Adaptation has been defined as "the decision-making process and the set of actions undertaken to maintain the capacity to deal with current or future predicted changes" (Nelson et al., 2007, pp. 396). Adaptation theories conceptualize adaptation as "actions," in order to provide a structure for analyzing the actual or proposed adaptations of specific actors (Eisenack \& Stecker, 
2012). Adaptation thus occurs through adjustment actions undertaken to create the capacity to deal with actual or expected changes in the environment (Nelson et al., 2007).

The marketing and strategic management literatures suggest that companies adapt to changing conditions through dynamic capabilities (e.g., Danneels, 2016; Day, 2011): the abilities to integrate, build, and reconfigure internal and external competences to adapt to changes in the environment (Helfat \& Winter, 2011; Teece, Pisano, \& Shuen, 1997). Dynamic capabilities thus enable businesses to make changes in their value-creation processes. First-order dynamic capabilities enable businesses to make changes in their routines and processes in response to changes in the environment (Schilke, 2014), whereas second-order dynamic capabilities enable them to create or add new first-order dynamic capabilities (Danneels, 2016; Schilke, 2014). Because environments can also be relatively stable for some time, these dynamic capabilities may lay dormant, being triggered only as businesses encounter changes within the business environment (Danneels, 2016), as in the case of approaching natural-resource scarcity (Varadarajan, 2014, 2017). Examples include the ability to build more flexibility in resource access by searching for alternative resources and creating closed-loop systems to recover used resources (Bell et al., 2013; Gonzalez, Koh, \& Leung, 2019).

Briefly stated, to respond to natural-resource scarcity, companies are likely to make adaptations that can be seen as dynamic capabilities that adjust the process of creating customer value to the changing realities. Deeper insight into these capabilities could identify the specific capabilities that could be used to intervene in the various stages of the value-creation process. This could help firms to decide which capabilities they should develop in anticipation of natural-resource scarcity. In this study, therefore, we identify concrete adaptation actions taken by family-based pastoralist 
businesses in response to natural-resource scarcity. We further explore how these adaptation actions relate to the process of creating customer value within the context of dynamic capabilities.

\subsection{Methods}

\subsubsection{Research strategy and context}

We conducted a qualitative study involving Ethiopian pastoralists based on the informed grounded theory method (Thornberg, 2012) - also known as the constructivist grounded theory method (Kenny \& Fourie, 2015). Glaser and Strauss (1967) originally developed their grounded theory as a way to keep researchers as free and open as possible to use data inductively to identify categories, concepts, and interrelationships. The approach delays the literature review until the end of the study. Although this allows researchers to avoid contaminating the investigation with pre-existing concepts, it limits them to conduct studies within their own areas of expertise (Kenny \& Fourie, 2015; Thornberg, 2012). Informed grounded theory takes an intermediate approach by allowing researchers to use pre-existing concepts, theories, and ideas as heuristic tools or lenses to focus their attention on specific phenomena (Thornberg, 2012). We use the method to categorize the adaptation actions observed along the stages of the processes used by the pastoralists to create customer value.

We conducted the qualitative study among family-based businesses of Borana pastoralists in southern Ethiopia. Borana pastoralists make their living by herding camels, cattle, goats, and sheep on commonly held natural grazing rangelands under arid climatic conditions (Gemedo-Dalle, Isselstein, \& Maass, 2006). The region is an important source of livestock for the live-animal traders and actors within the meat value chain operating in the country's local and export markets (Barrett, 2008; Barrett et al., 2004). Because of the region's arid climatic conditions, however, natural-resource scarcity remains the main challenge faced by the pastoralists in their efforts to 
produce livestock that will satisfy the requirements of markets (Luseno et al., 2003). The region's natural-resource conditions are further deteriorating due to population growth and global climate change (Thornton, van de Steeg, Notenbaert, \& Herrero, 2009). For Borana pastoralists, therefore, the creation of value for customers typically entails balancing customer expectations and resource availability. This context is thus particularly suitable for our study.

\subsubsection{Data Collection and Respondent Selection}

This study is based on both secondary and primary data. Secondary data include literature on Borana pastoralists from disciplines including ecology (e.g., Gemedo-Dalle et al., 2006), anthropology (e.g., Galvin, 2009), environmental management (e.g., Solomon, Snyman, \& Smit, 2007), economics (e.g., Barrett et al., 2004), and development (e.g., Kamara, Swallow, \& Kirk, 2004) that offers insight into the value-creation process and adaptation actions. We also examined reports published by research institutes, including the International Livestock Research Institute (ILRI) and the International Institute for Sustainable Development (IISD), as well as policy documents. Archived interview data from previous works by the co-authors in a related line of research in the same setting were also consulted in this study.

Primary data include in-depth qualitative interviews, observations, and focus-group discussions. Fifty interviews were conducted with individual pastoralists. After these interviews, a saturation point was reached, at which additional data did not generate any new emergent concepts (Saunders et al., 2018). All of the pastoralists who were interviewed were men and the heads of their respective households. In the study area, livestock production and marketing decisions are made at the household level, with the head of household bearing primary responsibility for such decisions (cf., Ingenbleek et al., 2013). The pastoralists were selected from six different administrative villages in the region. Three experts from the agriculture and pastoral development office of the 
region were consulted in the selection process. The villages were selected with the intent to capture variations in terms of distance from main roads and market centers. We then worked through the Development Agents (DAs) in each village to select respondents to reflect diversity in terms of socio-demographic situations (Eisenhardt \& Graebner, 2007; Yin, 2013). During the fieldwork, observations were also recorded in notebooks to help to triangulate the evidence and develop new emergent questions (Eisenhardt \& Graebner, 2007; Yin, 2013).

Before each interview, we first visited each village to select respondents and arrange an appropriate time and place for the interview. We used a semi-structured interview guide focusing on the process of creating customer value and on adaptation actions (see Table 2.1.). During the interview, the pastoralists were asked to provide detailed narratives on how they decide on the types of animals they will to raise and offer for sale, as well as on their level of understanding about the requirements of buyers, activities that they perform to meet the preferences of buyers, and actions that they undertake in order to optimize the quality of the animals they offer for sale during times when natural pasture and water resources are scarce. The narratives provide insight into the processes and activities that respondents undertake to meet the preferences of buyers, their dominant motives in doing business, their adaptation experiences and practices, the lessons they have learned, and their subjective understandings of markets and local ecological conditions. The first author interviewed the respondents with the help of interpreters who were familiar with the local culture and who spoke Oromiffa, the local language of the pastoralists. The interviews, each lasting about one hour, were recorded and then transcribed in English by the first author. 


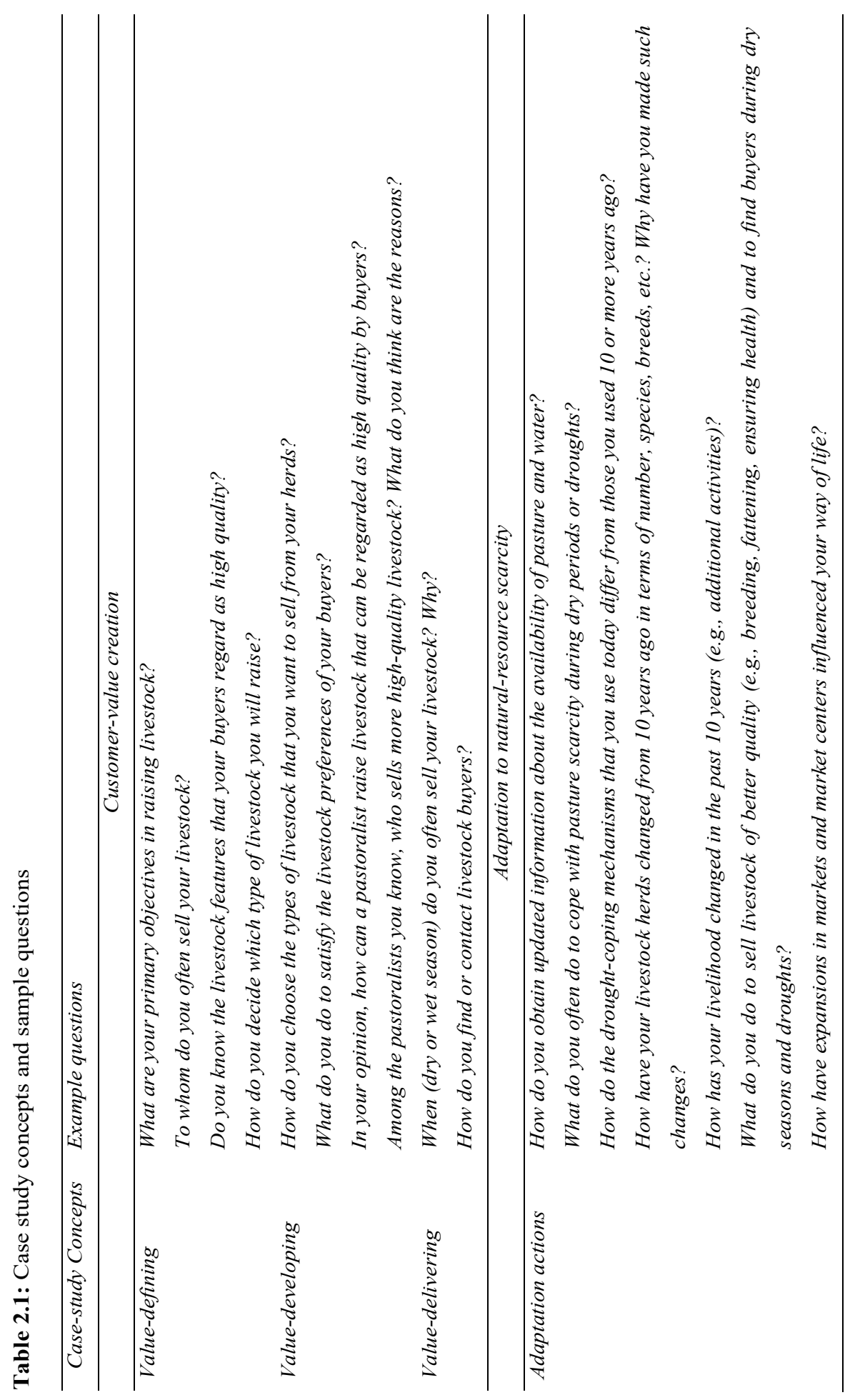


Following the interviews, we conducted three focus-group discussions with a group of five to eight pastoralists. In the discussion, the participants were asked to reflect on their perspectives on themes that had emerged from the individual interviews, thereby providing a source for triangulation (Eisenhardt \& Graebner, 2007; Yin, 2013). The discussions also generated additional insight as the participants exchanged comments with each other (D. L. Morgan, 1996).

In addition to the pastoralists, we interviewed six live-animal traders and five experts from research institutes and NGOs in the region. These interviews were intended to generate additional insight into the process of creating customer value and the adaptation actions of the pastoralists. All of the interviews and focus-group discussions in this study were conducted between August 22 and September 18 of 2017.

\subsubsection{Data Analysis}

We used Atlas.ti software to code and analyze the data (Friese, 2019). To gain familiarity with our study context, we started our analysis by reading each transcribed interview multiple times (Eisenhardt \& Graebner, 2007; Yin, 2013). To conceptualize the ability of pastoralists to adapt to natural resource scarcity in the process of creating customer value, we analyzed the data in three waves, as suggested by the modified grounded theory method (Thornberg, 2012). First, we analyzed the transcribed individual interviews and focus-group discussions to identify processes and activities that pastoralists perform in raising and selling quality livestock to buyers. The transcripts were examined line-by-line to identify and highlight passages indicating the processes and activities of the pastoralists involved in raising and selling livestock to buyers. As part of the informed grounded theory method, we adopted the process of creating customer value (see Figure 2.1) as a theoretically grounding for categorizing the activities as processes of 'value-defining', 'value-developing', and ‘value-delivering' processes (Thornberg, 2012). 
Second, we analyzed the interviews and focus-group discussions to identify adaptation actions. We examined the transcripts line-by-line to identify and assign codes based on the expressions of the interviewees (Friese, 2019). The codes were then grouped under higher-order conceptual codes by comparing and assigning the same conceptual label to similar adaptation actions (Friese, 2019; Trochim, 1989). The analysis helped us to develop an understanding of how the pastoralists adapt to the scarcity of natural resources and why they undertake each adaptation action.

Finally, we searched for evidence to relate the processes of creating customer value to the adaptation actions (Eisenhardt, 1989; Thornberg, 2012). In this stage, we explored the data to learn about the ways in which each adaptation action alters the activities and processes that the pastoralists use to create customer value. Drawing on these results, we combined the adaptation actions that altered the same value-creating activities to reinforce the categorizations of valuedefining, value-developing, and value-delivering process, and we subsequently conceptualized them as adaptation capabilities for adjusting the process of creating customer value to conditions of natural-resource scarcity.

\subsection{Findings}

\subsubsection{Traditional ecological knowledge}

The earliest records of the use of extensive grazing rangelands for to produce livestock as a livelihood in the Borana region date back to the $13^{\text {th }}$ century (Gemedo-Dalle et al., 2006), although the tradition is probably much older. For pastoralists, livestock has always served as a source of milk, which is a key element in their diets. In addition, the possession of livestock has traditionally reflected social status within the pastoralist culture. Many contemporary pastoralists continue to attach value to having large herds - especially cattle, which they regard as the most productive asset (e.g., Pastoralist 9 and FGD 2 in Table 2.2.). As explained by Expert 2, "livestock is a tool for 
creating and strengthening social relationships through livestock loans, gifts, and acts of solidarity." Finally, pastoralists have always sold animals when they needed cash (e.g., to buy additional food items) (Barrett, 2008).

Pastoralists manage grazing rangelands by classifying them into different functional land-use units (e.g., dry-season and wet-season grazing units; Pastoralist 41 in Table 2.2). They monitor conditions of pasture and water resources in order to determine their mobility in search of green pastures and freshwater during dry seasons. Indigenous ecological indicators (e.g., the species, color, and density of plants observed in the grazing rangelands) are used for measuring the type and quality of pasture resources (Homann et al., 2008). The behavior and performance of animals (e.g., modes of grazing, breathing, dung color, physical condition, and milk production) are also used and combined with the ecological indicators to monitor pasture quality in grazing rangelands (Homann et al., 2008).

These practices are deeply ingrained in the culture of the Borana pastoralists. They thus depend on traditional ecological knowledge to sustain livestock production within a fragile environment. The store of traditional ecological knowledge is the cumulative product of centuries of practical exercises in matching the specific demands of their herds to the unpredictable supply of natural resources in a resource-scarce environment (Gemedo-Dalle et al., 2006). The traditional ecological knowledge subsumes the information and skills that have allowed pastoralists to derive the greatest possible benefits from the sustainable use of scarce natural resources (Homann et al., 2008). Borana pastoralists maintain their ecological knowledge in the Gada system-the traditional institution that governs the social and economic life of the Borana pastoral community (Homann et al., 2008). Leaders of the system (often elders) maintain authority for the effective functioning of social norms, values, and traditional mechanisms of sanctioning that have been devised to ensure 
compliance with the rules for the use of natural resources (Homann et al., 2008; Kamara et al., 2004). Individual pastoralists have inherited this knowledge from their grandparents in the form of traditional institutions, values, and norms. They apply this heritage of ecological knowledge in the classification, assessment, and use of natural resources, as well as in livestock husbandry and reproduction (Homann et al., 2008). 


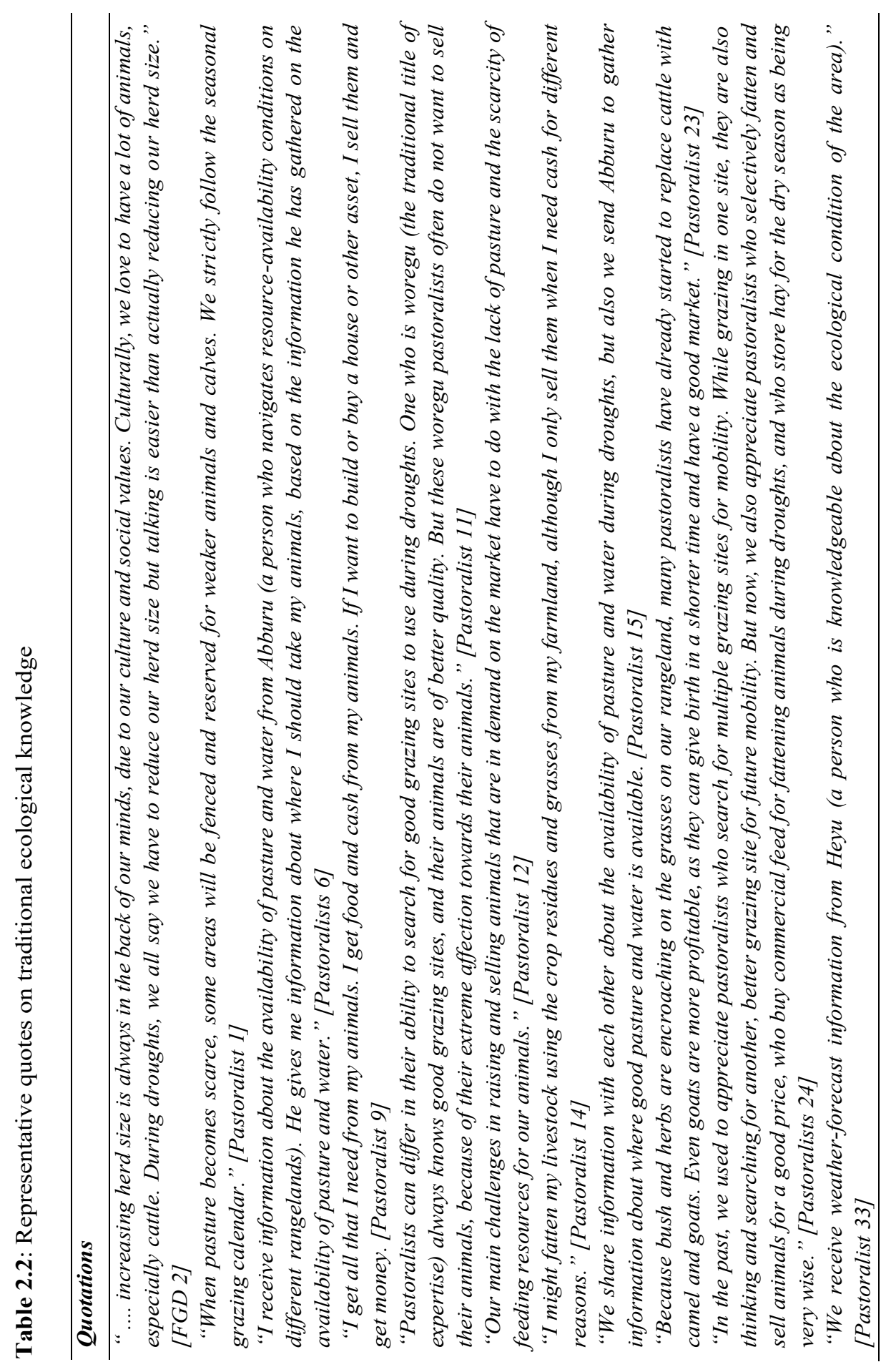




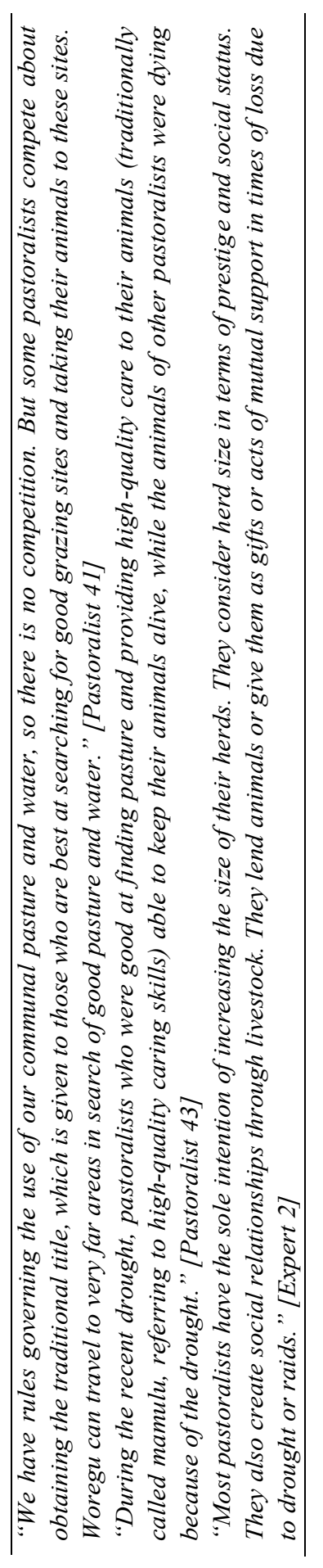




\subsubsection{Market knowledge}

For many generations, pastoralists in the region have led a subsistence-oriented, semi-nomadic lifestyle. They herd livestock primarily for their personal consumption of milk and meat, as well as for commercial endeavors that enable them to buy complementary food items, healthcare, and schooling for their children (Barrett, 2008). Recent decades, however, have witnessed a fundamental shift, in which pastoralists are increasingly integrating into local and international supply chains (Tessema et al., 2019). These larger networks are increasingly looking to pastoralists as important sources of live animals (e.g., camels, cattle, goats, and sheep) to meet the increasing demand for protein-rich foods. The pastoralists sell their livestock to a variety of buyers, including traders, fattening operators, abattoir operators, and exporters (Barrett, 2008; Catley et al., 2013). To encourage the participation of pastoralists in the market, policymakers and development workers are making considerable investments in expanding market infrastructures, including roads, market centers, and communication technology to reach the pastoral regions (FAO, 2018; Kamara et al., 2004). As noted by several of our respondents, the expansion of market centers reduces their travel time and transportation costs associated with selling livestock (e.g., Pastoralist 4 in Table 2.3). At the same time, however, the decrease in livestock productivity due to the adverse effects of climate change is increasing the amount of livestock that pastoralists must sell in order to buy household food items. Many of the pastoralists pointed out that their main reason for increasing their livestock sales is the need for cash to purchase food items, given that milk production is decreasing due to the scarcity of pasture land in the region (e.g., Pastoralist 10 and Expert 3 in Table 2.3). 


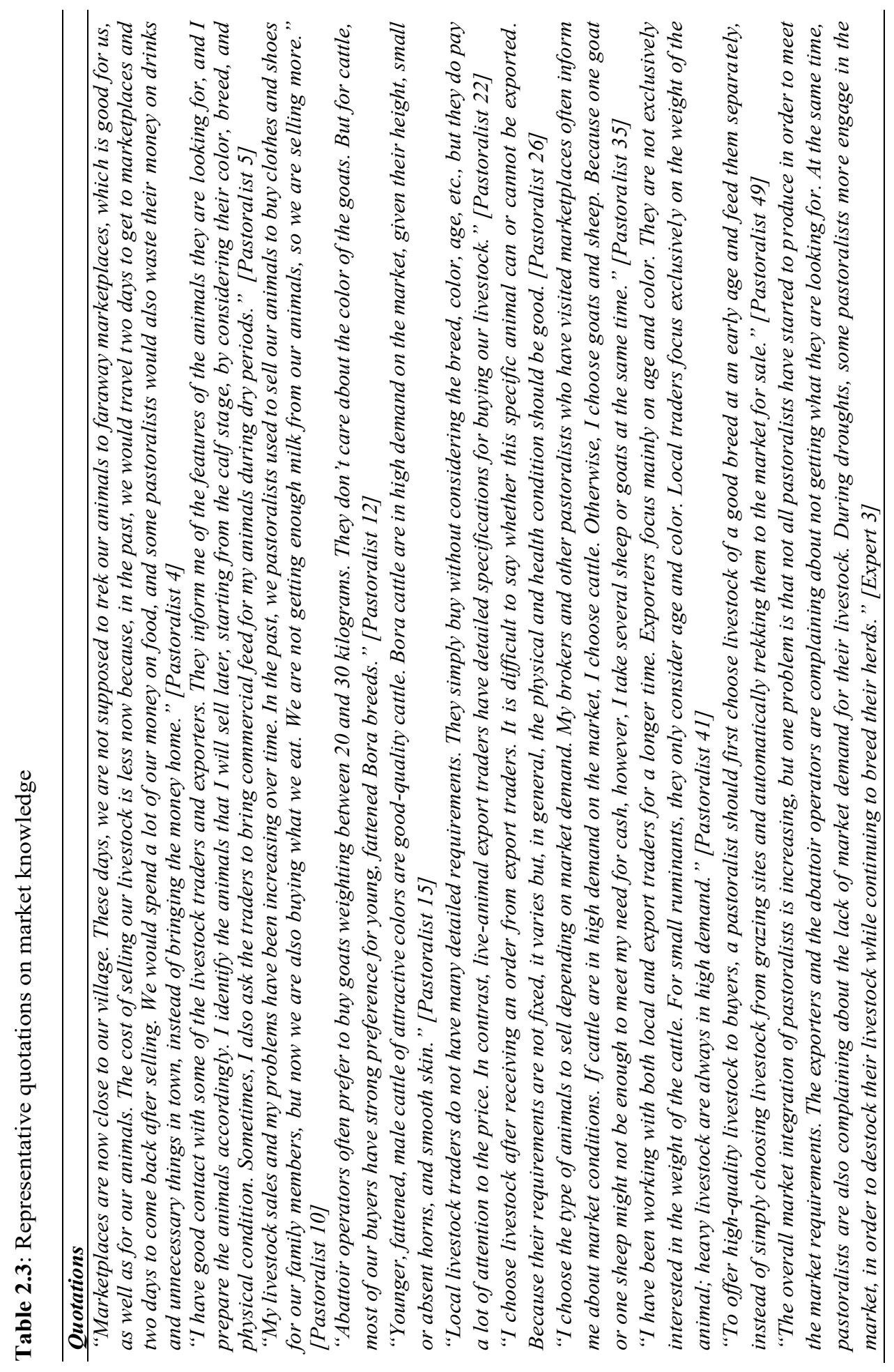




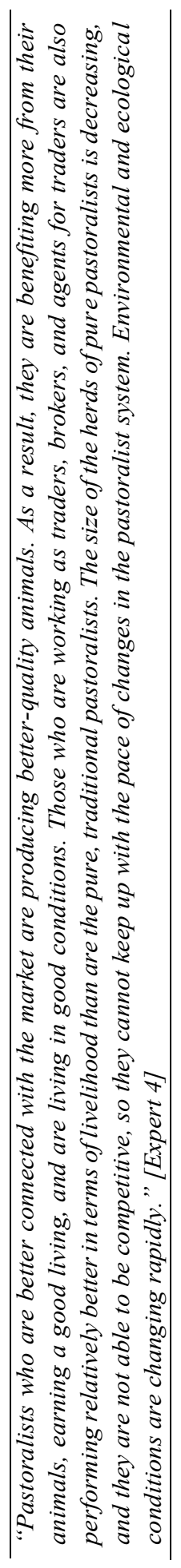


As the pastoralists integrate into the market, they come into interaction with market actors. For example, the pastoralists make personal visits to the market, speak to other pastoralists who have already visited particular marketplaces, and communicate with clan-based livestock brokers (e.g., Pastoralist 35 in Table 2.3). Such interactions provide the pastoralists with access to market information, thus allowing them to make inferences about the types, breeds, and qualities of livestock that buyers prefer and to learn the times at which the demand for their livestock will be highest. They are developing knowledge about the preferences of specific buyer groups (e.g., abattoir operators, exporters, and local traders; Pastoralists 15 and 41 in Table 2.3). Market integration is thus supplementing the traditional knowledge system with a second, market-based knowledge system. These two sources of knowledge are leveraged in the day-to-day decisions that pastoralists must make in order to create value for their buyers while maintaining their naturalresource environment.

\subsubsection{The process of creating customer value within the pastoralist context}

Like other businesses, the business of the pastoralists — breeding and fattening livestock — reflects all three stages of the process of creating customer value: value-defining, value-developing, and value-delivering. To satisfy their buyers, some pastoralists adjust the composition of their livestock herds in terms of species (e.g., camels, cattle, goats, and sheep), breed, herd size, and herd structure (e.g., sex and age composition) (e.g., Pastoralists 14 and 39 in Table 2.4). Based on their understanding of the market, they are increasingly attempting to align their livestock production with the requirements of the market in order to fulfill the needs of their buyers. This was illustrated in the focus-group discussion (FGD), in which one participant explained the objectives for livestock production: "we raise livestock for both the market and our livelihood as pastoralists. We have mixed cattle breeds; some are good at resisting droughts, and Bora cattle are good for 
the market but weak at resisting droughts." Pastoralist 5 stated, "we pastoralists are increasingly reducing the size of our herds and raising a diversity of animal species, due to resource scarcity and an increase in demand for different types and species of animals." Expert 3 added, "Borana pastoralists are increasingly shifting from predominantly cattle herding to diversified animal herding. They are increasing the numbers of goats and sheep in their herds. They are doing so because of an increase in the market demand for small ruminants, as well as the pressure due to the scarcity of pasture resources." 


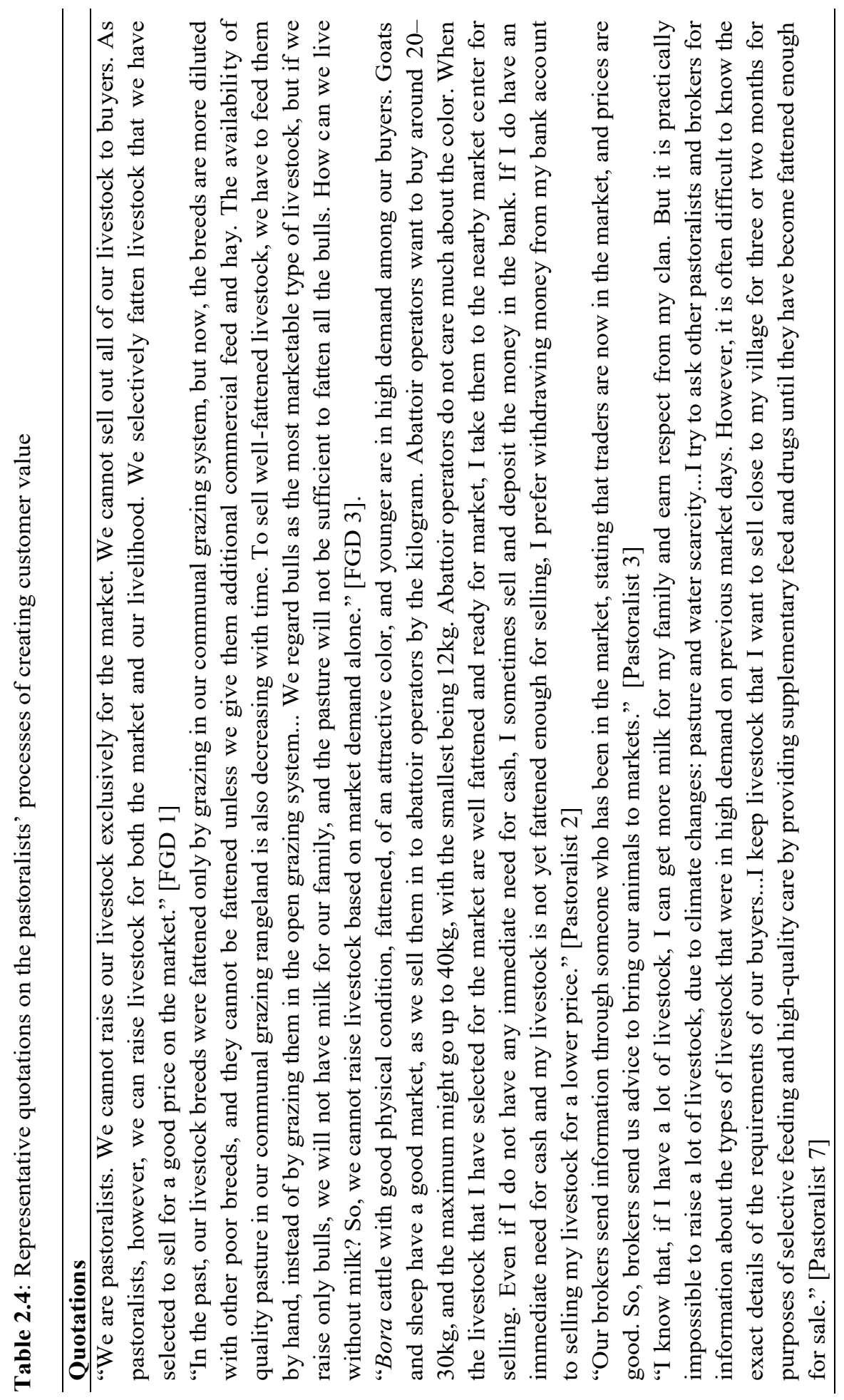




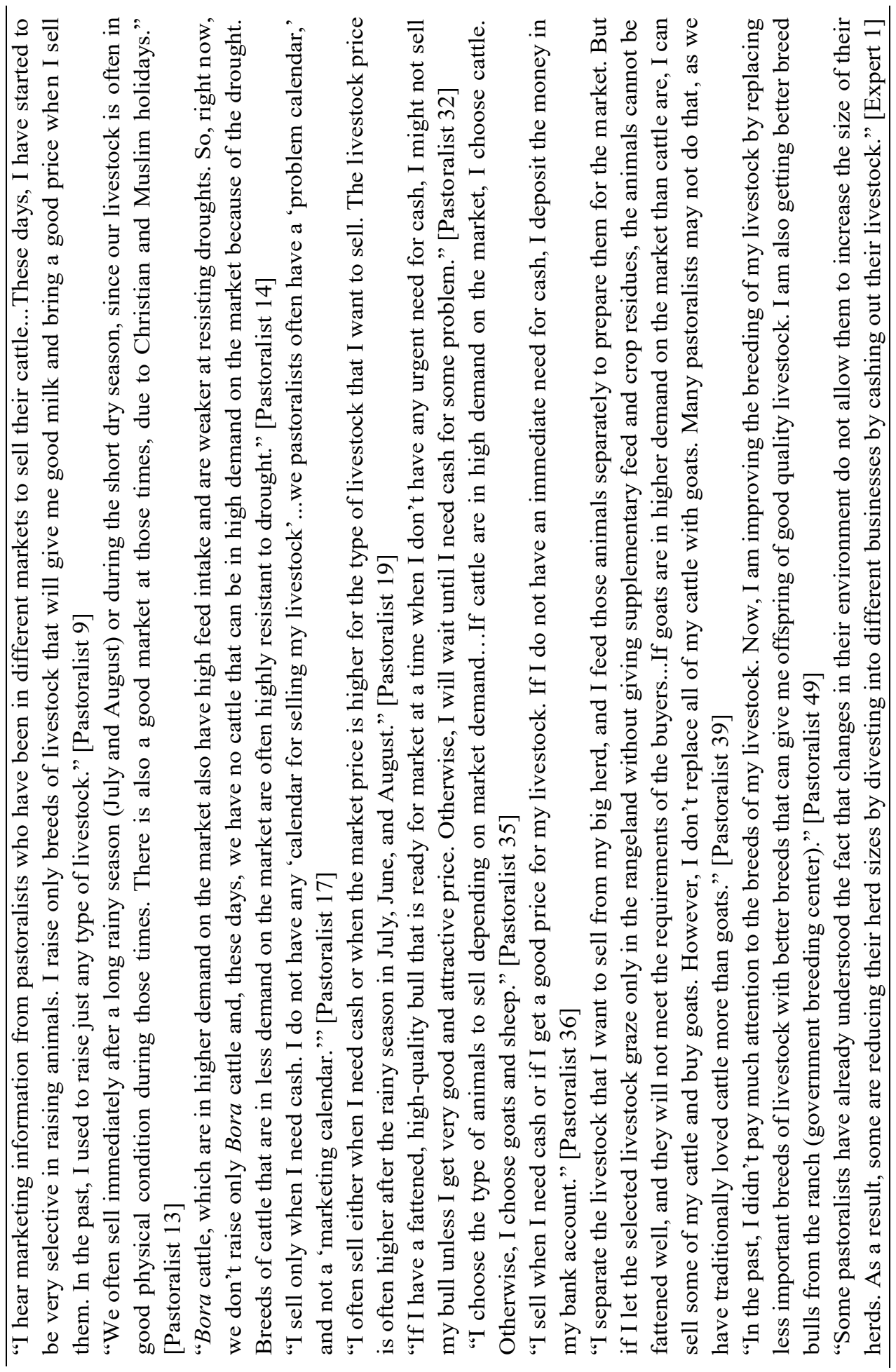


Decisions concerning the composition of livestock herds can be regarded as strategic marketing decisions, as they largely determine the animal species and breeds that pastoralists could potentially offer to buyers for a long period of time. Herd size influences the level of livestock quality, as large herds can be unmanageable for pastoralists in terms of proper feeding and high-quality care (e.g., Pastoralist 7 in Table 2.4). When pastoralists decide to sell livestock, they first select the animals they wish to sell from their large herds and provide them with special treatment, in order to enhance their quality to meet the requirements of buyers (e.g., Pastoralists 39 and 49 in Table 2.4). Decisions concerning the composition and size of herds have an impact on the types of animals that pastoralists will be able to offer to customers in the future. From the perspective of strategic marketing, these decisions can be regarded as a value-defining process, as they must be made before any livestock is available to offer to buyers, although they nevertheless affect the livestock that will ultimately be available (Kotler \& Keller, 2006).

Pastoralists also respond to market requirements by fattening the animals that they have selected for sale. Most of the pastoralists noted that they tend to select the livestock they wish to sell at least a few months before they intend to sell them (e.g., Pastoralist 7 in Table 2.4). For example, as stated by Pastoralist 5, "from the calves, I identify the animals that I will later sell to my customers by considering their color, breed, and physical condition. I then give special treatment to the animals that I have selected for the market until they are fattened and ready for sale. "Several respondents described that they allowed the animals that had been selected for the market to graze on more fertile lands. They also sometimes provide additional feed (e.g., stored pasture, crop residues, and commercial animal feed), veterinary drugs, and salt or other minerals (e.g., FGD 3 and Pastoralist 7 in Table 2.4). 
Within the pastoralist context, activities relating to increasing the quality of animals selected for the market in order to satisfy the requirements of buyers can be regarded as a value-developing process. This is because these activities are performed after the type of animals to be offered to buyers has been selected, and thus, are intended to improve the specific features (e.g., physical and health conditions) of the animals to be offered to buyers. From the perspective of strategic marketing, the activities are more tactical, involving a short time frame and focusing on specific resources (Kotler \& Keller, 2006).

Finally, once the animals that have been selected for the market are fattened and ready for sale, pastoralists must decide when, where, and how much to sell. Some pastoralists decide the timing of their livestock sales based on their need for cash, selling only when they need money (e.g., Pastoralist 17 in Table 2.4). Others decide the timing of their livestock sale depending on the physical conditions of the animals. More specifically, many pastoralists sell livestock after rainy seasons, because the physical conditions of their animals are often good during those times (e.g., Pastoralist 13 in Table 2.4). Before trekking the animals to marketplaces, pastoralists often communicate with their clan-based livestock brokers and/or traders to determine the marketplace and price for the livestock they will be selling (e.g., Pastoralist 3 in Table 2.4). The livestock brokers help the pastoralists to find buyers and negotiate prices. These activities can be regarded as a value-delivering process because they focus on communicating with livestock buyers and making the exchange (Kotler \& Keller, 2006).

As indicated by the discussion above, pastoralists create customer value by combining resources along the known stages of the process of creating customer value: value-defining, value-developing and value-delivering, while also looking at the natural environment. This is because creating customer value in their natural scarce environment requires them to develop insight into the market, 
as well as with regard to vegetation coverage in the rangelands, seasonal variations in pasture resources, the spatial distribution of resources, and rain conditions. The process by which pastoralists create customer value is thus driven by an intricate combination of knowledge from the market and from the natural environment. Insight into the natural environment helps them to adjust their process of creating customer value to current and predicted scarcity of natural resources. In the following section, we discuss adaptation actions and the ways in which pastoralists address the scarcity of natural resources in their process of creating customer value.

\subsubsection{Adaptation actions in the process of creating customer value}

The existing literature suggests that pastoralists take a variety of adaptation actions to adjust their livestock production to the scarcity of natural resources (e.g., Galvin, 2009; Solomon et al., 2007). These adaptation actions include mobility, herd splitting, herd diversification, selective breeding, herd-size management, the commercial destocking of animals, buying commercial animal feed, and livelihood diversification (e.g., integrated crop-livestock production). Our interview data provide further evidence of these adaptation actions. Representative quotations and descriptions for each of the adaptation actions are provided in Tables $2.5,2.6$, and 2.7. In this study, these adaptation actions are regarded as capabilities for adapting to the scarcity of natural resources. Like other capabilities (cf. Helfat \& Winter, 2011), adaptation actions reflect the combination of knowledge and skills that enable pastoralists to earn a living in a resource-scarce environment by enhancing their ability to adapt their livestock-production processes to changes in the natural environment. In this section, we discuss these natural-resource adaptation capabilities within the context of their respective stages in the process of customer value creation. 


\section{Value-defining: Matching value propositions}

The value-defining process of pastoralists entails those activities that pastoralists undertake in order to decide on the type of livestock they will raise by considering the requirements of the market, as well as the natural resource environment. According to our analysis of how adaptation actions make changes in the value-defining process, the participating pastoralists adapt the value-defining process to the scarcity of natural resources by pursuing herd diversification, selective breeding, and herd-size management (see Table 2.5). These adaptation actions influence their strategic-marketing decisions concerning the type, composition, and number of animals that they will raise, thus leading to adjustments to the value-defining process. These adaptation actions have an impact on the types of animals that pastoralists can potentially fatten and sell to buyers. By adjusting the livestock they raise, the pastoralists are thus matching the types of animals they will potentially supply to customers (the value propositions) (cf. Payne, Frow, \& Eggert, 2017) to current and expected changes in the availability of natural pasture resources. Within the context of pastoralists, the adaptation capability of "matching value propositions" manifests itself in the more specific ability to undertake the adaptation actions of herd-size reduction, livestock diversification, and selective breeding. 


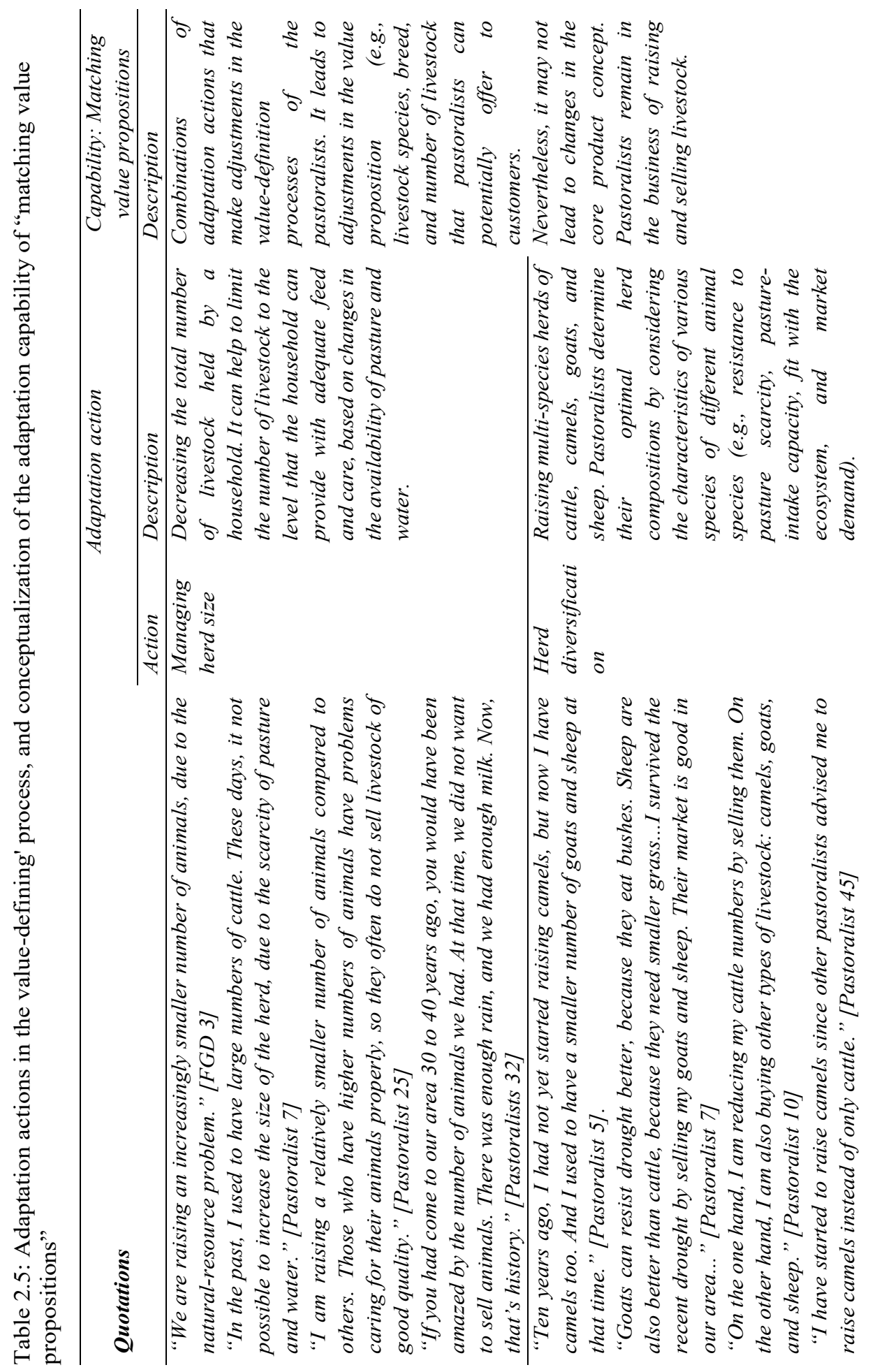




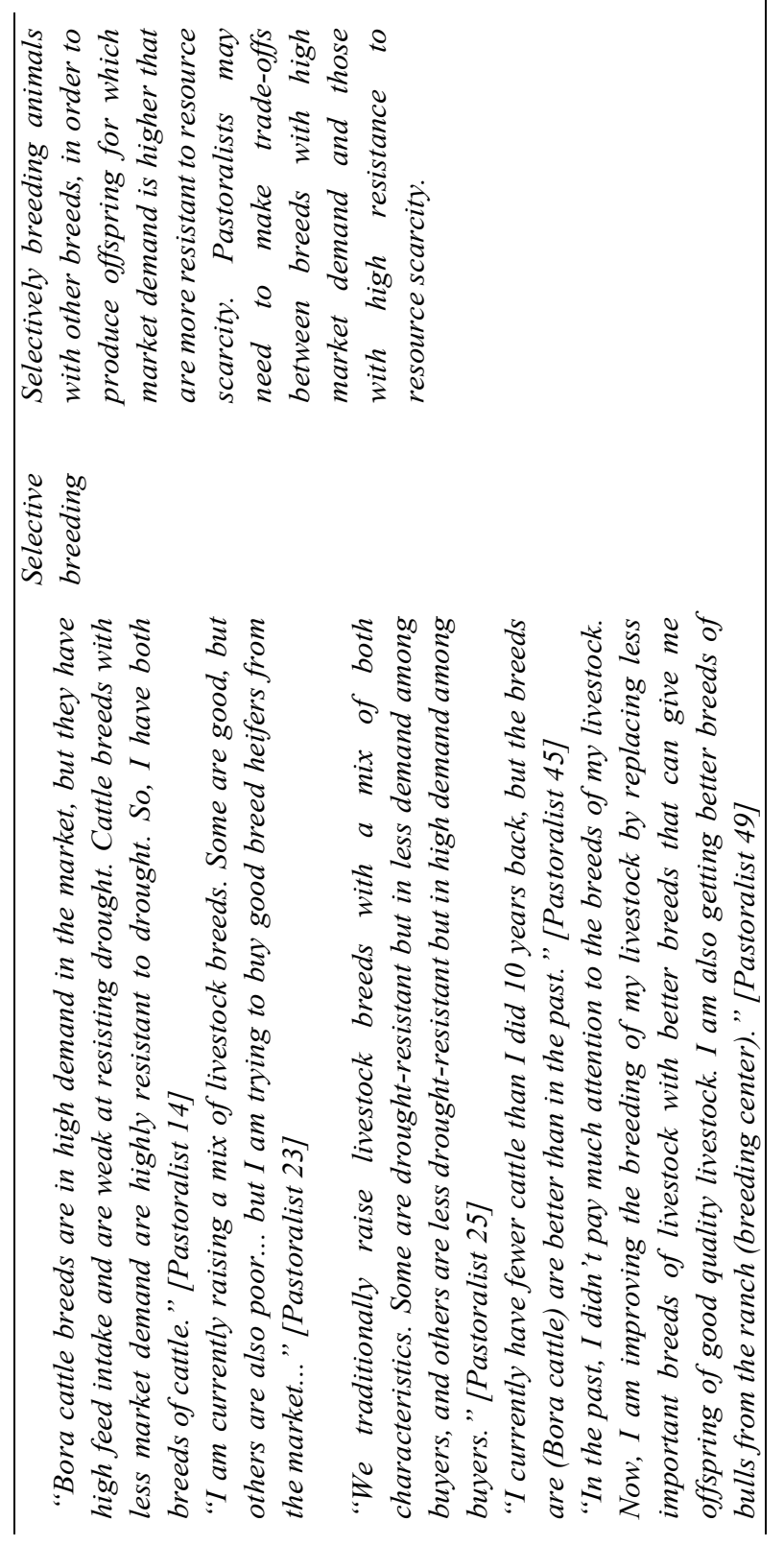


According to the pastoralists, the increasingly arid climatic condition is causing bush, herbs, and woody plant species to encroach upon the high-quality grass species in their grazing rangelands (see Table 2.5). They attempt to adapt to these changes in the natural-resource environment by reducing the total number of animal holdings per household (e.g., Pastoralist 32 in Table 2.5) and herding multiple species of animals, including camels, cattle, goats, and sheep (e.g., Pastoralist 5 in Table 2.5). They do this primarily by replacing grazing species (most notably, cattle and sheep) with browsing species (most notably, camels and goats) (e.g., Pastoralist 45 in Table 2.5). Some pastoralists also respond by replacing animals with higher pasture intake (e.g., cattle) with those with lower pasture intake (e.g., goats and sheep) (e.g., Pastoralist 5 in Table 2.5). As the numbers of animal holdings per household decrease, pastoralists are also becoming more selective in their breeding practices. For example, they are favoring breeds that are in higher demand on the market over those with high fertility potential (e.g., Pastoralist 49 in Table 2.5).

Overall, the adaptation actions within the value-defining process help pastoralists to maintain a balance between their livestock production and changes in the availability of natural resources. These adaptation actions are rooted in the pastoralists' knowledge about the market and changes in the natural resource environment. The ability to perform these adaptation actions enables them to supply livestock of better quality or to minimize quality loss to their buyers during periods of resource scarcity. For example, as described by Expert 4 stated, "During dry seasons, pastoralists who raise diversified livestock, especially goats and sheep, supply their buyers with livestock of relatively better quality, as goats and sheep are better at resisting drought than cattle are." According to pastoralists, reducing herd size and raising animals of better breeds can help them to sell better-quality animals and earn a higher income (e.g., Pastoralists 25 and 49 in Table 2.5). This is because the adaptation actions help them to maintain a fit between their production and the 
resources that are available in the natural resource environment. As a result, enhanced ability to undertake adaptation actions enables pastoralists to offer livestock of relatively better quality to their buyers.

\section{Value-developing: Natural resource deployment}

Within the context of pastoralists, the value-developing process entails the activities that pastoralists undertake to increase the quality of the livestock that they have selected for the market by providing adequate animal feed and high-quality care. The effective and efficient deployment of the available natural resources allows pastoralists to optimize the use of the available natural pasture and other resources in the process of fattening and preparing livestock for sales in ways that satisfy the quality requirements of buyers. When pasture resources are scarce, pastoralists try to maintain the quality of the livestock that they supply to customers by minimizing the unnecessary usage and waste of natural pasture, by using the available pasture in ways that add greater value for buyers, and by replacing grazing with other more plentiful types of animal feed. Pastoralists also use herd splitting and mobility to make effective use of pasture resources that are spatially distributed across their grazing rangelands (see Table 2.6). In the literature on resource management, the term "resource deployment" is used to refer to actions and activities that firms undertake to enhance their efficiency and effectiveness in utilizing the available resources (Sirmon et al., 2007; Slotegraaf, Moorman, \& Inman, 2003). We therefore identify the ability of pastoralists to perform adaptation actions that enhance their capacity to make efficient and effective use of the available natural resources for creating quality offerings as the adaptation capability of "natural resource deployment". 


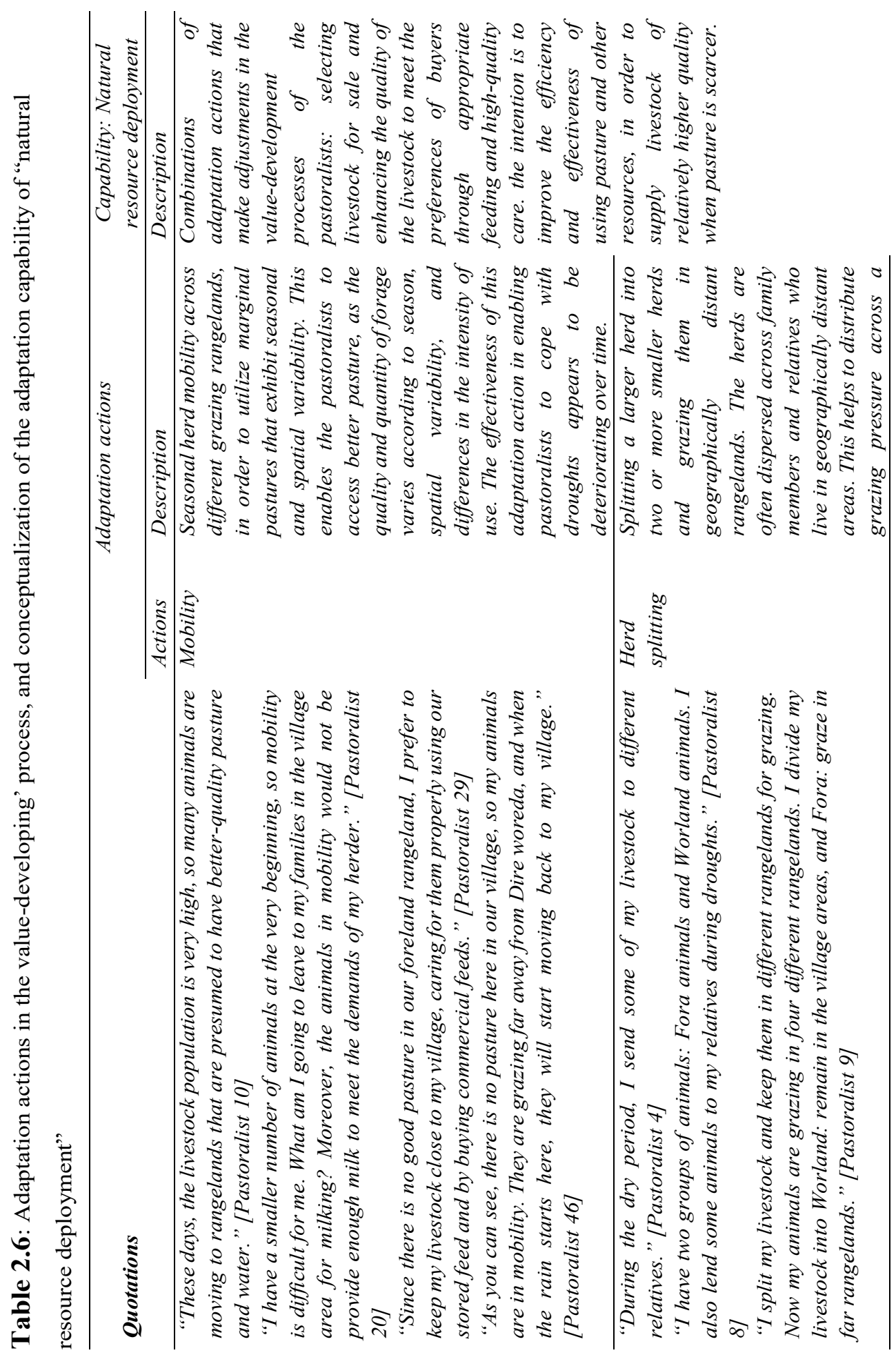




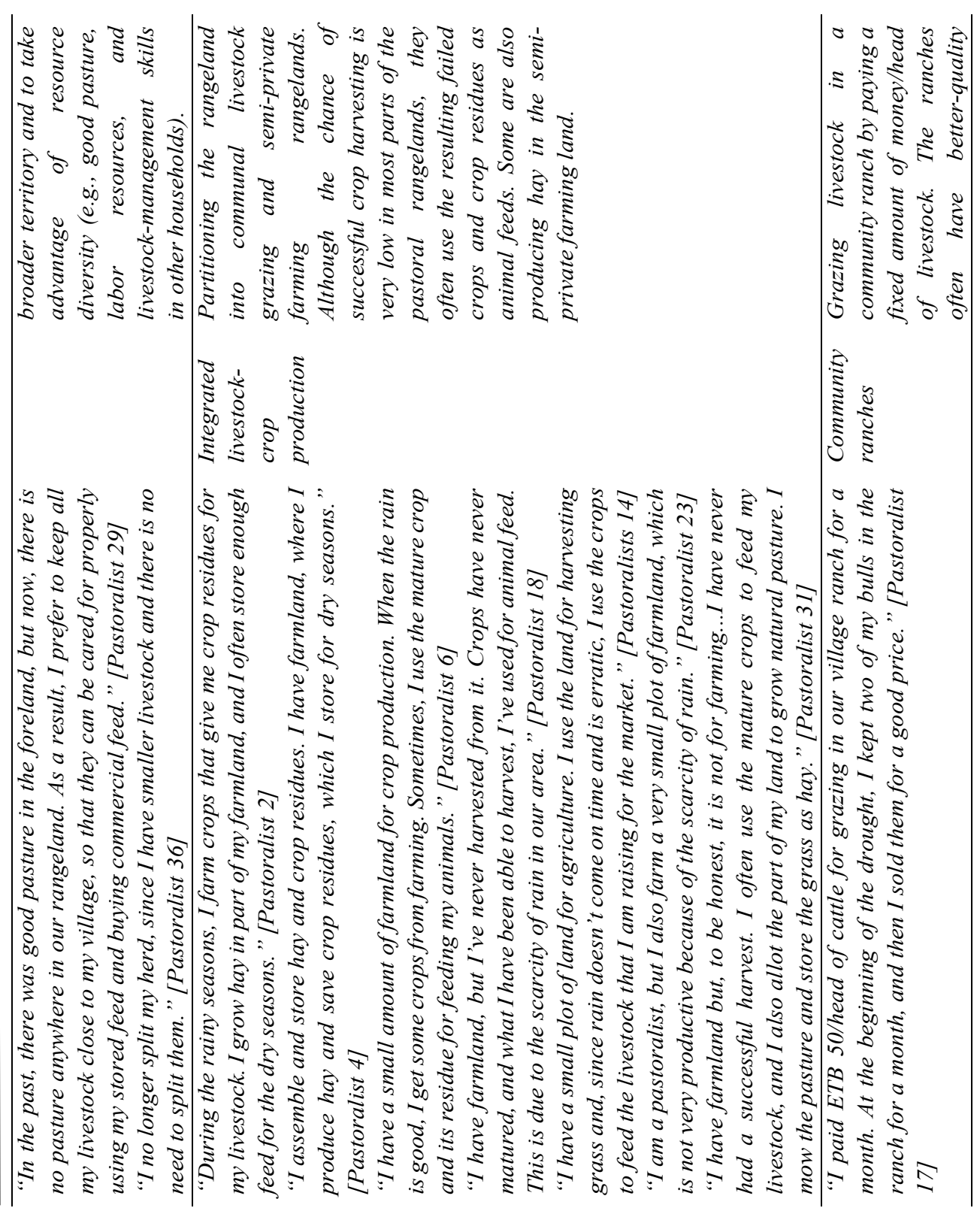




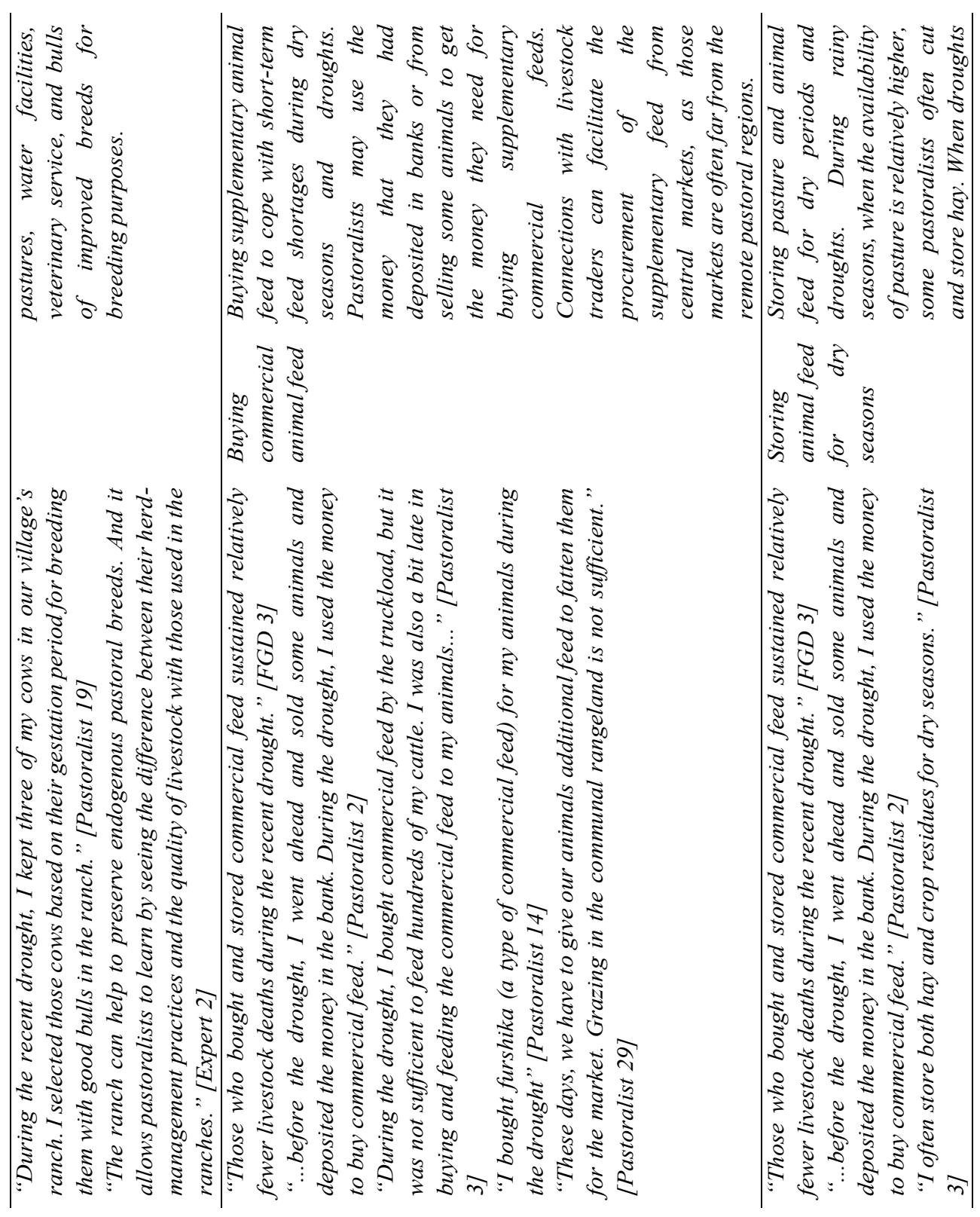




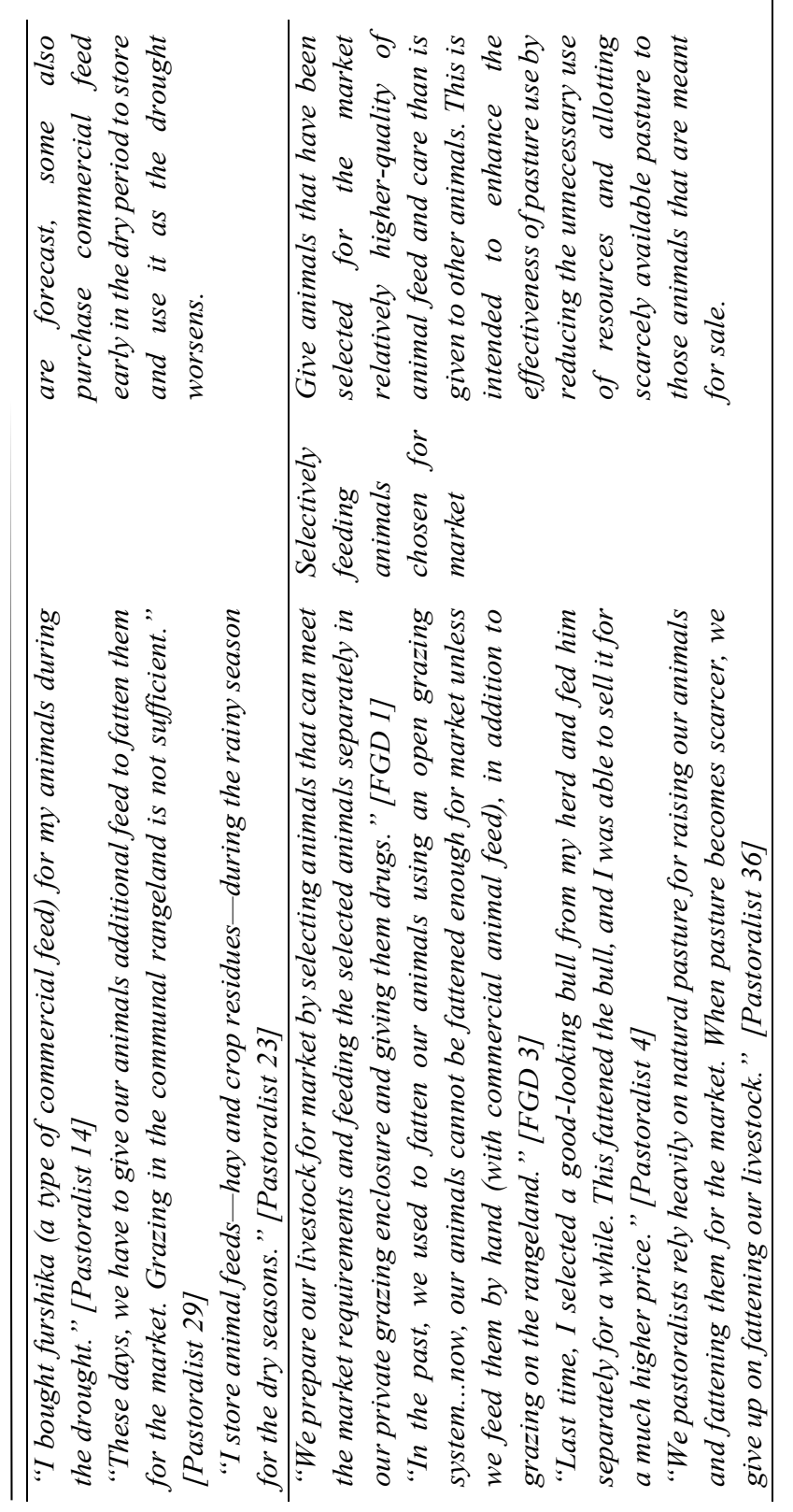


The natural resource deployment capability manifests itself in the ability of pastoralists to undertake adaptation actions of herd mobility, herd splitting, integrated livestock-crop production, buying commercial animal feed, storing animal feed for dry seasons, using community ranches, and selectively feeding livestock (see Table 2.6). The primary impact of these adaptation actions is on the pastoralists' ability to utilize the available natural resources in the process of developing value to satisfy the requirements of their buyers. These adaptation actions enhance their ability to make efficient and effective use of scarcely available pasture, while making flexible use of alternative resources in the process of fattening and preparing livestock for markets. During periods of resource scarcity, such actions help pastoralists to offer livestock of relatively high quality, or at least to minimize value loss for their buyers.

During dry periods, pastoralists often move their livestock to high-quality grazing rangelands. The effectiveness of this adaptation action (i.e., mobility) is decreasing, however, due to shrinkage in the available grazing rangelands and decreases in the animal holdings of each household (e.g., Pastoralist 10 in Table 2.6). Some pastoralists are also splitting large herds into two or more smaller herds and dispersing them across distant grazing sites during period of pasture scarcity (e.g., Pastoralist 8 in Table 2.6). Crop residues and failed crops intended for human consumption are also used to fatten animals during dry periods (e.g., Pastoralist 18 in Table 2.6). To enhance the efficient use of shared grazing sites, community ranches are also established to provide an alternative for fattening animals during dry periods (e.g., Pastoralist 17 in Table 2.6). Buying commercial animal feed (e.g., Pastoralist 29 in Table 2.6), storing animal feed for periods of resource scarcity (e.g., Pastoralist 23 in Table 2.6), and selectively feeding animals that have been selected for the market (e.g., FGD 1 in Table 2.6) are common adaptation actions that pastoralists undertake to offer livestock of relatively better quality to their buyers during resource-scarce times. 


\section{Value-delivering: Managing customer expectations}

Within the context of pastoralists, the value-delivery process entails activities related to communicating with and informing buyers about the timing and type of livestock that they will offer for sale. When the quality of livestock falls short of the buyers' requirements due to pasture scarcity, some pastoralists in communicate in advance with local traders, live-animal exporters, and the operators of fattening facilities and abattoirs concerning the quality condition of the livestock they will offer for sale. Livestock buyers also receive information about climate conditions and pasture scarcity through brokers. As a result, during dry periods and droughts, some livestock buyers may be persuaded to buy animals that are in relatively poor shape compared to what they usually buy when resources are abundant. Many traders subsequently fatten these animals in their feedlots for a time, instead of directly selling or exporting them. Establishing strong relationships and communication with traders enables some pastoralists to use commercial livestock destocking as a strategy for selling their animals sufficiently early in a period of drought, thereby minimizing quality loss for buyers and damage to the natural environment (see Table 2.7). Managing customer expectations can therefore help pastoralists to sell more livestock during periods of natural-resource scarcity, even when the animals are in relatively poor shape. Managing customer expectations refers to the management of relationships and interactions with customers to create an appropriate level of value expectation in their minds (Coye, 2004; Day, 2000; Sheth \& Mittal, 1996). 


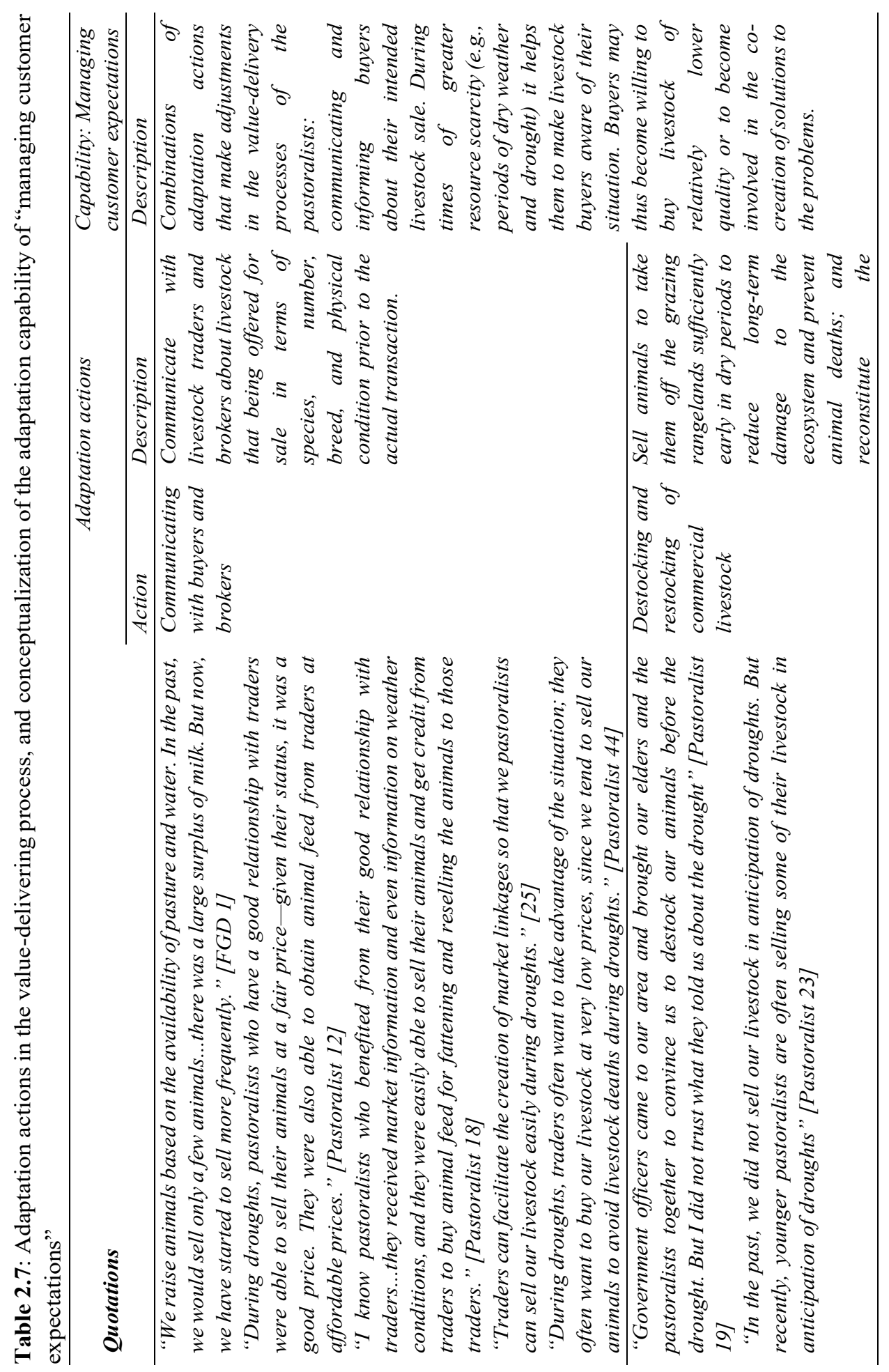




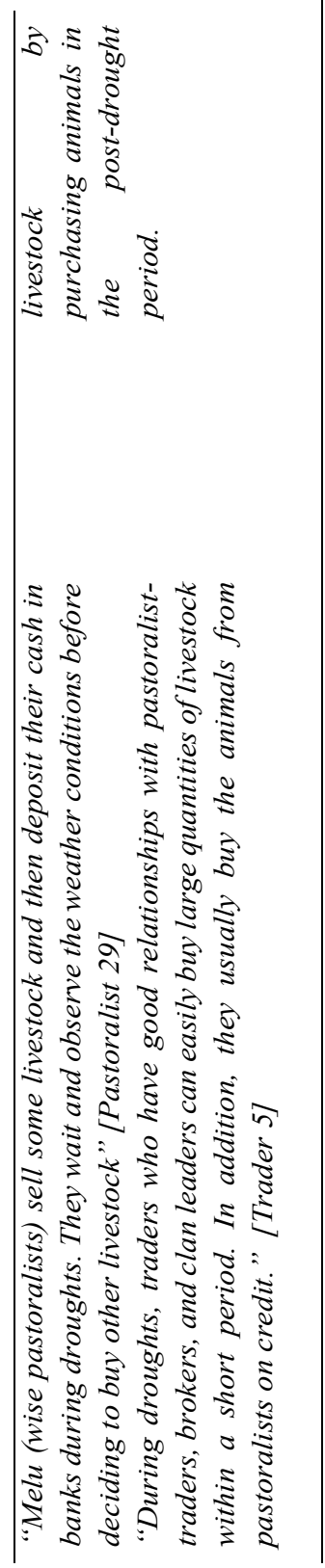


Before trekking their animals to marketplaces in order to sell them, pastoralists communicate with livestock brokers and/or traders about the types of livestock that they will offer for sale (e.g., Pastoralist 12 in Table 2.7). Pastoralists often provide livestock brokers with important information in advance of the intended date of sale concerning their market offerings: type of livestock (e.g., species and physical condition), number of animals for sale, and the intended date of the transaction. This notifies livestock traders in advance with regard to the types of livestock that pastoralists will be offering for sale, before the actual transaction takes place. Such communication helps pastoralists to create an appropriate level of expectation in the minds of buyers. It can also enhance the adaptation action of "commercial destocking and restocking of livestock" that pastoralists take during droughts (e.g., Pastoralist 23 in Table 2.7).

During droughts, when pasture becomes extremely scarce, pastoralists may temporarily take their animals off the grazing rangelands sufficiently early in the drought to reduce animal deaths and long-term damage to the grazing rangelands (e.g., Pastoralist 12 in Table 2.7). They subsequently reconstitute their livestock during the post-drought through the sale and purchase of animals. The capacity of pastoralists to destock livestock commercially during droughts depends on their ability to manage the expectations of livestock buyers and to persuade buyers to purchase the animals that are more likely to be in poor shape due to the drought (e.g., Pastoralist 29 in Table 2.7). For traders, the drought-stress situation of pastoralists provides an advantage opportunity to buy livestock at lower prices. According to Trader 3, "during droughts, the animals I buy from pastoralists require additional expenses for feeding them before they can be resold. So, I don't buy those animals unless I can get a very low price." Some traders also buy livestock on credit during droughts (e.g., Trader 5 in Table 2.7) 
Although managing customer expectations does not improve the quality of the product that customers will ultimately receive, it does affect their perceptions of product quality. It thus complements or even compensates for any shortfalls in the previous two adaptation capabilities: matching value propositions and natural resource deployment. This is because these adaptation capabilities may help to minimize the reduction of livestock quality for buyers through adjustments made before the point of delivery or transaction of livestock. Buyers may nevertheless experience some reduction in livestock quality during periods of extreme resource scarcity. Managing customer expectations can therefore help pastoralists to minimize the extent to which buyers perceive reductions in livestock quality by communicating to their customers in advance about the quality of livestock that they will offer for sale.

\subsection{Conceptual Model}

At a higher level of abstraction, our findings provide lessons on how businesses may adapt their processes of creating customer value to conditions of resource scarcity (see Figure 2.2). As displayed at the top of panel A in Figure 2.2, the process in which resources are integrated to create customer value is preceded by market knowledge and results in business performance. This part of the model thus depicts a simple version of current strategic-marketing thinking, in which the creation of customer value (consisting of processes of value defining, developing, and delivering) is the main driver of business performance (Kotler \& Keller, 2012; Webster, 2002). Following the knowledge-based view in marketing, market knowledge is a critical resource for the creation of customer value (De Luca \& Atuahene-Gima, 2007; Slater et al., 2012). We bring natural-resource scarcity into this model by comparing it to the traditional pastoralist model and by integrating the pastoralists' adaptation actions into the process of creating customer value. In the following sections, we formulate propositions on these processes. 


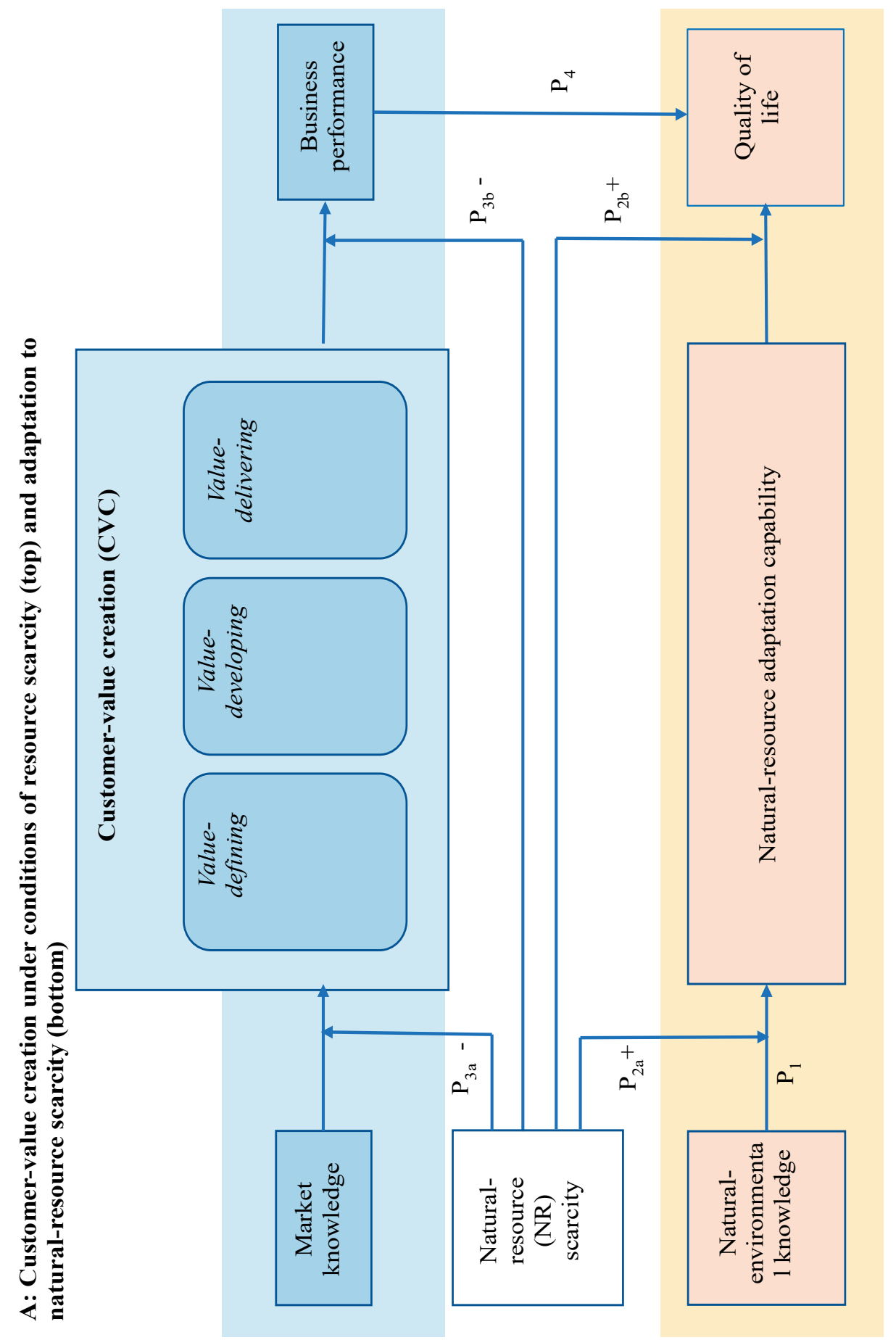




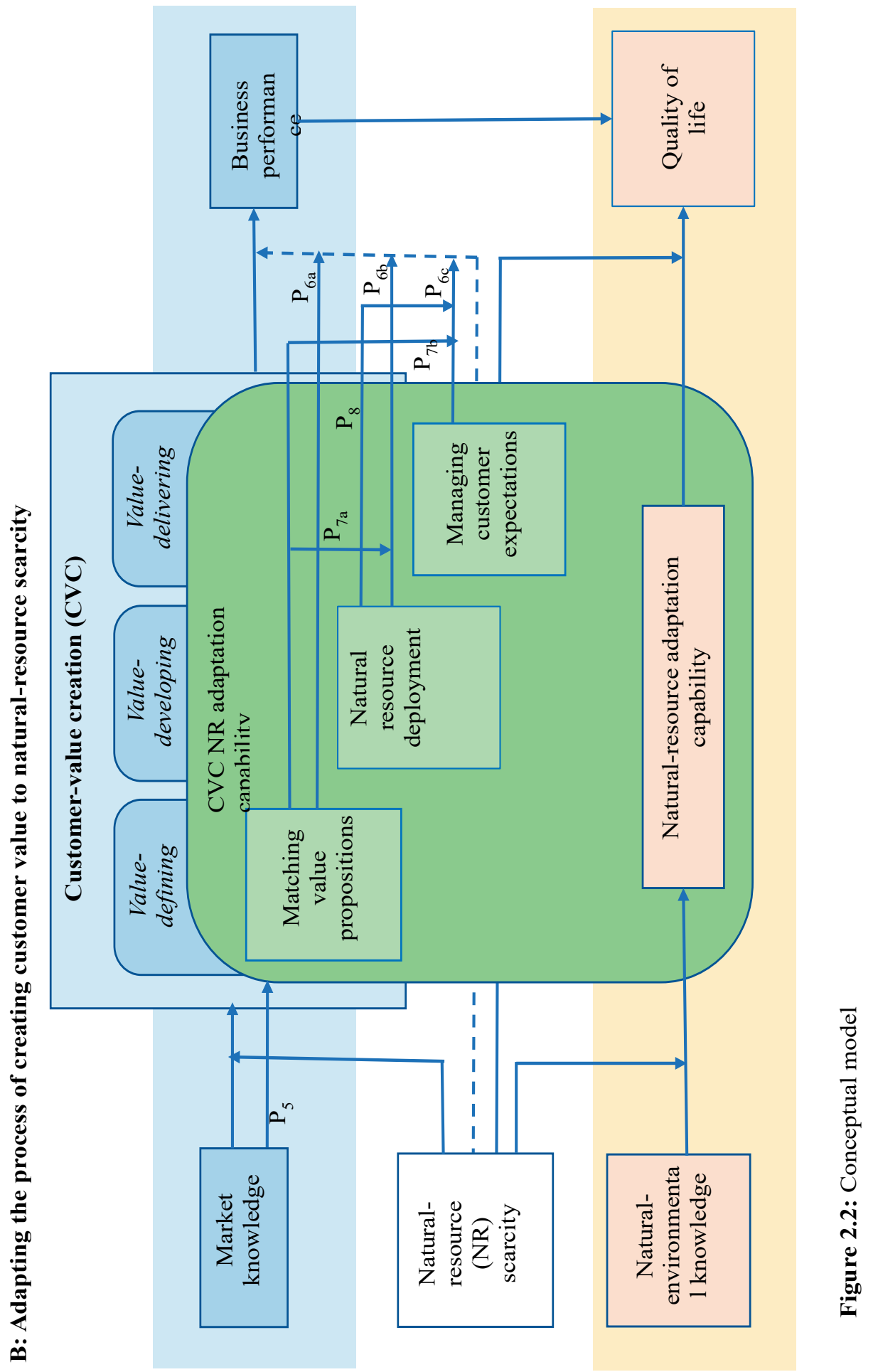


First, the bottom of the model in Panel A of Figure 2.2 mirrors the three stages of customer-value creation: knowledge, resource integration, and performance. It is based on the traditional pastoralist way of life, however, which constitutes a fundamentally different knowledge system. A knowledge system is a mechanism through which knowledge is managed, including the creation, storage, retrieval, transfer/share, and application of knowledge (Alavi \& Leidner, 2001, pp.114). Pastoralists have developed a considerable store of knowledge about the natural environment in which they live, and this knowledge enables them to adapt to conditions of natural-resource scarcity, thereby maintaining or improving their quality of life. As such, the causal chain that proceeds from market knowledge to the process of creating customer value and, subsequently, to business performance is grounded in a knowledge system that is fundamentally different from the foundation of the causal chain for quality of life, which proceeds from the natural environment knowledge to the capability of adapting the use of natural-resources and, subsequently, to quality of life in the pastoralist system. Quality of life consists of the expectations that individuals have for what they perceive as a good life. These expectations are guided by the values, goals, and sociocultural contexts in which individuals live (Layton, 2009; Nussbaum, Sen, \& Sen, 1993). In line with marketing scholars who have argued that business performance contributes to a wider range of life objectives in terms of quality of life (Layton, 2009), our findings reveal that the actions taken by the pastoralists participating in our study were aimed in part to diversify the diets of their families and to enhance their social status by increasing the size of their herds. Business performance has the potential to contribute to the achievement of such goals (as was the case with the pastoralists who used the cash generated by their business to purchase food and livestock).

Scarcity of natural resources affects both of the aforementioned causal chains. First, it weakens the impact of market knowledge on the creation of customer value. Even though 
businesses possess knowledge concerning how to integrate resources in a way that will satisfy customers, they may lack basic, vital physical resources that are needed in order to do so. Second, scarcity of natural resources decreases the effectiveness of the process of creating customer value. Resource scarcity thus weakens the relationship between customer-value creation and business performance. Third, resource scarcity affects the relationship between knowledge of the natural environment and the capability to adapt to the availability of natural resources, with scarcity serving as a catalyst to convert knowledge into action. Once resources are perceived as or expected to become scarce, this triggers the activation of adaptation capabilities. This corresponds to the notion that dynamic capabilities can be dormant unless triggered by changes in the environment (Danneels, 2016). Fourth, natural-resource adaptation capabilities help to maintain quality of life in periods of resource scarcity, which thus strengthens the relationship between natural-resource adaptation capabilities and quality of life. We therefore propose:

Proposition 1: The higher the knowledge on the natural environment, the higher the adaptation capability to natural resource scarcity.

Proposition 2: The higher the natural-resource scarcity, the higher (a) the influence of knowledge on the natural environment on the adaptation capability, and (b) the influence of the natural resource adaptation capability on quality of life.

Proposition 3: The higher the resource scarcity, the weaker (a) the relationship between market knowledge and customer-value creation, and (b) between customer-value creation and business performance.

Proposition 4: The higher the business performance, the higher the quality of life. 
Because pastoralists also create value for their customers in the livestock businesses that they run, the findings of this study suggest opportunities for integrating the capability of adapting to natural-resource scarcity with the process of creating customer value. This is depicted in Panel B of Figure 2.2. For each of the three stages of the value-creation process, the pastoralists examined in this study leveraged capabilities that helped them to reduce the impact of resource scarcity. In the value-defining stage, the ability to match value propositions enables pastoralists to exploit changes in the natural-resource environment to satisfy the needs of customers by creating a fit between the characteristics of their product offerings and those of the changes in the natural environment. In the value-developing stage, natural resource deployment enhances the effective and efficient use of resources by minimizing unnecessary usage and waste of resources, by allocating resources in ways that maximize customer value, and by finding alternatives to the scarce resources. In the value-delivering stage, the ability to manage customer expectations helped pastoralists to create an appropriate level of value expectations in the minds of their buyers, thereby minimizing the buyers' perceived product-quality reductions during periods of resource scarcity. These capabilities therefore build on the natural resource adaptation capabilities of pastoralists. In this regard, the natural-resource adaptation capabilities associated with the process of creating customer value (CVC NR) can be regarded as first-order dynamic capabilities, as they enable a business to make changes in its processes of creating customer value in order to respond to changes in the environment (Danneels, 2016; Schilke, 2014). The underlying natural-resource adaptation capability can be regarded as a second-order dynamic capability, as it enables the business to create or add the new first-order CVC NR dynamic capabilities (Danneels, 2016; Schilke, 2014).

Adapting the process of creating customer value entails more than blindly deploying actions that enable adaptation to the changes in the natural environment. As demonstrated by our results, 
at least some of the pastoralists weighed the interests of the customers in order to minimize losses in customer value. The natural-resource adaptation capabilities of the pastoralists were thus not the only resources on which the CVC NR adaptation capabilities built. They also built on market knowledge, once again emphasizing the role of knowledge in capabilities (Bharadwaj \& Dong, 2014; Menguc \& Auh, 2006). We therefore propose:

Proposition 5: The higher the market knowledge, the higher the abilities to (a) match value propositions, (b) natural resources deployment, and (c) manage customer expectations.

In conditions of resource scarcity, adaptation capabilities strengthen the impact of customer-value creation on business performance. In other words, without CVC NR adaptation capabilities, business performance is likely to be lower. Because the three adaptation capabilities activate changes in three subsequent stages in the value-creation process, their effects are contingent upon each other. The effective deployment of matching value propositions is likely to reduce the need to deploy the other two adaptation capabilities, as the resource scarcity is largely overcome in the first stage of the process. Likewise, natural resource deployment may reduce the need to manage customer expectations. Hence, managing customer expectations is necessary only when the resource scarcity is too great to be managed by the other two capabilities and/or when the other two capabilities have not been deployed effectively. This implies that the involvement of customers is only a last resort in overcoming resource scarcity. We therefore propose:

Proposition 6: The higher the (a) matching value propositions, (b) natural resource deployment, and (c) managing customer expectations, the weaker the impact of natural resource 
scarcity on the relationship between customer value creation and business performance.

Proposition 7: The weakening impact of (a) natural resource deployment, and (b) managing customer expectations as stated in Propositions $6 \mathrm{~b}$ and $6 \mathrm{c}$ will be reduced if the matching value propositions capability is higher.

Proposition 8: The weakening impact of managing customer expectations as stated in Proposition $6 \mathrm{c}$ will be reduced if the natural resource deployment capability is higher.

\subsection{Theoretical implications}

The results of this study have several theoretical implications. First, the existing marketing literature on the knowledge-based view of the firm regards market knowledge as the most strategically important resource to create customer value (e.g., Slater et al., 2012). As the understanding of resource scarcity is becoming increasingly important to the process of creating customer value, market knowledge should be complemented by knowledge about the natural environment within resource-scarce contexts. This also has implications for related concepts (e.g., market orientation). In the strategic-marketing literature, market orientation is regarded as the generation and dissemination of market information about customers and competitors, as well as about the factors that affect them (Kohli \& Jaworski, 1990). Our findings illustrate that naturalresource scarcity can be such a factor. For this reason, the generation and dissemination of information about natural-resource scarcity should be included within the domain of market orientation (see also Hult, 2011). This means that firms can differ in the level to which they are oriented to actual (potential) natural resource scarcities and that will likely affect how they perform in resource-scarce environments. 
Second, previous research in marketing has developed frameworks describing how firms explore and develop value propositions (e.g., Edvardsson, Klaus, Payne, \& Frow, 2014; Lusch, Vargo, \& Tanniru, 2010). As such, firms should first identify key dimensions of customer value and then develop their resource base by considering their own resources, as well as those of their partners (e.g., Edvardsson et al., 2014; Lusch et al., 2010). Such discussions have nevertheless stopped short of addressing the potential impact of future resource scarcities on a firm's ability to deliver value propositions to customers. The present study extends the literature by suggesting that the process of developing value propositions should also include evaluation for resilience to actual and future resource scarcities. This finding could encourage firms to explore value propositions that could best satisfy the value needs of their customers, given the actual and predicted scarcity of resources. This could maximize the likelihood that firms will be able to identify new or improved value propositions that can enable them to maintain their value creation during periods of resource scarcity.

Third, our findings indicate that market knowledge enhances a firm's ability to adapt to naturalresource scarcity if it is accompanied by knowledge about the natural environment concerning actual and predicted resource scarcity. This suggests that market knowledge complements naturalenvironment capabilities, and the combination of these two types of knowledge can enable firms to adapt the process of creating customer value to the scarcity of natural resources. This finding is in line with the literature that claims marketing capabilities are strategically important resources, but that the potential value of specific capabilities depends on other resources and capabilities (e.g., Orr, Bush, \& Vorhies, 2011). It is also consistent with the growing body of work calling for studying marketing capabilities with broader models that include other important performance antecedents, like organizational responsiveness (e.g., Hult, Ketchen, \& Slater, 2005) and product 
innovation (e.g., De Luca \& Atuahene-Gima, 2007), rather than simply linking them directly to firm performance.

Fourth, the dominant logic in the literature on strategic marketing and management concerning how to cope with resource scarcity is based on resource-dependency theory, which stresses the importance of strengthening relationships with stakeholders who control resources. The theory suggests forming alliances, joint ventures, mergers, and acquisitions to overcome dependency on scarce resources (Drees \& Heugens, 2013; Pfeffer \& Salancik, 2003). Such theorizing overlooks internal capabilities that reduce dependency on scarce resources. It also neglects the fact that competition over control of natural resources can exacerbate the scarcity of those resources. For common-pool natural resources (e.g., fresh water, fishing resources, and forests), such competition may lead to the depletion of those resources, as nobody owns them. Our study suggests that naturalresource adaptation capabilities could offer alternative strategies for reducing dependency on scarce resources, thereby enhancing the autonomy of organizations and complementing stakeholder-management strategies (Drees \& Heugens, 2013; Pfeffer \& Salancik, 2003). The literature has also suggested that dynamic capabilities could serve as a means of adapting to changing conditions within the business environment. The present study extends this to the natural environment, identifying the capabilities and types of knowledge that should be leveraged in order to make companies resilient to the scarcity of natural resources.

\subsection{Practical implications}

The results of this study imply that managers should start to gather, interpret, and share information about actual and predicted resource scarcities. Knowledge about the natural environment fosters capabilities that can be leveraged in the value-creation process. 
The results further highlight the importance of close cooperation between marketing managers and functional managers who make decisions concerning the appropriation and utilization of resources, especially when resources are acutely in short supply. By sharing their market knowledge with other functional managers (e.g., production and product-line managers), marketing managers could help to reduce potential mismatches between resource-scarcity adaptation actions and the value needs of customers. Market insight can provide guidance to functional managers concerning which adaptation actions are acceptable for which customers, given their impact on the value needs of customers. Managers should be aware that a lack of market insight could exacerbate the impact of resource scarcity by creating a mismatch between adaptation actions and the value needs of customers.

The results of this study also emphasize the importance of the supply-chain management approach to promote enhanced adaptation capabilities with regard to resource scarcity. Adaptation capabilities demand strong collaboration and the integration of marketing, logistics, and operation functions. Firms thus should integrate these activities internally, as well as with partners in their supply chains, both upstream (resources) and downstream (customers).

The traditional view of marketing communication as a messenger of "good news" (VillarejoRamos \& Sanchez-Franco, 2005) might not hold in the future. During acute shortages of resources, firms might not be able to deliver their products and services at the level that their customers expect. The traditional view of marketing communication as a means of conveying good messages to consumers (e.g., "our product is better than it was; our product is better than what you can find anywhere else") might not be logically possible for the marketers of the future. These marketers might also need to convey "bad news" to consumers and appeal to their responsibility. As a result, 
the theme of the marketing communication might need to change accordingly (e.g., "our product is not better than it was, but it is still much better than what you can find anywhere else").

\subsection{Future Research}

Our study represents an initial attempt to draw lessons from pre-existing resource-scarce settings. It nevertheless examines this issue based on only one context: Borana Pastoralists in Ethiopia. Borana pastoralists have their own unique collective culture and traditional self-governance system, which shapes their resource-scarcity adaptation practices and their management of natural resources (Homann et al., 2008). Future research could extend the results of this study to other resource-scarce settings (e.g., pastoralists in Kenya or small-scale farmers in Africa and Asia) to generate additional insight.

Our findings suggest that collaborative relationships between marketing and other business functions (e.g., logistics and production) is essential to the development of adaptation capabilities that create the capacity to cope with resource scarcity within the value-creation process. To this end, future studies could examine how the interface between marketing and other business functions affects the ability of firms to cope with actual and future resource scarcities.

The study suggests that customer-focused business processes require insight above and beyond market insight, as derived from the natural environment about actual and anticipated scarcity of resources in order to ensure business success. This implication has been derived from a qualitative case study of the real-life experiences of businesses in creating customer value within contexts of extreme resource scarcity. Future quantitative studies on the contributions of such adaptation capabilities to business performance are therefore needed in order to reinforce the findings of this study. 


\subsection{Conclusion}

Businesses can develop natural-resource adaptation capabilities within the process of creating customer value by using knowledge about the market and the natural environment to guide their value-creation processes. By studying the effect of internalizing insight about actual and predicted natural-resource scarcities during the value defining, developing, and delivering stages of the process of creating customer value, this study has identified three natural-resource adaptation capabilities: matching value propositions, natural resource deployment, and managing customer expectation. The findings suggest that knowledge about the natural environment can enable businesses to develop these adaptation capabilities and that market knowledge can foster the deployment of these capabilities within the value-creation process. Based on these findings, we conclude that marketing must be a learning process, not only about the market, but also about the natural environment with regard to actual and future resource scarcity. 



\section{Chapter 3}

\section{Market knowledge as a driver of adaptation capabilities in managing natural resource scarcity}

This chapter is to be submitted for publication as Desalegn A. Gugissa, Paul T.M.

Ingenbleek, \& Hans van Trijp. Market knowledge as a driver of adaptation capabilities in managing natural resource scarcity 


\begin{abstract}
In the marketing literature, market knowledge is regarded as a key resource for business performance in resource-rich contexts. This is because market knowledge can serve as a fuel that provides businesses with a superior understanding of the markets in which they operate. We posit that, in contexts in which even natural resources cannot be taken for granted, market knowledge also has a positive effect on performance, albeit for a different reason: it influences the ability of businesses to adapt to the scarcity of natural resources. In this study, we propose and test the mediating effects of natural-resource adaptation capabilities on the relationship between market knowledge and two key outcomes (product quality and quality of life). Our research focuses on an emerging market setting in which natural-resource scarcity is a common phenomenon: pastoralists in Ethiopia. The study is based on a cross-sectional dataset from 120 Ethiopian pastoralists who raise livestock in a context in which natural pasture is often scarce. The results confirm that market knowledge has a positive effect on adaptation capabilities. They further indicate that the effects of market knowledge on product quality and quality of life are mediated by capabilities to adjust value propositions to natural-resource scarcity and the ability to deploy natural resources in order to make efficient and effective use of existing resources. Managing customer expectations has only a marginal effect on quality of life. The results imply that enhancing market knowledge is a logical strategy for improving the capacity of businesses to adapt to natural-resource scarcity.
\end{abstract}

Keywords: Market knowledge, adaptation capabilities, natural resources, managing natural resource scarcity 


\subsection{Introduction}

In the marketing literature, it is widely recognized that businesses serve customers based on their market knowledge (e.g., Slater et al., 2012), which is their understanding of customers and competitors (Marinova, 2004; Slater et al., 2012). Market knowledge provides insight that businesses can use to guide their processes and activities toward the creation of superior value for customers (Moustaghfir, 2009; Slater et al., 2012). Market knowledge is leveraged into the capabilities of firms, which subsequently shape the products and services that they offer to customers, thereby impacting performance (Moustaghfir, 2009; Slater et al., 2012). Studies of market knowledge have demonstrated that a sharp understanding of markets enables businesses to provide advantageous products to customers (e.g., De Luca \& Atuahene-Gima, 2018; Joshi \& Sharma, 2004). Market knowledge is therefore regarded as the primary resource underlying the creation of superior customer value (Olavarrieta \& Friedmann, 2008; Slater et al., 2012).

Most existing studies on the knowledge-based view of the firm in marketing have been conducted in resource-rich markets (e.g., Northern America, Western Europe, and wealthy parts of Asia). This article extends the body of work on the knowledge-based view of the firm to the context of an emerging market characterized by scarcity of natural resources. The global economy is increasingly expanding into contexts that are often located in developing and emerging markets, where the creation of customer value is more dependent on the availability of natural resources. It is important to understand the role of market knowledge in the key outcomes of the process of creating customer value (e.g., product quality) within these contexts. Such understanding can help businesses to thrive, satisfy their customers, and improve the quality of life in impoverished settings. It is also relevant to contexts in which resources are plentiful, but that are facing increasing scarcity in specific resources, like rare-earth elements for high-tech industries (Bell et al., 2013). 
Studies on market knowledge and innovation have demonstrated that market knowledge facilitates creative behavior within firms (Troilo et al., 2014; Zhou \& Li, 2012). It also provides insight that can be used to generate creative solutions to business problems and to make changes in the processes and routines of a business (Atuahene-Gima \& Wei, 2011; Zhou \& Li, 2012). Scholars have consistently argued that creative ideas for resolving problems of resource scarcity can stem from a superior understanding of markets (Radjou et al., 2012; Slater, Mohr, \& Sengupta, 2014). Nevertheless, this effect has yet to be tested within contexts in which natural resources are scarce. This gap should be addressed for at least two reasons. First, understanding how market knowledge can help businesses to adapt to conditions of resource scarcity could enhance the development of environmentally sustainable marketing theories and practices (Kotler, 2011). Second, such understanding could help firms to cope effectively with actual or anticipated risks associated with resource scarcity.

In this article, we examine abilities that businesses use in order to adapt to natural-resource scarcity as mediators between market knowledge and two key outcomes of the process of creating customer value: product quality and quality of life. We report on quantitative tests to determine whether adaptation capabilities that intervene in the value defining, developing, and delivering stages of the process of creating customer value (Kotler \& Keller, 2012; Webster, 2002) mediate the effect of market knowledge on these outcomes within a resource-scarce setting. The study focuses on the resource-scarce context of Borana pastoralists in Ethiopia. The basic hypothesis of this article is that market knowledge enhances the ability of pastoralists to adapt to the scarcity of natural resources, thereby resulting in superior product quality for customers and higher quality of life for pastoralists. 
In the remainder of this article, we first provide a conceptual background on market knowledge and adaptation capabilities in the process of creating customer value. We then formulate hypotheses for our empirical study assessing the mediation effect of adaptation capabilities in the relationship between market knowledge and performance. We subsequently describe the method and present the results. We conclude the article with a discussion of our conclusions and implications for business development and future research.

\subsection{Conceptual background}

\subsubsection{The role of market knowledge in the process of creating customer value}

Existing marketing studies on the knowledge-based view of the firm suggest that market knowledge is the primary resource underlying the creation of superior customer value (Slater et al., 2012). Market knowledge refers to organized and structured information about markets, including customers, competitors, and dynamics within the market environment (De Luca \& Atuahene-Gima, 2018; Li \& Cavusgil, 1999). Satisfying customer preferences requires businesses to understand the wants and needs of their customers and competing offerings, to share this knowledge throughout the company, and to make coordinated use of resources to offer products that will better satisfy the needs of the customers (Slater et al., 2012). Businesses that are capable of offering superior product quality to customers are most likely able to do so because they have a better understanding of customer needs and competing offerings. Market knowledge thus serves as a basis for generating new ideas and for making decisions to use these ideas to develop a strong market position and take advantage of market opportunities (Sandvik \& Sandvik, 2003).

Capabilities are complex bundles of skills and knowledge exercised through organizational processes (Day, 1994; Sanchez \& Heene, 1997). The knowledge-based view of the firm regards capabilities as the primary basis upon which firms establish their value-creation strategies (Grant, 
1996a). Researchers have highlighted capabilities as specific resources that act upon other resources (Sanchez \& Heene, 1997; Teece, 2007), thereby enabling the integration of resources into products that customers perceive as being of valuable quality. The capability perspective thus suggests that capabilities enable businesses to engage in processes and actions aimed at creating value, as they enable superior coordination of these processes and activities.

This study is based on the notion that market knowledge is an important foundation for capabilities that enhance the integration of resources within the value-creation process (Day, 1994). Accordingly, market knowledge injects capabilities with an inherent customer focus throughout the resource-integration process (Slater et al., 2012; Webster, 2002). Capabilities that are injected with a customer perspective are likely to enable businesses to offer superior product quality to their customers. This is because market knowledge enhances their ability to understand how resources underlie the creation of superior customer value, thus improving their ability to steer the integration of resources toward the creation of superior customer value.

Empirical studies on the role of market knowledge have demonstrated that market knowledge influences performance in product innovation (e.g., Marinova, 2004; Zhou \& Li, 2012). During the process of product development, market knowledge enables businesses to coordinate the design of products to the needs of their customers and to expedite the execution of complex tasks in the product-innovation process, thereby accelerating the product-development process (Claudy et al., 2016; Im \& Workman Jr, 2004). A related study by Atuahene-Gima and colleagues (2011) indicates that market knowledge affects the quality of new products through problem-solving competence. Taken together, these studies suggest that market knowledge is a key factor fostering the problem-solving ability of businesses. In resource-scarce settings, the ability of businesses to adapt to the scarcity of resources also requires problem-solving ability. Natural-resource adaptation 
capabilities might therefore mediate the relationship between market knowledge and outcomes of the value-creation process (e.g., product quality).

\subsubsection{Capabilities for adapting the process of creating customer value to conditions of natural-resource scarcity}

The depletion of natural resources deprives firms of key productive resources. This affects their processes of creating customer value, given that natural resources are the biophysical foundations for all forms of resource-integration by firms (Hart \& Dowell, 2011). As the depletion of natural resources increases, businesses should adapt their processes of creating customer value to the existing resource scarcities. Adaptation refers to "the decision-making process and the set of actions undertaken to maintain the capacity to deal with current or future predicted changes" (Nelson et al., 2007, pp. 396).

In a less munificent environment, the continuity of the process of creating customer value requires insight into the availability of resources. Based on conditions of resource availability, businesses should adjust their value-creation processes in order to maintain their performance in delivering superior value to customers (Kotler, 2011). Consistent with the notion of a three-stage process of creating customer value (Webster, 2002), we propose three adaptation capabilities corresponding to the value defining, developing and delivering stages of the value-creation process.

The capability of "matching value propositions" refers to the ability of businesses to explore new opportunities for creating value and to make changes to existing value propositions by considering actual and predicted resource constraints. From the perspective of businesses, value propositions represent value-creation opportunities expressed in terms of the value needs of target customers and the attributes of intended value offerings (Dopfer, Fallahi, Kirchberger, \& Gassmann, 2017; Payne et al., 2017). By identifying and recognizing the actual and future resource constraints in the 
value propositions, businesses make adjustments to their value propositions in ways that match the resources needed to deliver the value propositions to customers to the resource constraints. This allows businesses to recognize new or improved value-creation opportunities. In effect, businesses may develop new or improved products that use fewer materials, reduce/avoid the use of scarcely available resources, and/or substitute existing products, thereby helping to minimize the experienced loss of value for customers during periods of resource scarcity. For example, driven primarily by resource scarcity, GE redesigned its ECG machine to be more resource-efficient by using less plastic and a smaller LCD screen (Sharma \& Iyer, 2012). With regard to reducing the use of scarce materials in product design, George, Schillebeeckx, and Liak (2015) provide interesting examples of Fusion and C-Max car models. For these models, Ford switched to lithiumion batteries primarily to reduce the need for dysprosium, the most expensive rare earth metal. Examples of developing substitute products include Beyond Meat and The Vegetarian Butcher, which have developed meat analogues that look and taste like meat, but that are made from plantbased proteins, like soy and peas (Ingenbleek \& Zhao, 2018).

The capability of " natural resource deployment" refers to the ability of businesses to make efficient and effective use of resources within the value-development process in order to maintain outcomes of the value-creation process during periods of resource scarcity (cf., Kor \& Mahoney, 2005; Slotegraaf et al., 2003). It entails flexibility and effectiveness in the deployment of resources, rather than merely "efficiency." During periods of natural-resource scarcity, businesses can enhance their usage of natural resources by re-deploying resources in ways that create the maximum value for customers, as well as by building up slack resources that can serve as shock absorbers (e.g., larger inventories, flexible production processes, redundant suppliers, and access to alternative resources). The re-deployment of resources across product categories, customers, and market 
segments based on the potential for improving profits can help businesses to reduce the impact of resource scarcity on their primary target markets (e.g., Venkatesan \& Kumar, 2004). For example, Amazon identifies consumers - and not its sellers, enterprises, and content providers-as its primary customers. The company therefore allocates maximum resources in order to satisfying consumers, even if this implies that sellers or content providers will sometimes experience resource constraints and a need for additional resources (Simons, 2014). To reduce the impact of supplychain disruptions, businesses can also build up slack resources (e.g., larger inventories and redundant suppliers) as a buffer for such disruptions (e.g., Bode, Wagner, Petersen, \& Ellram, 2011). For example, Li and Fung, the largest trading company in Hong Kong, established a supply network of more than 4,000 suppliers in order to mitigate supply-chain disruptions (Tang \& Tomlin, 2008).

Finally, in the value-delivering process, businesses communicate their value offerings to customers in order to exchange these offerings with customers. At this stage, they manage the expectations of customers based on the anticipated impact of resource scarcity. Managing customer expectations refers to the management of relationships and interactions with customers in order to create an appropriate level of value expectation in their minds (Coye, 2004; Sheth \& Mittal, 1996). This means that businesses inform customers about the condition of resource scarcity and its consequences for the value that can be created for the customers. Managing customer expectations thus affects the expectations that customers have of the value offering, which subsequently influences their perceptions of value losses during periods of resource scarcity. 


\subsection{Conceptual model and propositions}

A model of the proposed relationships between market knowledge (antecedent), adaptation capabilities (mediators), and the two outcomes — product quality and quality of life — is presented in Figure 3.1.

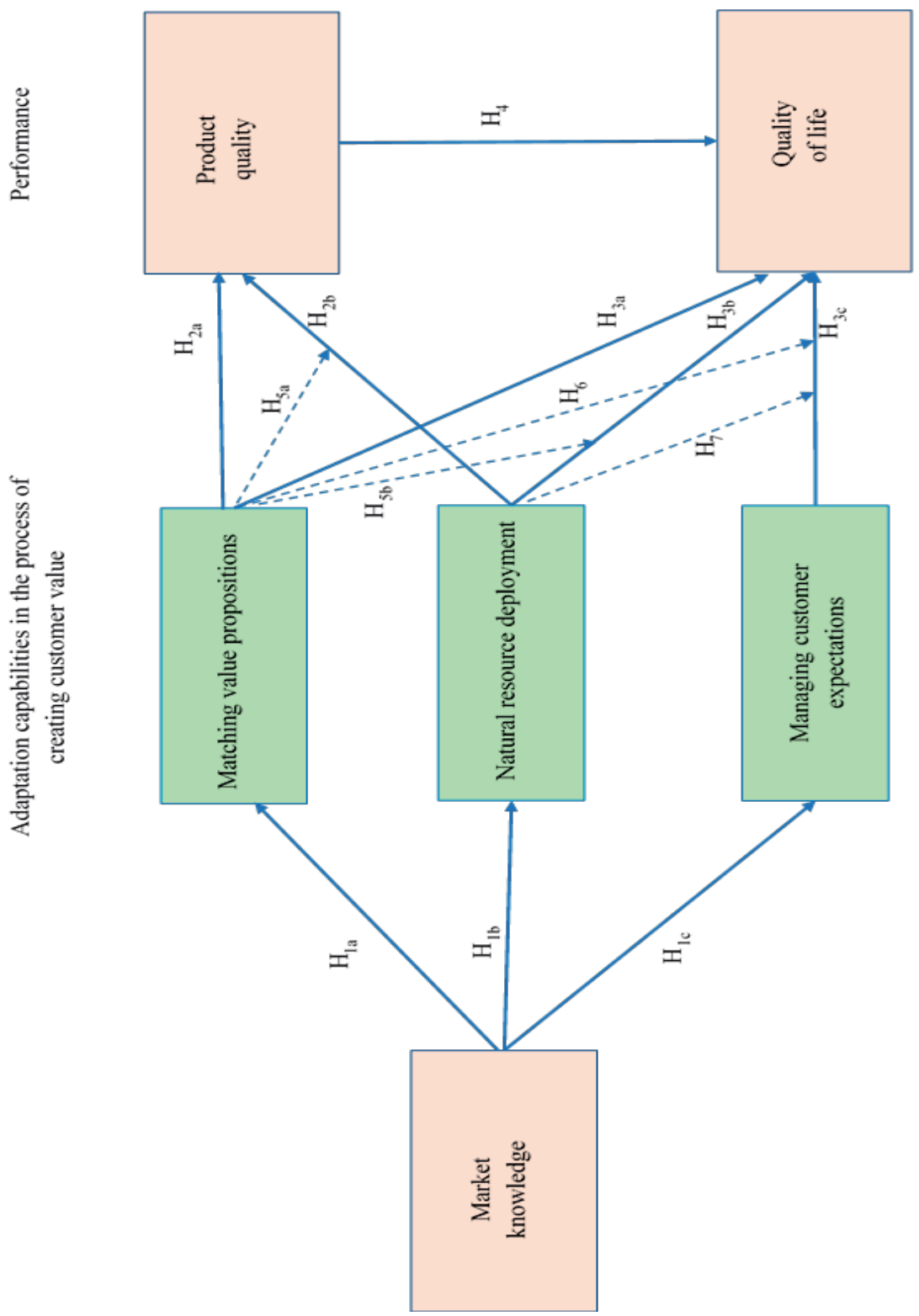




\subsubsection{The effect of market knowledge on adaptation capabilities}

Adaptation capabilities represent the ability of businesses to undertake adaptation actions that create the capacity to cope with resource scarcity in the value-creation process. As capabilities, the matching of value propositions, the natural resource deployment, and the management of customer expectations comprise bundles of knowledge and skills that enable businesses to be effective and efficient in the production of market offerings that have value for customers (Teece, 2007). We argue that market knowledge is a particularly essential component of these capabilities. The literature suggests that fundamental knowledge on the functioning of markets, the needs of customers, and the influence of competitors' actions is essential to be competitive in the creation of customer value (Kim \& Atuahene-Gima, 2010; Slater et al., 2012). In a less munificent environment, firms need to undertake adaptation actions in order to create customer value. The extent to which they are able to undertake such action is affected by their level of market knowledge.

To adapt the value-creation process and maintain business performance, businesses should consider the outcomes: value for customers. The understanding of customer value is enhanced by market knowledge on which the capabilities are drawn. In the value-defining stage, market knowledge allows businesses to evaluate adjustments to their value propositions (matching value propositions) from the perspective of satisfying key customer values: economic, functional, emotional, and symbolic (Edvardsson et al., 2014; J. B. Smith \& Colgate, 2007). Market knowledge can therefore help businesses to adjust their value propositions in ways that minimize the impact of resource scarcity on key dimensions of customer value. In the value-developing stage, market knowledge provides insight into how resources underlie customer value (Day, 1994; Slater et al., 2012), thus helping to reduce the risk of potential misfits between the value needs of customers and the 
deployment of natural resources during resource-scarce times. Finally, in the value-delivering stage, a sharp understanding of the needs and wants of customers can help businesses to create stronger relationships with their customers (Campbell, 2003). Firms with greater market knowledge are thus in a better position to leverage their relationships with customers to manage the expectations of customers during periods of resource scarcity. We therefore hypothesize:

$\mathrm{H}_{1}$ : The higher the market knowledge, the higher the (a) matching value propositions, (b) natural resource deployment, and (c) managing customer expectations.

\subsubsection{The effect of adaptation capabilities on product quality}

Product quality refers to the characteristics of products or services that contribute to the fulfillment of the stated or implied needs and wants of customers (Kroll, Wright, \& Heiens, 1999; Zhou, Li, Zhou, \& Su, 2008). Product quality is widely recognized as a primary source of competitive advantage. It plays a central role in marketing strategy, as it allows businesses to satisfy the needs and wants of customers more effectively than their competitors (Zhou et al., 2008). Studies on resource management suggest that the possession of resources alone cannot guarantee the fulfillment of the needs and wants of customers. The extent to which businesses can fulfil these needs and wants depends on the actions that they undertake to manage the use of resources (Ndofor, Sirmon, \& He, 2011; Sirmon et al., 2007). The strategic marketing literature also suggests that offering product quality to customers requires businesses to acquire capabilities that will enable them to carry out the activities involved in the value-creation process (Day, 1994). Taken together, these two streams of literature suggest that a business's ability to manage the use of resources toward activities that create customer value plays an important role in its ability to deliver superior product quality to customers. In less munificent environments, this ability involves undertaking adaptation actions, including matching value propositions to resource conditions, deploying 
resources efficiently and effectively, and managing customer expectations based on the anticipated impact of resource scarcity.

A business that is good at undertaking adaptation actions from the perspective of satisfying the requirements of customers within the value-creation process is more likely to have the advantage of maintaining product quality for its customers during periods of resource scarcity. First, in the value-defining stage, matching value propositions increases the likelihood that a business will be able to adjust its value propositions in ways that will create the highest value for customers, given anticipated uncertainties in the availability of natural resources. Subsequently, in the valuedeveloping stage, the capability to deploy natural resources can increase the likelihood that a business will direct the allocation of its existing resources toward maximizing value creation for customers or/and use its slack resources (e.g., inventories and alternative resources) to minimize the impact of resource scarcity on the creation of customer value. Nevertheless, the capability of managing customer expectations has no impact on the actual quality of the products delivered to customers, as it affects only the ways in which customers perceive product quality. All else being equal, therefore, businesses that are more proficient in matching value propositions and natural resource deployment will create more quality than their competitors will. We therefore hypothesize:

$\mathrm{H}_{2}$ : The higher the ability to adapt the process of creating customer value by (a) matching value propositions, and (b) natural resource deployment, the higher the product quality.

In addition to enhancing the quality of products to be offered on the market, the adaptation capabilities that help to minimize the impact of natural-resource scarcity on product quality will also have a positive effect on quality of life. In the literature, quality of life refers to the general well-being of individuals (Layton, 2009; Nussbaum et al., 1993). More specifically, it consists of 
the expectations that individuals have for a good life, which are guided by their values, goals, and the socio-cultural contexts within which they live (Layton, 2009; Nussbaum et al., 1993). The capabilities influence quality of life through product quality. This is because product quality enhances business performance, which subsequently increases disposable income, which can be used to satisfy wants and needs, thereby enhancing quality of life (Layton, 2009). Given that quality of life extends beyond economic performance, the adaptation capabilities may also have a direct effect, due to their environmental and social impact. The adaptation capabilities affect the living environment by reducing the over-exploitation of natural resources (García-Sánchez, GallegoÁlvarez, \& Zafra-Gómez, 2019; Khan, Daddi, \& Iraldo, 2020). We therefore hypothesize:

$\mathrm{H}_{3}$ : The higher the ability to adapt the process of creating customer value by (a) matching value propositions, b) natural resource deployment, and (c) managing customer expectations, the higher the quality of life.

$\mathrm{H}_{4}$ : The higher the product quality, the higher the quality of life.

As discussed earlier, the adaptation capabilities of matching value propositions, natural resource deployment, and managing customer expectations lead to sequential adjustments in the respective stages of the process of creating customer value (i.e., value defining, developing and delivering). These stages comprise the horizontally sequential activities necessary to satisfy the needs of customers (cf. Day, 1994; Webster, 2002). The effects of the adaptation capabilities on the outcomes - product quality and quality of life - are thus likely to be contingent on each other. Effective leveraging of the capability of matching value proposition is likely to reduce the effects of the other two adaptation capabilities, as it partially mitigates the impact of natural-resource scarcity during the first stage of the value-creation process. Likewise, the capability of natural 
resource deployment is likely to reduce the need to manage customer expectations. The capability of managing customer expectations may thus be necessary only if the scarcity of resources is so great to be managed by leveraging the first two capabilities and/or if these two capabilities were not leveraged effectively enough to reduce the impact of resource scarcity. We therefore hypothesize:

$\mathrm{H}_{5}$ : The higher the ability to match value propositions, the weaker the impact of natural resource deployment on (a) product quality and (b) quality of life.

$\mathrm{H}_{6}$ : The higher the ability to match value propositions, the weaker the impact of managing customer expectations on quality of life

$\mathrm{H}_{7}$ : The higher the ability to natural resource deployment, the weaker the impact of managing customer expectations on quality of life

\subsection{Methods}

\subsubsection{Research context}

To test our hypotheses empirically, we collected data within the setting of Borana pastoralists in southern Ethiopia. These pastoralists earn their living by producing livestock and livestock products in arid areas, where the natural resources necessary to sustain their livestock production are often scarce (Angassa \& Oba, 2008; Gemedo-Dalle et al., 2006). They primarily use natural pasture and water resources in the process of breeding and fattening livestock to satisfy the needs of both buyers and their own households. Their family-based businesses depend on the availability of these natural resources, which are often scarce and seasonally variable, due to arid and semiarid climatic conditions of the region (Luseno et al., 2003). The scarcity of natural resources is an important factor that forced many of the pastoralists into a subsistence-orientated semi-nomadic 
lifestyle (Davies, 2008; Galvin, 2009; Lee et al., 2009). The subsistence-oriented livestock production system mostly focuses on sustaining the livelihoods of individual pastoralists and their families. Their traditional system of ecological knowledge, which is the cumulative result of centuries of practical experience in matching the specific demands of their herds to the unpredictable supply of natural pasture and water in a fragile environment, has enabled them to develop a wide variety of adaptation actions to use in coping with natural-resource scarcity (Gemedo-Dalle et al., 2006; Homann et al., 2008).

In the past few decades, Borana pastoralists have been increasingly integrating into local and international market-oriented food-supply chains (Catley et al., 2013). This trend is expected to make them more market-driven, which will require them to guide their livestock-production systems from the perspective of satisfying the requirements of their buyers. Previous studies have demonstrated that pastoral households can generate more value for customers and enhance their performance by organizing their production processes according to market insight (e.g., Ingenbleek et al., 2013; Tessema et al., 2019). Cultural values and clan norms discourage the selling of livestock, however, thus pressuring individual pastoralists to prioritize protecting their traditional way of life over breeding and fattening animals for the market (cf. Tessema et al., 2019). As a result, the decisions that pastoralists make regarding livestock production may not focus entirely on satisfying the needs of customers. Instead, such decisions tend to be directed toward both satisfying the requirements of buyers and preserving their traditional way of life. Market integration thus provides pastoralists with the opportunity to continue using the best aspects of their traditional livestock-production system (which can be regarded as natural-resource adaptation practices) in the process of producing livestock that satisfies the requirements of buyers. 
In this study, we collected data from 120 Borana pastoralists living in southern Ethiopia. The participants were selected from a broader marketing-training project. In the project, 60 pastoralists were trained in marketing knowledge and compared to a control group of the same size (Teklehaimanot, 2017). The experimental marketing training was delivered in October 2015. The participants were selected using a multi-stage sampling procedure. Four villages from two administrative districts in the region-Yabello and Dire-were used as sampling units for selecting the 120 participants (Teklehaimanot, 2017). The data for this study were collected in August 2018, during a dry season in the region. The rationale for selecting this period is that, during dry seasons, pastoralists are more likely to exercise adaptation actions due to the scarcity of pasture and water resources. This was expected to enable us to collect data on adaptation actions while they were still fresh in the minds of our respondents.

\subsubsection{Measures}

Multi-item scales were used to measure market knowledge, adaptation actions for natural-resource scarcity (matching value propositions, natural resource deployment, and managing customer expectations), product quality and performance (the items are listed in Appendix 3.1). All items were measured along a five-point Likert scale ranging from "strongly disagree" to "strongly agree". The measures were developed based on a qualitative pre-study consisting of 61 individual interviews, three focus-group discussions, and observations conducted across the Borana pastoral region. The study helped us to formulate the measures to be concrete and easily understood by our respondents. We then selected a sample of 20 pastoralists to pre-test the measurement scales, after which we revised the scales further for consistency, wording, and meaning. As recommended by Churchill (1979), we used principal component analysis and Cronbach's alpha to refine and retain items of the multi-item measurement scales. 
Fundamental market knowledge (e.g., understanding how the market operates, competitors' actions, and the needs of buyers) is essential to success in creating and delivering value (Ozkaya, Droge, Hult, Calantone, \& Ozkaya, 2015; Slater et al., 2012). We operationalized market knowledge as the level of understanding of fundamental market knowledge needed to create, communicate, deliver, and exchange livestock according to buyer preferences. After deleting items loading lower than 0.70 on the common factor, we used seven items to measure market knowledge. The measure includes items pertaining to the respondent's level of understanding concerning the benefits of working to satisfy the needs of buyers, as well as of searching for ways to satisfy these needs, performing activities aimed at meeting these needs, and communicating with buyers in order to explain the quality attributes and pricing of the value that they are able to offer.

Matching value propositions is operationalized as the ability of pastoralists to adjust the composition of their herds (size, species, and breed) in ways that enhance their ability to satisfy the requirements of customers under actual and predicted changes in the availability of natural pasture. The measure consists of seven items related to how well pastoralists adjust their herd size, species composition, and breeds in order to raise livestock that could potentially meet the requirements of buyers by matching their livestock structure to actual and predicted changes in the availability of natural pasture in the grazing rangelands. Respondents rated their performance in terms of how well they were performing such adjustments, as compared to others.

Natural resource deployment is operationalized as the ability of the pastoralists to adjust their ways of gathering, storing, and using natural pasture and other supplementary inputs in order to minimize the impact of natural-pasture scarcity in fattening selected livestock to the level of quality required by buyers. It was measured according to seven items reflecting the extent to which pastoralists buy animal feed and supplementary inputs, store animal feed for dry seasons, produce hay and crop 
residues, and selectively feed animals for the market. Our scale builds on the existing scale developed by Teklehaimanot (2017) to measure the ability of pastoralists to use natural pasture to fatten animals for the market.

Managing customer expectations is operationalized as the ability of pastoralists to communicate with buyers in order to make them aware of potential decreases in the desired quality attributes of the livestock they intend to sell during resource-scarce times. The measure consists of six items reflecting the extent to which pastoralists communicate with livestock buyers and brokers in advance with regard to the quality of livestock that they intend to offer for sale during dry periods and droughts.

We operationalize product quality as a pastoralist's self-rated desirable quality attributes of livestock offerings to buyers, as compared to other pastoralists. Previous studies (e.g., Chang \& Chen, 1998) have indicated that self-reported product-quality measures are highly correlated with objective measures. Our product-quality measure consists of six items reflecting the quality of livestock in terms of breed, body condition, fattening, health condition, fewer ticks, and quality from the buyer's perspective.

We measure quality of life with a context-specific, formative scale of livelihood performance indicators. The items reflect outcomes that are typically desired within the pastoralist culture, including herd size, earning money, saving money, sending children to school, engaging in additional economic activities, and making contributions to clan members (Ingenbleek et al., 2013).

\subsubsection{Data Analysis}

The partial least squares structural equation model (PLS-SEM) was used to predict the relationships among the constructs involved in our conceptual model (see Figure 3.1). PLS-SEM is a causal 
modeling approach aimed at maximizing the explained variance of endogenous latent constructs (Hair, Ringle, \& Sarstedt, 2011). We selected PLS-SEM instead of the covariance-based structural equation model (CB-SEM), as the estimators generated by PLS-SEM are more stable than those of CB-SEM for a wider range of sample sizes (Hair et al., 2011). Our relatively small sample size makes PLS-SEM more appropriate (Hair, Sarstedt, Ringle, \& Mena, 2012). In our study, the maximum number of indicators per construct is seven, thus satisfying the popular guideline stating that the minimum sample size should be 10 times the maximum number of indicators per construct (Hair et al., 2012). The relative stability of the estimators generated by PLS-SEM also applies to complex structural equation models (Hair et al., 2012). With six latent constructs and 10 relationships to be estimated, our conceptual model is relatively complex (Hair et al., 2012). The use of the PLS-SEM approach is also recommended for measurement scales that include formative scales (Hair et al., 2012).

We followed a two-stage approach in estimating our model, in order to create interaction terms between latent factors. The scores of the latent predictor and latent moderator factors from the main-effect model (without the interaction terms) are used to create interaction terms (Becker, Ringle, \& Sarstedt, 2018). The latent variable scores are subsequently saved and used in the secondstage analysis, which involves the interaction term, in addition to the predictor and moderator variables (Becker et al., 2018). This approach is recommended, as it draws on standardized product terms and provides more stable estimates than other approaches (e.g., the product-indicator approach) (Becker et al., 2018). 


\subsection{Results}

\subsubsection{Measurement validity and reliability}

We used Cronbach's alpha and composite reliability to evaluate the internal consistency or reliability of the constructs in the reflective outer model. For all constructs, these scores were greater than .70 , thereby confirming the internal consistency of the constructs (Churchill, 1979; Fornell \& Larcker, 1981). As recommended by Hair, Sarstedt, Hopkins, and Kuppelwieser (2014), convergent validity was assessed by examining the factor loadings and the average variance extracted (AVE). The loadings of all items were greater than the desired .70 loading level, and all AVE values exceeded the required .50 for convergent validity (Hair et al., 2014) (see Table 3.1).

The discriminant validity of the scales was also assessed, in order to verify whether the scales effectively measure different factors. We did so by comparing the squared inter-factor correlation with the AVE values of the constructs (Hair et al., 2014). All squared inter-factor correlations were less than the AVE value for all constructs (see Table 3.1). These results provide evidence that our scales measure different constructs. 


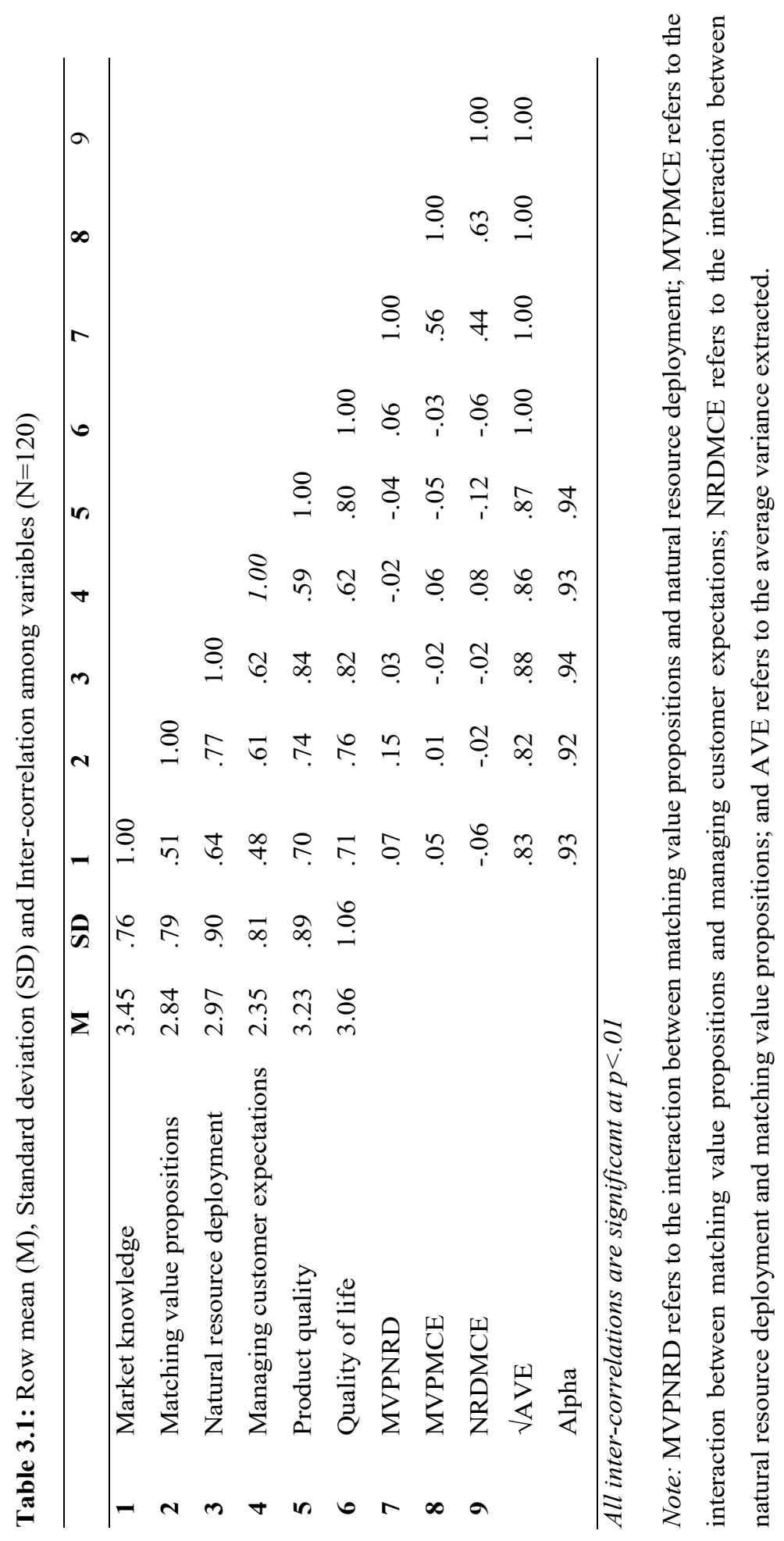




\subsubsection{Hypothesis testing}

We tested the hypotheses by examining the standardized path coefficients in our conceptual model (Figure 3.1) which includes the interaction terms (Stage 2 of the analysis). Hypotheses 1a, 1b, and lc predict that market knowledge has direct positive effects on the adaptation capabilities of matching value-propositions, natural resource deployment, and managing customer expectations. A hypothesis is supported if there is a statistically significant and positive standardized beta coefficient for the direct effect of market knowledge on the capabilities. As presented in Table 3.2, the results indicate that the direct effects of market knowledge on the capabilities of matching value proposition, natural resource deployment and managing customer expectations are $\beta=.51(\mathrm{p}<.01)$, $\beta=.64(p<.01)$, and $\beta=.48(p<.01)$, respectively. These results provide strong support for Hypotheses 1a, lb, and lc. 
Table 3.2: Standardized path coefficients

\begin{tabular}{llll}
\hline Structural path & Path coef. & t-value & ${ }^{1} \mathrm{R}^{2}$ \\
\hline Market knowledge -> Matching value propositions & $.51^{* * *}$ & 6.38 & .26 \\
Market knowledge -> Natural resource deployment & $.64^{* * *}$ & 9.16 & .42 \\
Market knowledge -> Managing customer expectations & $.48^{* * *}$ & 6.00 & .23 \\
Matching value propositions -> Product quality & $.26^{* *}$ & 3.36 & .74 \\
Natural resource deployment -> Product quality & $.65^{* * *}$ & 8.62 & \\
Matching value propositions -> Quality of life & $.18^{* *}$ & 2.22 & .75 \\
Natural resource deployment -> Quality of life & $.36^{* *}$ & 3.36 \\
Managing customer expectations -> Quality of life & $.13^{*}$ & 1.97 & \\
Product quality -> Quality of life & $.29^{* * *}$ & 3.06 \\
MVPNRD -> Product quality & $-.10^{* *}$ & -2.02 \\
MVPNRD -> Quality of life & .08 & 1.32 \\
MVPMCE -> Quality of life & -.03 & -1.52 \\
NRDMCE -> Quality of life & -.04 & 2.08 \\
\hline
\end{tabular}
${ }^{*} p<.10 ; * * p<.05 ; * * * p<.01$.

Hypotheses $2 \mathrm{a}$ and $2 \mathrm{~b}$ predict that the natural-resource adaptation capabilities of matching value propositions and natural resource deployment have direct positive effects on product quality. As presented in Table 3.2, the results provide support for these hypotheses: matching value propositions $-\beta=.26(\mathrm{p}<.05)$ and natural resource deployment $-\beta=.65(\mathrm{p}<.01)$. Consistent with our expectations, the direct effect of managing customer expectations was not significant $(\beta=.08$, $\mathrm{p}>.10)$.

Hypothesis 3 predicts that the adaptation capabilities have direct positive effects on quality of life. Hypotheses $3 \mathrm{a}, 3 \mathrm{~b}$, and $3 \mathrm{c}$ predict that the capabilities of matching value propositions, natural resource deployment, and managing customer expectations have direct positive effects on quality

\footnotetext{
${ }^{1}$ Represents the R-square for the dependent variable in the path
} 
of life. As presented in Table 3.2, the results provide support for these hypotheses: matching value propositions $-\beta=.18(\mathrm{p}>.05)$, natural resource deployment $-\beta=.36(\mathrm{p}<.01)$, and managing customer expectations $-\beta=.13(\mathrm{p}<.10)$. These results provide strong support for Hypotheses $3 \mathrm{a}$ and $3 \mathrm{~b}$, but the support for Hypothesis $3 \mathrm{c}$ is only marginally significant.

Hypothesis 4 predicts that product quality has a direct positive effect on quality of life. As presented in Table 3.2, the results provide support for this hypothesis: $\beta=.29(\mathrm{p}<.01)$.

\subsubsection{Moderation tests}

Hypothesis 5 predicts that a stronger capability of matching value propositions weakens the effects of the capability of natural resource deployment on product quality and quality of life. As presented in Table 3.2, the interaction between matching value propositions and natural resource deployment had a significant negative effect on product quality $(\beta=-.10, \mathrm{p}<.05)$, but not on quality of life $(\beta=$ $.08, \mathrm{p}>.10$ ). The results thus provide support for Hypothesis $5 \mathrm{a}$, but not for Hypothesis $5 \mathrm{~b}$. To probe the moderation effect of matching value proposition, we performed floodlight analysis, which helps to test the conditional effects of a predicting variable over a moderating variable, in order to identify the regions where the effect is and is not significant (Spiller, Fitzsimons, Lynch Jr, \& McClelland, 2013). Figure 3.2 shows a graph of the estimated conditional effect of natural resource deployment on product quality, with confidence intervals. The graph reveals a nonsignificant JN (Johnson-Neyman) region (values of a moderating variable in which the conditional effect of a predicting variable becomes insignificant) (cf. Spiller et al., 2013), although the effect decreases as the capability of matching value propositions increases (see Figure 3.2). This result suggests that the capability of matching value propositions does indeed moderate the effect of natural resource deployment on product quality and that - regardless of the capability of matching 
value propositions - the capability of natural resource deployment continues to play an important role in maintaining product quality during times of resource scarcity.

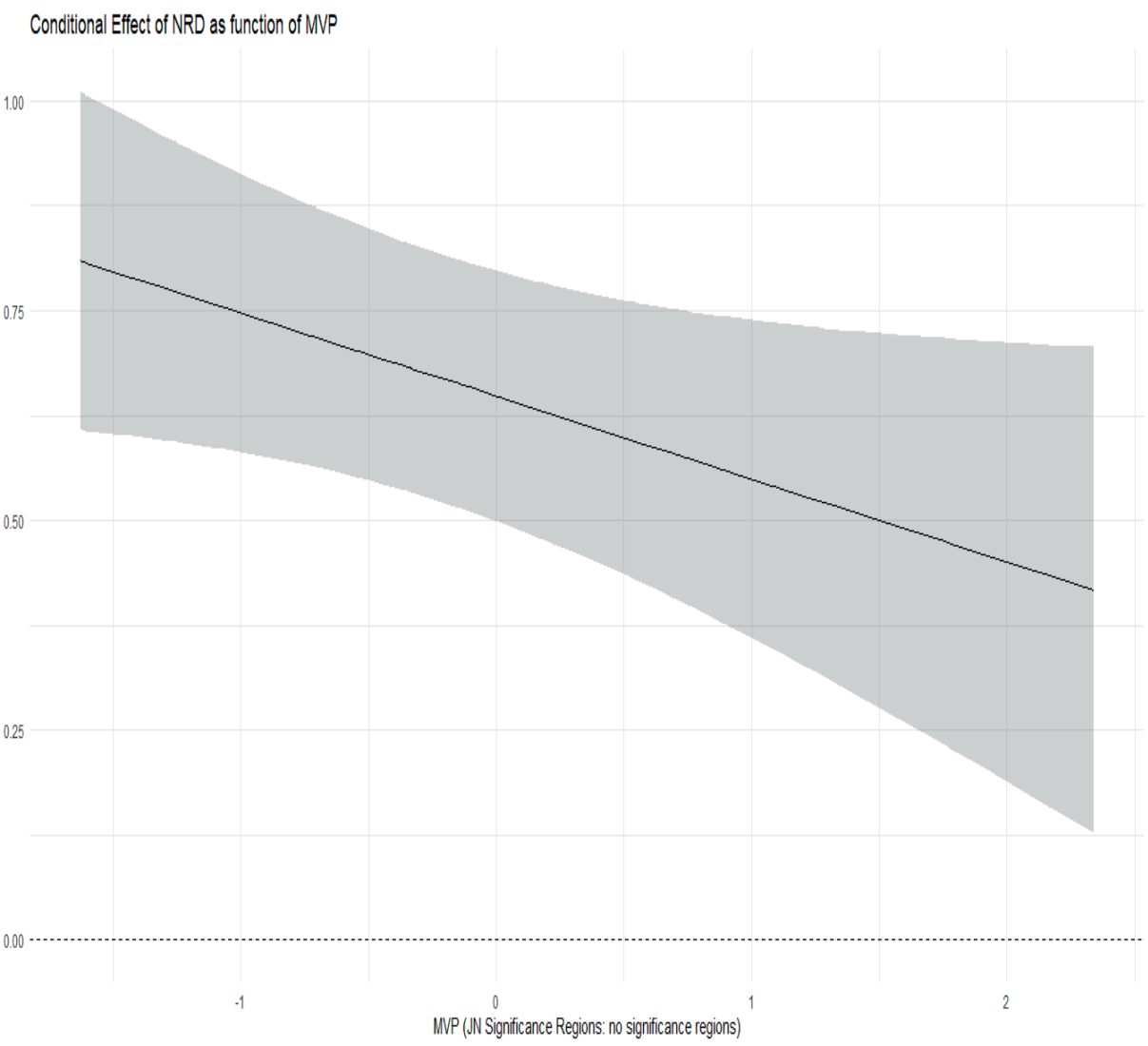

Figure 3.2: The conditional effects of the capability of natural resource deployment (NRD) on product quality, as a function of the capability of matching value propositions (MVP), with confidence intervals.

Hypothesis 6 predicts that higher capability of matching value propositions capability weakens the impact of managing customer expectations on quality of life. The results indicate that the interaction term between the capabilities of matching value propositions and managing customer expectations has no significant effect on quality of life $(\beta=-.03, p>.10)$. The hypothesis is thus not supported. 
Finally, Hypothesis 7 predicts that higher capability of natural resource deployment weakens the impact of managing customer expectations on quality of life. The results do not support this hypothesis, as they reveal no significant effect of the interaction term between natural resource deployment and managing customer expectations on quality of life $(\beta=-.04, p>.10)$.

\subsubsection{Mediation tests}

We conducted an additional analysis in order to determine whether the impact of market knowledge on product quality and quality of life was mediated by the adaptation capabilities. We tested for mediation effects by following the two-step mediation procedure developed by Nitzl, Roldan, and Cepeda (2016). First, we examined the significance and effect size of the indirect effect of market knowledge on product quality and quality of life, after controlling for its direct effects of market knowledge on product quality and quality of life (Nitzl et al., 2016). We then assessed the significance of the direct effects of the market knowledge on the mediating variables (adaptation capabilities) and those of the mediating variables on the outcome variable (product quality), in order to identify mediation effects. The results provide evidence of mediation effects if the indirect effects of market knowledge and the direct effects predicted in Hypotheses 1 and 2 are statistically significant after controlling for the direct effects of market knowledge on product quality and quality of life. The direct, indirect, and total effects are presented in Table 3.3. 
Table 3.3: Results of the mediation test (direct, indirect, and total effects after controlling for the direct effect of market knowledge on product quality and quality of life)

\begin{tabular}{|c|c|c|c|c|c|c|}
\hline \multirow[b]{2}{*}{ Structural path } & \multicolumn{2}{|c|}{ Direct effect } & \multicolumn{2}{|c|}{ Indirect effect } & \multicolumn{2}{|c|}{ Total effect } \\
\hline & Coef. & $\begin{array}{l}\text { t- } \\
\text { value }\end{array}$ & Coef. & $\begin{array}{l}\text { t- } \\
\text { value }\end{array}$ & Coef. & $\begin{array}{l}\mathrm{t}- \\
\text { value }\end{array}$ \\
\hline Market knowledge -> Matching value propositions & $.51 * * *$ & 6.38 & & & $.51 * * *$ & 6.38 \\
\hline Market knowledge->Natural resource deployment & $.64 * * *$ & 9.15 & & & $.65 * * *$ & 9.15 \\
\hline Market knowledge -> Managing customer expectations & $.48 * * *$ & 5.98 & & & $.48 * * *$ & 5.98 \\
\hline Market knowledge -> Product quality & $.27 * * *$ & 4.90 & $.44 * * *$ & 8.27 & $.71 * * *$ & 12.46 \\
\hline Matching value propositions -> Product quality & $.26 * * *$ & 3.64 & & & $.26 * * *$ & 3.64 \\
\hline Natural Resource Deployment -> Product quality & $.47 * * *$ & 6.08 & & & $.67 * * *$ & 6.08 \\
\hline Matching value propositions-> Quality of life & $.23 * * *$ & 3.02 & .04 & 1.44 & $.27 * * *$ & 3.72 \\
\hline Natural resource deployment ->Quality of life & $.29 * * *$ & 3.16 & .07 & 1.52 & $.36 * * *$ & 4.50 \\
\hline Managing customer expectations -> Quality of life & .09 & 1.46 & & & .09 & 1.46 \\
\hline Product quality -> Quality of life & .14 & 1.57 & & & $.14 * * *$ & 3.20 \\
\hline Market knowledge -> Quality of life & $.26 * * *$ & 1.48 & $.45^{* * *}$ & 8.11 & $.72 * * *$ & 13.12 \\
\hline
\end{tabular}

Significance level: $* * *: p<.01 * *: p<.05, *: p<.10$.

As shown in the table 3.3, market knowledge has significant effects on product quality, both direct $(\beta=.27 ; \mathrm{p}<.01)$ and indirect $(\beta=.44 ; \mathrm{p}<.01)$. These results suggest that at least one of the two adaptation capabilities have a mediating effect. The results also indicate that the capabilities of matching value propositions and natural resource deployment continue to have significant direct effects on product quality $(\beta=.26 ; \mathrm{p}<.01$ and $\beta=.47 ; \mathrm{p}<.01$, respectively). Market knowledge has also significant direct effects on matching value propositions $(\beta=.51 ; \mathrm{p}<.01)$ and natural resource deployment $(\beta=.64 ; p<.01)$. The results thus provide evidence to support the mediating effects of the capabilities of matching value propositions and natural resource deployment on the relationship between market knowledge and product quality. The mediation is only partial, however, as the direct effect of market knowledge on product quality remains significant (Hayes, 2013). 
The results further indicate that the direct and indirect effects of market knowledge on quality of life are significant $(\beta=.26 ; p<.01$ and $\beta=.56 ; p<.01$, respectively). The capabilities of matching value propositions and natural resource deployment have significant direct effects on quality of life $(\beta=.23 ; p<.01$ and $\beta=.29 ; p<.01$, respectively). However, the capability of managing customer expectations has no significant direct effect on quality of life $(\beta=.09 ; \mathrm{p}>.10)$. The results thus provide support for the mediating effects of the capabilities of matching value propositions and natural resource deployment on the relationship between market knowledge and quality of life.

As demonstrated in Table 3.3, the total effects of market knowledge on product quality are significant $(\beta=.71 ; p<.01)$, as are the direct effects of matching value propositions $(\beta=.26 ; p<.01)$ and natural resource deployment $(\beta=.47 ; \mathrm{p}<.01)$. Market knowledge has significant direct effects on the capabilities of matching value propositions $(\beta=.51 ; \mathrm{p}<.01)$ and natural resource deployment $(\beta=.64 ; \mathrm{p}<.01)$. These results imply that $42 \%(.47 * .64 / .71=0.42)$ of the total effect occurs through the capability of natural resource deployment, with nearly $20 \%\left(.26^{*} .51 / .71=0.19\right)$ occurring through the capability of matching value propositions. Finally, the total effect of market knowledge on quality of life is significant $(\beta=.72 ; \mathrm{p}<.01)$, with $16 \%$ occurring through the capability of matching value propositions $(.23 * .51 / .72=0.16)$ and nearly $26 \%(.29 * .64 / .72=0.26)$ occurring through the capability of natural resource deployment.

Finally, as noted previously, we adopted our sampling frame from a marketing-training intervention in October 2015 (cf. Teklehaimanot, 2017). As a validity check, we assessed whether this training had affected the data that we collected in August 2018. The assessment consisted of post-hoc tests comparing the factor-score values of the participants from the original experimental and control groups on the scores on the latent variables. The Bonferroni, Scheffe, and Sidak posthoc tests revealed no statistically significant differences between the experimental and control 
groups for any of the latent factors. These results imply that the training intervention had no significant effect on our results.

\subsection{Discussion}

In this article, we examine the mediating role of natural-resource adaptation capabilities in the relationship between market knowledge and the outcomes of the process of creating customer value within a resource-scarce setting. Data were collected from family-based pastoral businesses in Ethiopia. Pastoralists often operate under conditions of natural-resource scarcity, due to the arid climatic conditions of their region. They have long-established cultural practices of adapting their livestock production to natural-resource scarcity. As such, their situation offers an interesting context within which to test the role of the adaptation capabilities. The findings indicate that the adaptation capabilities of matching value propositions and natural resource deployment act as positive mediators on the relationship between market knowledge and two key outcomes within the process of creating customer value: product quality and quality of life.

Our results provide support for the mediating effects of the adaptation capabilities of matching value propositions and natural resource deployment on the impact of market knowledge on product quality and quality of life. Managing customer expectations was found to have no significant mediation effect. The most likely explanation for this result is that the capability of managing customer expectations intervenes at a later stage in the value-creation process. Its effects are thus likely to be weaker if the former two capabilities have already been effectively leveraged at earlier stages in this process.

Our results further show that the capability of matching value propositions acts as a negative moderator of the relationship between natural resource deployment and product quality. Contrary 
to our predictions, neither matching value propositions nor natural resource deployment had any significant moderation effect on the impact of managing customer expectations on quality of life. This finding supports our earlier conclusion that the capabilities of matching value propositions and natural resource deployment are relatively more effective at mitigating the adverse effect of natural-resource scarcity on the outcomes, thereby reducing the need to manage customer expectations.

\subsection{Theoretical implications}

The study has implications for the marketing literature on the knowledge-based view of the firm (e.g., Slater et al., 2012). According to this literature, market knowledge is the most strategically important resource to create customer value (e.g., Slater et al., 2012). Because most existing studies have been conducted within resource-rich contexts, however, they do not provide much insight into the role of market knowledge in developing and emerging markets, which are often characterized by resource scarcity. The present study addresses this gap in the literature by examining the role of market knowledge under conditions of natural-resource scarcity. The findings indicate that market knowledge continues to affect performance in resource-scarce settings, as it influences adaptation capabilities aimed at coping with the scarcity of natural resources. Market knowledge enables businesses to leverage adaptation capabilities from the perspective of maintaining product quality, thus enabling them to maintain their performance in periods of resource scarcity. Our study thus provides empirical evidence that market knowledge can be an important component of resourcescarcity adaptation capabilities within the value-creation process.

The study has implications for discussions on the contribution of marketing to sustainability. The existing literature on the relationship between marketing and the natural environment often focuses on resource-rich contexts in North America and Western Europe (e.g., Mariadoss, Tansuhaj, \& 
Mouri, 2011; Mu, 2015; Weerawardena, 2003). This study contributes to the literature by demonstrating how market knowledge leads to more adaptation actions aimed at coordinating business operations and practices to changes in the natural environment during periods of resource scarcity. It indicates that market knowledge accelerates adaptation actions aimed at naturalresource scarcity at every stage in the value-creation process. One important contribution of this study is therefore the suggestion that, in addition to helping businesses to thrive, market knowledge can also help businesses to adapt their value-creation processes in response to changes in the natural environment. Such adjustments are essential to balancing business practices with the need to pursue sustainability (Duffy et al., 2017; Kotler, 2011).

The results of this study also have implications for the contribution of marketing to development within the context of developing and emerging markets in which businesses are likely to be more dependent on scarce natural resources (Layton, 2009; Viswanathan, Sridharan, Gau, \& Ritchie, 2009). Of the three adaptation capabilities that are directly affected by market knowledge, matching value propositions and natural resource deployment appear to have the greatest impact on business performance in periods of natural-resource scarcity. Market knowledge can thus help enterprises to reduce the impact of resource scarcity on their business performance. This finding is consistent with those of previous studies emphasizing the importance of market knowledge for helping businesses to thrive, satisfy their customers, and improve the quality of life in developing countries (e.g., Teklehaimanot et al., 2017; Viswanathan et al., 2009). The results of our study suggest that programs aimed at enhancing market knowledge (e.g., marketing-training interventions) can be an effective tool for promoting the development of enterprises in developing countries, in which businesses are often faced with natural-resource scarcity. 


\subsection{Practical implications}

The results of this study imply that managers need an in-depth understanding of the needs and want of customers in order to be effective in leveraging resource-scarcity adaptation capabilities within the value-creation process. They further identify market knowledge as an important component of adaptation capabilities. Marketing managers should therefore seek ways to share market knowledge with other functional managers (e.g., production and product line managers), especially during periods of resource scarcity. This is because the lack of market insight can lead to mismatches between the adaptation actions undertaken by different functional managers and the value needs of customers. To avoid such mismatches, marketing managers should work very closely with other functional managers who make decisions concerning adaptation actions during periods of resource scarcity.

According to our findings, adaptation actions undertaken at early stages in the value-creation process are more effective in coping with resource scarcity. By focusing on adaptation actions that adjust value propositions based on anticipated resource scarcities and that enhance the ability to make efficient and effective use of existing resources, businesses can cope effectively with resource scarcity before it affects the value that they ultimately deliver to their customers. Managing customer expectations is relatively less effective in coping with resource scarcities. Managers should therefore consider managing customer expectations as the last resort in coping with resource scarcity, to be applied only if the capabilities of matching value propositions and deploying natural resources are not sufficiently effective in coping with resource scarcity.

Our results further suggest that policy-makers in developing and emerging countries can accelerate business development by helping business owners to develop market knowledge. Marketingtraining interventions have been used to overcome gaps in the business knowledge that is needed 
in order to cater to the needs of specific markets (Teklehaimanot et al., 2017; Viswanathan et al., 2009). This study further highlights the need for such market interventions by providing empirical evidence that market knowledge can also contribute to the development of businesses in resourcescarce environments by strengthening their capabilities for adapting to resource scarcity. Marketing interventions could therefore also be designed to address gaps in the adaptation capabilities of businesses operating within resource-constrained contexts, as is the case with small-scale farmers and pastoralists in Africa and Asia.

\subsection{Limitations and Directions for Further Research}

The present study is subject to several limitations that highlight opportunities for future research. First, we collected data only once from 120 observations during a single dry season, during which the pastoralists normally experience scarcity of pasture resources. Future studies could extend our findings by testing the relationship using panel data collected over multiple conditions of naturalresource availability (e.g., multiple reasons: dry, rainy, and drought) and for longer periods. The use of panel data could provide additional insight into how the mediation effect of adaptation capabilities varies over time, based on changes in conditions of natural-resource availability.

The insights reported in this article are based on a study in the unique context of Ethiopian pastoralists. This context differs in many ways from other emerging and developing market contexts, in which enterprises also experience various types of resource scarcity in the process of value creation. To obtain a broader understanding of how the lessons learned through this study could be translated to other contexts, we encourage more research in different resource-scarce contexts in which businesses must cope with the scarcity of different types of critical resources. For instance, entrepreneurs in urban areas in Africa, Latin America, and Asia experience scarcity of financial resources and other input supplies. Farming businesses in rural areas in those parts of 
the world also experience scarcity of natural resources and other important input supplies. Empirical evidence from diverse contexts could thus further refine and strengthen the findings reported in this article.

This study examines the role of market knowledge for value creation only within contexts in which natural resources are scarce. It does not examine whether enhancements in the value creation takes place through the over-exploitation or sustainable use of natural resources. Previous studies have demonstrated that with increasing market integration communities can adopt different approaches regarding the sustainable use of natural resources (e.g., Oldekop et al., 2013; Vaccaro, Zanotti, \& Sepez, 2009). This is because an increase in market integration can act as both an incentive and a disincentive for the over-exploitation of natural resources (Oldekop et al., 2013; Vaccaro et al., 2009). It can lead to over-exploitation of resources by providing access to cash resources for shortterm interest (Acheson, 2006; Mutenje, Ortmann, \& Ferrer, 2011). At the same time, however, it can foster the sustainable use of resources by influencing the perception of gains and losses associated with over-exploitation (e.g., Oldekop et al., 2013; Vaccaro et al., 2009). Future research could thus extend the findings of this study by assessing the impact of market knowledge on the sustainable use of natural resources, based on an experiment involving a common-pool resource dilemma. Such studies could provide additional insight into the effect of market knowledge on the decisions of resource users with regard to the use of common-pool natural resources.

\subsection{Conclusion}

To our knowledge, this study is the first to suggest market knowledge as an antecedent to capabilities for adapting to natural-resource scarcity within the value-creation process. Higher market knowledge enhances three important natural-resource adaptation capabilities: matching value propositions, natural resource deployment, and managing customer expectations. This 
subsequently enhances the capacity of businesses to cope with natural-resource scarcity within the value-creation process. This implies that businesses with a better understanding of the needs and wants of customers are better equipped to cope with the adverse effects of natural-resource scarcity. This is because market knowledge helps businesses to explore, evaluate, and implement adaptation actions from the perspective of minimizing the impact of resource scarcity on the process of creating customer value. Conversely, the lack of market insight can generate mismatches between the adaptation actions of businesses and the value needs and wants of customers. The results of our study further demonstrate that capabilities of matching value propositions and natural resource deployment, which intervene early in the value-creation process (i.e., in the value-defining and value-developing stages), are more effective at coping with natural-resource scarcity than is the capability of managing customer expectations, which intervene later in the process (i.e., in the value-delivering stage). 


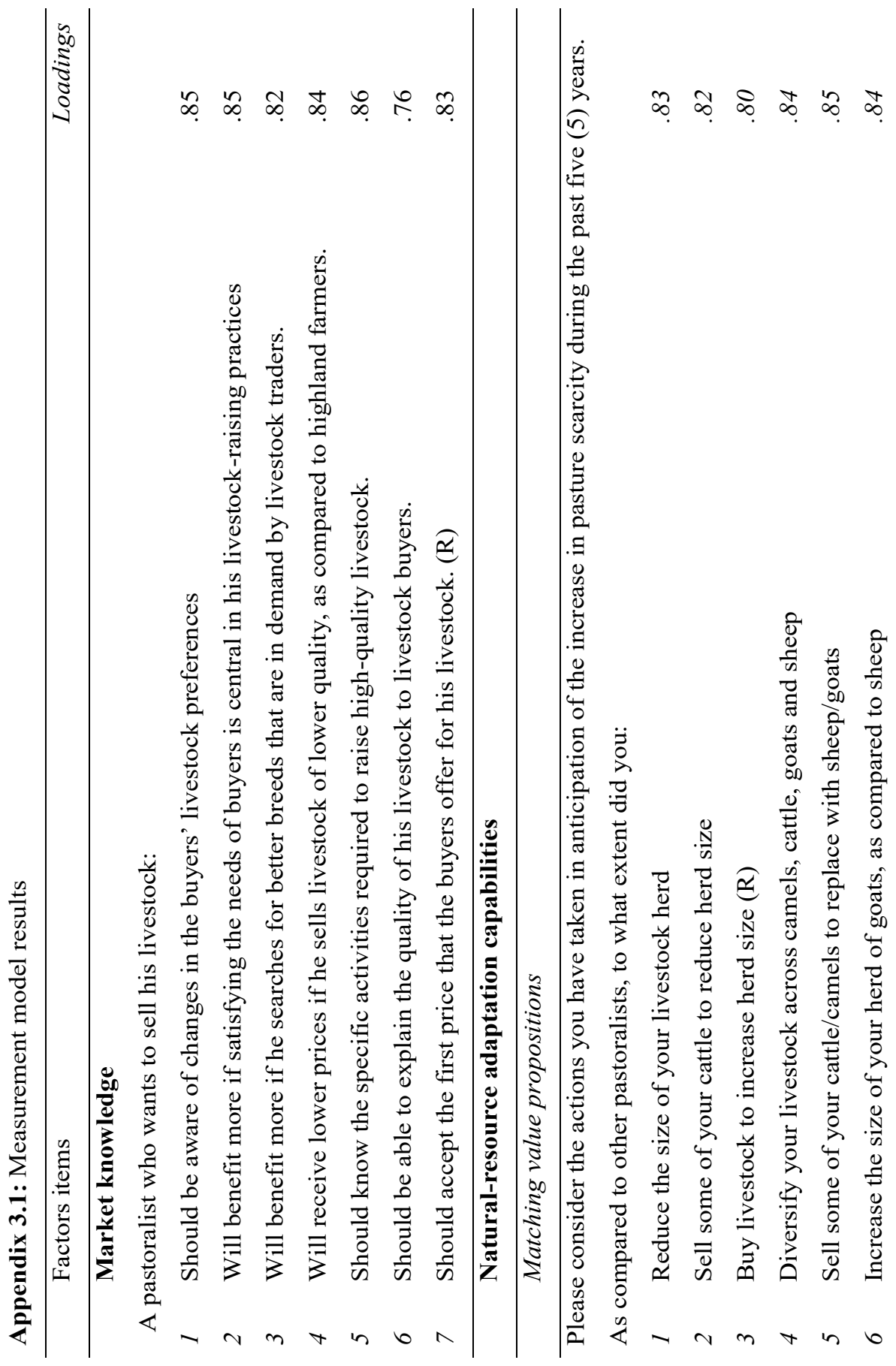




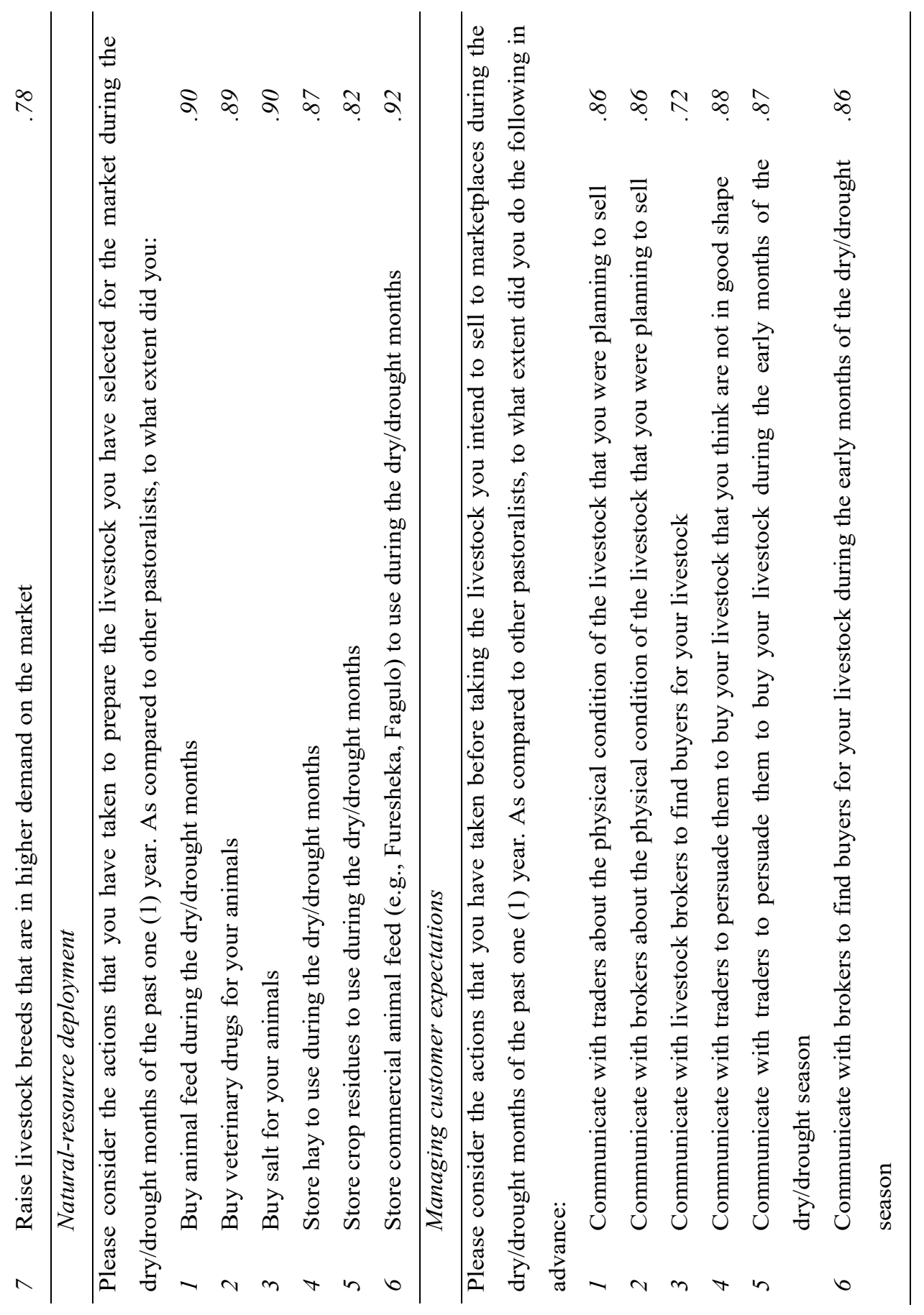




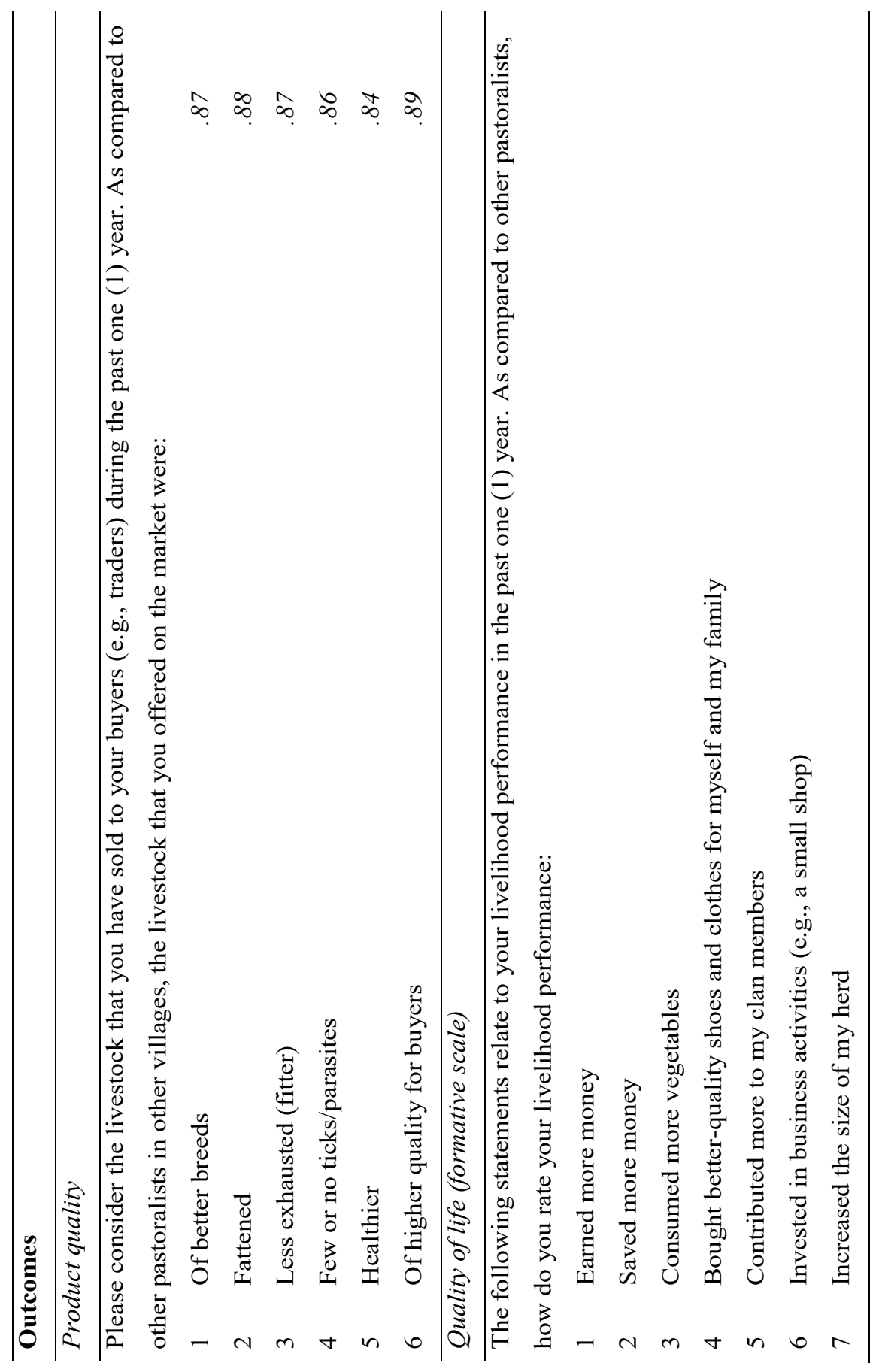





\section{Chapter 4}

\section{When natural resource run out, market knowledge steps in: Natural resource deployment studies in a resource-scarce emerging market context}

This chapter is submitted for publication as Desalegn A. Gugissa, Paul T.M. Igenbleek,

Mebrahtu L. Teklehaimanot, Workneh K. Tessema \& Hans van Trijp.

When natural resource run out, market knowledge steps in: Natural resource deployment studies in a natural resource-scarce emerging market 


\begin{abstract}
With the increasing scarcity of natural resources, the ability to maintain quality standards during resource-scarce times becomes more critical for firm performance. Theories on the effectiveness of resource scarcity management practices cannot be easily tested in affluent contexts where resources are still abundant. This study therefore turns to an emerging market context in which natural resource availability naturally varies strongly between seasons, namely that of Ethiopian pastoralists. Using three-wave longitudinal data from 120 pastoral family-based livestock businesses, the study shows that pastoralists minimize the drop in product quality during resourcescarce times through resource deployment of pasture and rooting decisions on the resource deployment in market knowledge. The lesson for firms that are confronted with approaching resource scarcity is therefore to start developing their resource deployment capabilities and strengthen their market knowledge in which such capabilities are rooted.
\end{abstract}

Keywords: Resource deployment, market knowledge, product quality, resource scarcity management, resource deployment capabilities 


\subsection{Introduction}

With the increasing scarcity of natural resources, the development of business strategies to deal with this issue becomes a key concern (Beermann, 2011; Field et al., 2012). Due to drought, in 2012 the water supply to rice farmers in Texas was cut off, which reduced yields (Phillips, Rodrigue, \& Yücel, 2013). The Dutch industry sees itself confronted with a sudden decrease in gas supply after earthquakes occurred in gas winning regions (Schmidt, Boersma, \& Groenewegen, 2018). The standard response to this issue from strategic management is to strengthen access to resources through power or strengthening stakeholder relations (cf. Pfeffer \& Salancik, 2003). Consistent with this advice, firms and governments facing realistic scenarios of acute resource shortages have started to secure access to the world's remaining resources of metals, agricultural lands, and water (Moyo, 2012). In more peripheral parts of the global economic system that lack the power to exercise control, direct threats of resource shortages may already be more acute. For example, in Africa, droughts in grain-producing nations caused an increase in food prices and stockouts in bakeries and empty bread shelves in supermarkets (Berazneva \& Lee, 2013). With a continuing increase in resource consumption, such shortages will gradually spread to more affluent parts of the world, putting more pressure on companies that rely on policies to secure access to the scarce resources. These companies should, therefore, think strategically about how much resources they necessarily need to use in which value-creating processes for which customers and using alternative solutions for other purposes.

The existing literature on business strategy and sustainability has mostly neglected such strategies to manage acute natural resource scarcity. The literature tends to see natural resource availability as a long-term sustainability objective (Bansal \& DesJardine, 2014; Dyllick \& Hockerts, 2002) rather than an issue that needs acute attention. This bias is logically explained by the fact that 
studying acute scarcity is virtually impossible in the resource affluent environments in which the business literature has its roots. In another line of research, authors have argued that resource scarcity can also trigger product innovation because acute scarcity requires creative solutions (e.g., Cunha et al., 2014; Troilo et al., 2014). Stretching this line of thinking further, Radjou et al. (2012) look at resource-scarce contexts in emerging markets to derive valuable lessons for innovation that may also be implemented in contexts that are still resource-rich. These works address the sidebenefits of resource scarcity, but don't address the direct threat of scarcity to ongoing operations. This study therefore examines natural resource deployment, which refers to the management of resource scarcity that enables firms to survive in resource-scarce environments by enhancing their ability to make efficient and effective use of the available resources for creating quality offerings (cf. Kor \& Mahoney, 2005; Slotegraaf et al., 2003). The concept relates to the ability of firms to maintain performance in resource-scarce conditions through flexible and effective deployment of resources, rather than only through the "efficient" deployment of resources. The study answers the question of whether natural resource deployment stabilizes quality across resource-rich and resource-scarce times, and it examines the role of market knowledge as a strategic asset underlying resource deployment capability.

To accomplish these objectives, this study turns to the context of Ethiopian pastoralists. Pastoralists make a living by raising herds of cattle, camels, sheep, and/or goats in arid lands where natural resources necessary to sustain their livestock production are often scarce and temporally fluctuating (Lee et al., 2009). They see themselves faced with the challenges of breeding and fattening livestock such that they meet the needs of live animal traders and their own needs for food, which stimulates them to develop capabilities that allow them to deal strategically with scarce resources. The pastoralist context has been used for decades to draw lessons on adaptation to resource scarcity 
in disciplines such as ecology (e.g., Davies, 2008), anthropology (e.g., Galvin, 2009), and economics (e.g., Barrett \& Carter, 2010), but business researchers have developed an interest only recently (e.g., Ingenbleek et al., 2013). In this complex context, we collected three waves of data from 120 pastoral family-based livestock businesses at low, high, and extremely high resourcescarce periods.

This study makes the following contributions: First, we provide insight into a strategic capability that helps firms to be resilient to resource scarcity, namely natural resource deployment, a topic that is mostly absent in the debate on strategy and environment. Second, we show that market knowledge helps to overcome the shortage of natural resources, in that the effect of market knowledge on natural resource deployment is stronger during resource-scarce times. In other words, we show that the effect of market knowledge on natural resource deployment is positively moderated by natural resource scarcity. This result provides a deeper insight into how market insights fuel the managerial decisions on how to deal with acute resource scarcity. Third, we contribute to the knowledge-based view of the firm (Grant, 1996b), in that market knowledge is not only a valuable asset to foster innovation and product differentiation (Luca \& Atuahene-Gima, 2007) but also it has another, less recognized role, namely to maintain quality standards by fuelling resource deployment capabilities with customer insights.

\subsection{Conceptual Model and Hypotheses}

\subsubsection{Natural Resource Deployment}

Literature on resource management distinguishes the ways firms manage resources. Resource structuring refers to the processes of acquiring, accumulating, and deleting the resources in a firm's stock of resources (Sirmon et al., 2007). Resource bundling refers to the process in which resources 
are integrated to develop capabilities. Leveraging is the processes used to configure and deploy capabilities specific to a particular market context (Sirmon et al., 2007).

With regard to the management of natural resources, the literature has mostly focused on the first two steps. Approaching the scarcity of natural resources that are vital for a firm may be anticipated when structuring resources. Stakeholder theory suggests that acting legitimately and creating and maintaining relationships with stakeholders is important for the firm so as to maintain access to the resources controlled by these stakeholders (Eesley \& Lenox, 2006; Mitchell, Agle, \& Wood, 1997). The natural resource-based theory of the firm also emphasizes stakeholder management as a strategic action to maintain control over natural resources (Hart \& Dowell, 2011).

With regard to resource bundling, firms may strengthen capabilities that help them to decrease their dependence on resources that may become scarce or are threatened to become perceived as illegitimate. Certification schemes like Rainforest Alliance and the Marine Stewardship Council, for example, help companies create new capabilities in their supply chains in order to increase their ability to comply with standards for sustainable natural resource usage (Fiorino \& Bhan, 2016; B. G. Smith, 2007).

In the leveraging of natural resources, we focus on natural resource deployment. Natural resource deployment is an example of what Hart (1995) calls strategic environmental capability because it helps businesses reduce the impact on the environment by minimizing the inputs required and improving the production method for natural resource efficiency. Building on Kor and Mahoney (2005) and Slotegraaf et al.'s (2003) concepts of resource deployment, natural resource deployment includes improving resource access and effectiveness in the apportionment and usage of natural resources. In the context of maintaining product quality, flexibility in resource access and 
apportionment are typical strategic capabilities that enable the firm to determine which customer will experience the most value from the application of the scarce natural resources, to replace natural resources with substitutes where possible, and to minimize the usage of scarce resources that cannot be replaced.

\subsubsection{Product Quality and Natural Resource Deployment}

Product quality refers to the characteristics of a product or service that contribute to the fulfillment of the stated or implied customer needs and wants (Kroll et al., 1999; Zhou et al., 2008). Studies on resource management suggest that the possession of resources alone cannot guarantee the creation of competitive advantage. Rather, the actions that businesses undertake to manage the use of resources in business processes underlie the competitive advantage (Ndofor et al., 2011; Sirmon et al., 2007). Those actions include decision-making regarding the deployment of natural resources.

A business that is good at natural resource deployment has an advantage in deciding which materials to use for which purposes and which customers, and therefore offers better quality products. A business that is more proficient in the deployment of natural resources, keeping everything else equal, therefore creates more quality than its competitors. Products with superior quality enable a business to achieve greater business performance that its competitors (e.g., Buzzell \& Gale, 1987; Kirca, Jayachandran, \& Bearden, 2005). This reasoning leads to our first hypothesis:

$\mathrm{H}_{1}$ : The better the natural resources deployment, the higher the product quality.

\subsubsection{The Effect of Market Knowledge on Natural Resource Deployment}

As a capability, natural resource deployment is a bundle of knowledge and skills (Teece, 2007). We propose that market knowledge in particular is one of its determinants. Market knowledge refers to organized and structured information about customers, competitors, and dynamics in the market 
environment (De Luca \& Atuahene-Gima, 2018). The literature suggests that fundamental market knowledge on how markets function, the needs of customers, and the influence of competitors' actions is essential to competitively create customer value (Slater, 1997). Satisfying customer needs with product quality requires a business to understand the needs of its customers, share the knowledge about those needs throughout the business, and make coordinated deployment of resources to offer products and services that satisfy those needs (Slater et al., 2012). Thus, it is the market knowledge of businesses that provides direction for the deployment of natural resources. A business with a better understanding of the customer needs can more easily find the opportunities for effective apportionment, substitutions, and efficient utilization of natural resources because it reduces the chance of potential misfits (Moorman \& Day, 2016). We therefore hypothesize:

$\mathrm{H}_{2}$ : The higher the level of market knowledge, the higher the level of natural resources deployment.

\subsubsection{The Moderating Effects of Natural Resource Scarcity}

In resource-rich environments, the decisions on which materials to use to satisfy the needs of particular customer groups are mostly of an operational nature. When some resources get scarce, natural resource deployment becomes a greater challenge because not all the resources for the desired purposes and customers may be available (Sirmon et al., 2007). The same process of using market knowledge to deploy natural resources in order to manage the product quality offered to the market then becomes a process of significant strategic importance. According to the marginal productivity theory, when resources have different availability levels, scarce resources are more productive because of an increased rate of marginal productivity for the scarce resources (Bleischwitz, 2001). The natural resource deployment actions like apportioning, substituting, and the effective use of scarcely available resources thus become more important for product quality when natural resources are relatively scarce. We hypothesize: 
$\mathrm{H}_{3}$ : The effect of natural resource deployment on product quality is stronger in high resource-scarce times than in low resource-scarce times.

We draw on contingency theory and research on creativity and resource scarcity to hypothesize that the effect of market knowledge on natural resource deployment becomes stronger if resources are scarcer. Studies on creativity and resource scarcity suggest that businesses engage more in innovative activities to accumulate resources, improve resource usages, and find substitutions when they operate in a resource-scarce environment (e.g., Baker \& Nelson, 2005; Berrone, Fosfuri, Gelabert, \& Gomez-Mejia, 2013; Cunha et al., 2014). These studies, however, don't specify the relationships that lead to the creative and enhanced use of resources. Contingency theory may help fill this gap as it suggests that the business environment, among others, influences the effectiveness of resource deployment and therefore acts as a moderator rather than an antecedent of resource deployment (Schoonhoven, 1981). Radjou et al. (2012) suggest that the creative ideas on resource usage probably stem from a superior understanding of customer needs, allowing them to come up with resource-efficient solutions that are also valued by the market. Following their line of reasoning, resource-scarce environments are likely to strengthen the relationship between market knowledge and natural resource deployment. We hypothesize:

$\mathrm{H}_{4}$ : The effect of market knowledge on natural resource deployment is stronger in high resourcescarce times than in low resource-scarce times.

\subsection{Methods}

\subsubsection{Research Context}

To test the hypotheses, we collected three waves of data from 120 Borana pastoralists in Southern Ethiopia. During the three waves, the ecological conditions were dry (hereafter $\mathrm{t}_{1}$ ), rainy (hereafter 
$t_{2}$ ), and droughty (hereafter $t_{3}$ ). As a result, the pastoralists were facing relatively distinct levels of scarcity of natural pasture and water at each wave of data collection. To create a panel data set of three seasons at relatively different levels of natural resource scarcity, the study builds on a broader project. Specifically, 60 pastoralists were trained in market knowledge and compared to a control group of the same size. The participants were selected using a multi-stage sampling procedure from four administrative villages of the region (cf. Teklehaimanot, 2017).

The data at $t_{1}$ were collected in March 2015, before the training experiment during a long dry season of the region, i.e., a resource-scarce period. The $t_{2}$ data were collected on November 2015 shortly after a rainy month in the region, thus denoting a low resource-scarce period. The data at $\mathrm{t}_{3}$ were collected in August 2017 during a drought, thus representing an extremely resource-scarce period. The timing of $t_{3}$ data collection was prudently selected to capture a distinct level of scarcity of natural resources compared with the data at $t_{1}$ and $t_{2}$. Thus, the natural pasture scarcity level can be comparatively described as extremely high at $\mathrm{t}_{3}$, high at $\mathrm{t}_{1}$, and low at $\mathrm{t}_{2}$. The data were collected using personal interviews that took place in grazing fields. Prior to the interviews, we got into contact with the pastoralists by contacting the development agents in each village. To minimize administrative method bias, we used the same data collection instruments, procedure, and technique used by Ingenbleek et al. (2013) to replace the traditional Likert scale with more visual tasks of choosing from five sticks. The data at $t_{1}, t_{2}$, and $t_{3}$ consisted of 120,120 , and 118 respondents, respectively. Two respondents were not reachable at $t_{3}$ since they had moved too far away from the research area to be traced. 


\subsubsection{Measures}

Multi-item scales (see Appendix 4.1 for the items) were used to measure market knowledge, natural resource deployment, and product quality constructs. All the items were measured using a fivepoint Likert scale ranging from 'strongly agree' to 'strongly disagree.' The items were developed based on a qualitative pre-study and formulated as concretely as possible to make them easily understandable to the respondents (Teklehaimanot, 2017). The market knowledge measures tested the pastoralists' level of understanding of how markets function; the customer needs; the influence of competitors' actions, that they need to know to produce, communicate, deliver, and exchange quality livestock in ways that satisfy the requirements of buyers and benefits them (Teklehaimanot, 2017). After deleting the items with variant loadings across time, the measure of market knowledge included six items.

Natural resource deployment was operationalized with five items that indicate the relative ability of pastoralists to use the natural pasture for fattening, and thereby increase the quality of the livestock that they have selected for the market, through separately feeding the livestock, assembling feeds, protecting some grazing areas, and reserving feeds. Product quality was measured as relative superior livestock attributes offered to the buyers compared with those of competitors. The measure includes four items pertaining to the relative livestock quality: the body condition, health condition, amount of ticks, and level of quality (Teklehaimanot, 2017).

We assessed the chance of common method bias in our estimates using Harman's one-factor method test (Podsakoff, MacKenzie, Lee, \& Podsakoff, 2003) and a full collinearity assessment approach (Kock, 2015). Both approaches suggest that it is unlikely that the results are affected by common-method bias. To check whether our measurement scales are consistent across the three data waves, we checked the invariance of the items' loading over the times using a likelihood-ratio 
test between unrestricted and restricted models (Acock, 2013). We first ran a multi-group confirmatory factor analysis (CFA) by taking data collection movements as a grouping variable without imposing any constraints on the loadings. Then we ran another CFA by imposing constraints that all the corresponding loadings are the same across $t_{1}, t_{2}$, and $t_{3}$. The result of the likelihood-ratio test indicates that the invariance of item loadings across time is satisfied with chi ${ }^{2}$ $(24)=32.67$ and prob $>$ chi $^{2}$ is .11 .

\subsubsection{Data Analysis}

The partial least square structural equation model (PLS-SEM) is used to predict the effects of market knowledge on natural resource deployment. PLS-SEM is a causal modeling approach aimed at maximizing the explained variance of endogenous latent constructs (Hair et al., 2011). We used PLS-SEM instead of the covariance-based SEM (CB-SEM) because PLS-SEM achieves more stable estimators than CB-SEM for a wider range of sample sizes (Hair et al., 2011). The relatively small sample size of our study also makes PLS-SEM more appropriate than CB-SEM (Hair et al., 2012). In our study, the maximum indicators per construct is six and thus satisfies the popular heurism that states that the minimum sample size should be ten times the maximum number of indicators per construct (Hair et al., 2012). In addition, PLS-SME yields more stable estimators with complex structural equation models (Hair et al., 2012). In our estimation model (see Figure 4.1), we have twelve latent constructs, which is considered relatively complex (Hair et al., 2012). 


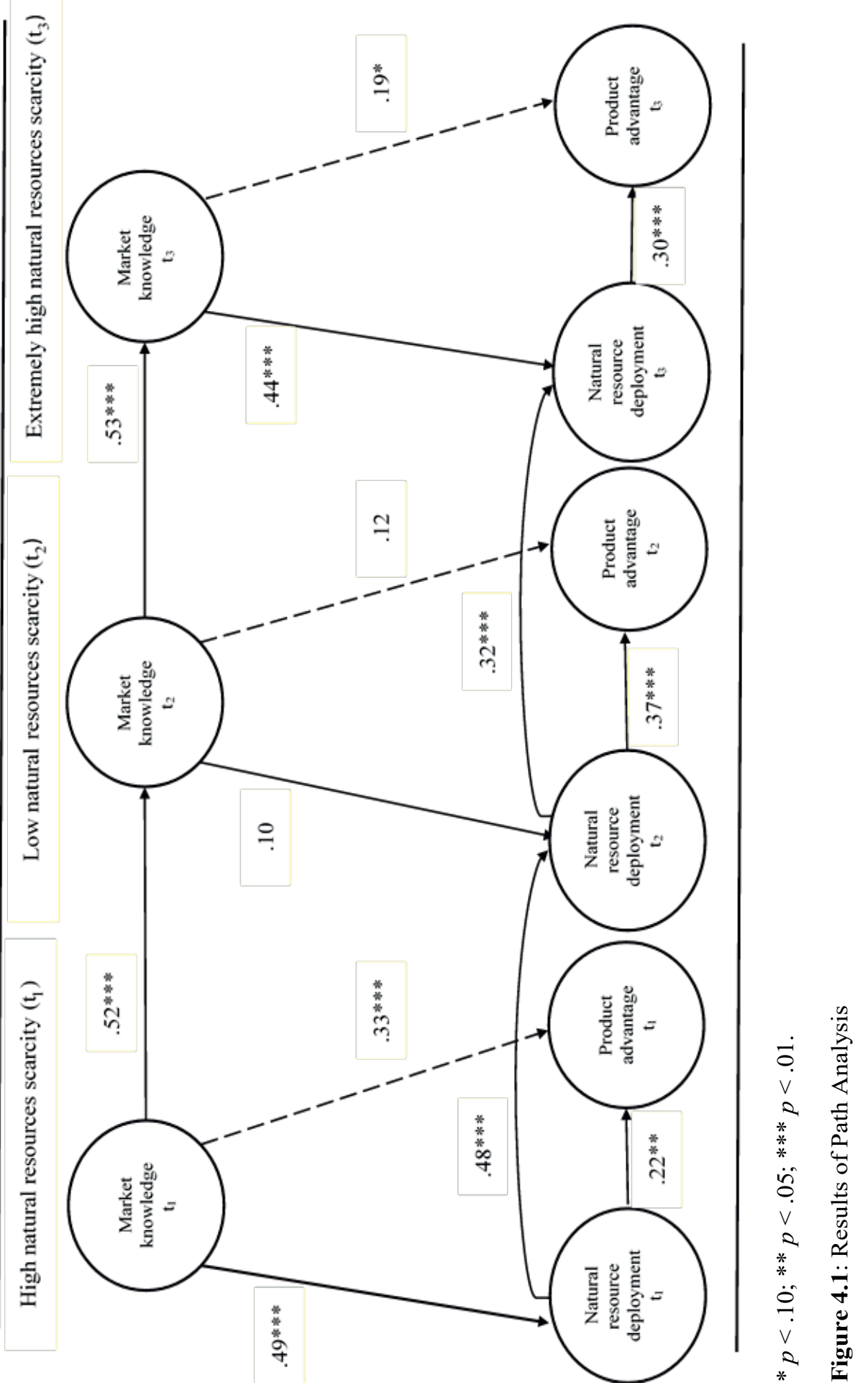




\subsection{Results}

\subsubsection{Measurement Validity and Reliability}

We verified both the reliability and validity of the reflective outer model. We used Cronbach alpha and composite reliability to evaluate the constructs' internal consistency or reliability. For all constructs, the Cronbach's alpha and composite reliability are higher than .70, confirming the constructs' internal consistency (Churchill, 1979; Fornell \& Larcker, 1981). As recommended by Hair et al. (2014), the convergent validity was checked by examining the constructs' item loadings and average variance extracted (AVE). All loadings are higher than the desired .70 loading level, except in three instances, and all AVEs are greater than the required .50 for convergent validity across the three waves of data. The discriminant validity is checked by comparing the inter-factor correlation with the square root of the constructs' AVE. All the inter-factor correlations are far lower than the square root of AVE for all constructs across the three periods. 


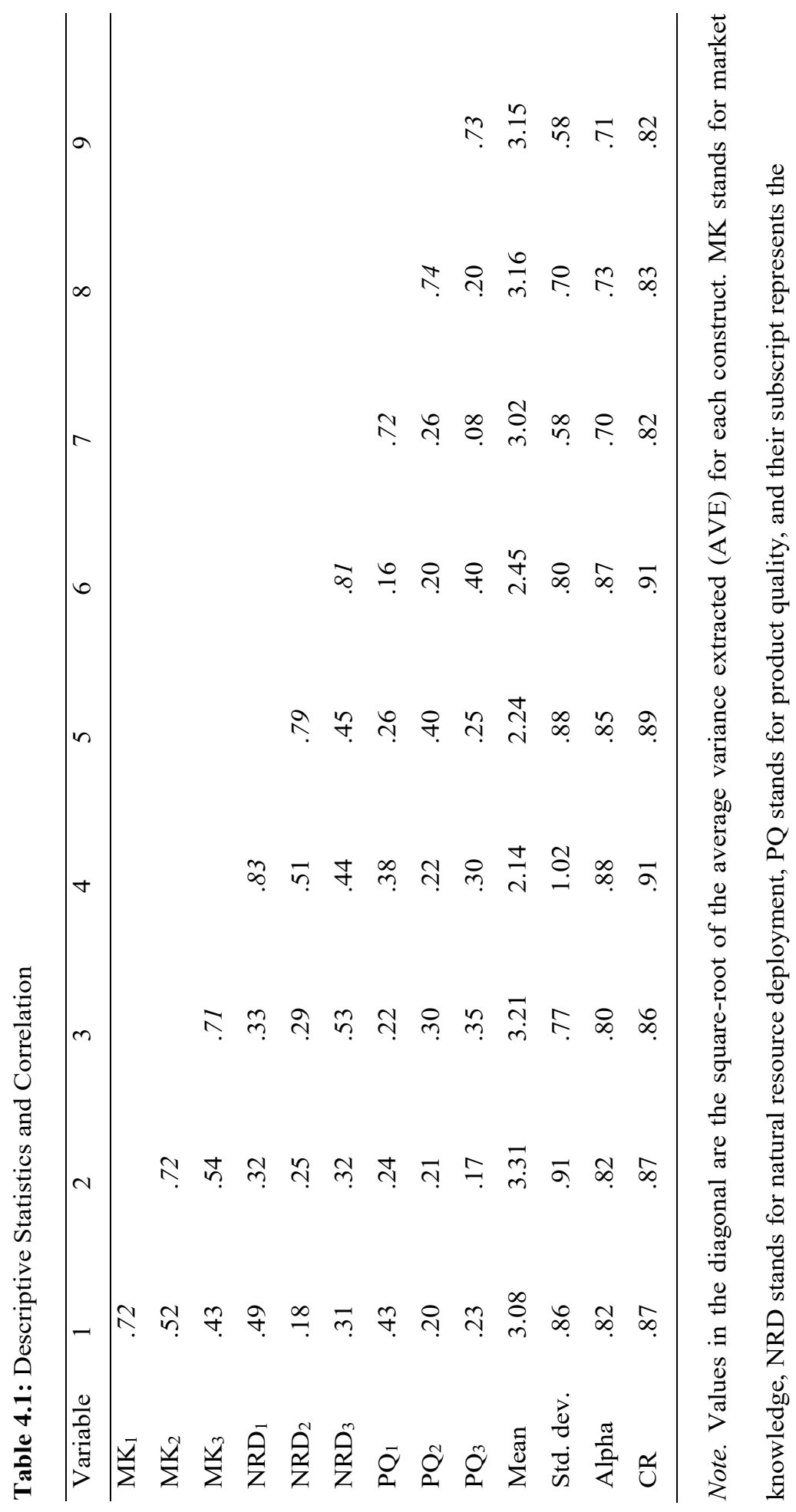




\subsubsection{Hypotheses Tests}

We tested the hypotheses using the model shown in Figure 4.1. The conceptual model captures the changes in the level of natural resource scarcity with the changes over $t_{1}, t_{2}$, and $t_{3}$. It also includes the lagged effects on market knowledge and natural resource deployment because these are resources that develop slowly over time. The levels of market knowledge and natural resource deployment, therefore, depend on the levels in previous periods.

Hypothesis 1 predicted positive direct effects of natural resource deployment on product quality. The hypothesis is supported if the direct effects of natural resource deployment on product quality are positive and significant for the three levels of natural resource scarcity. At $t_{1}, t_{2}$, and $t_{3}$, the test results support Hypothesis $1: \beta_{1}=.22(\mathrm{p}<.05), \beta_{2}=.37(\mathrm{p}<.01)$, and $\beta_{3}=.30(\mathrm{p}<.01)$.

Hypothesis 2 predicted positive, significant direct effects of market knowledge on natural resource deployment. The test results for $t_{1}$ and $t_{3}$ (time with high and extremely high resource scarcity, respectively) support Hypothesis $2\left(\beta_{1}=.49[\mathrm{p}<.01]\right.$ and $\left.\beta_{3}=.44[\mathrm{p}<.01]\right)$. However, the test results for $\mathrm{t}_{2}$ (time with low resource scarcity) show that the effect is not significant $\left(\beta_{2}=.10[\mathrm{p}>\right.$ $.10])$.

Hypothesis 3 predicted that the effect of natural resource deployment on product quality is relatively stronger at high resource-scarce times as compared with low resource-scarce times. We tested the hypothesis by comparing the differences in the standardized beta coefficients of the effects across $t_{1}, t_{2}$, and $t_{3}$. The hypothesis is supported if the effect is stronger at $t_{1}$ than at $t_{2}$ and if it is stronger at $t_{3}$ than at $t_{2}$ and $t_{1}$. However, it is not supported since we did not find any statistically significant positive differences in the effects. 
Hypothesis 4 predicted that the effect of market knowledge on natural resource deployment is relatively stronger when natural resource scarcity is higher. We tested this hypothesis by also comparing $t_{1}, t_{2}$, and $t_{3}$. The hypothesis is supported if the effect is stronger at $t_{1}$ than at $t_{2}$ and if it is stronger at $t_{3}$ than at $t_{2}$ and $t_{1}$. The results show that the effect drops from $\beta_{1}=.49(p<.01)$ at $t_{1}$ to $\beta_{2}=.10(\mathrm{p}<.24)$ at $\mathrm{t}_{2}$. There is a positive and significant difference of $\beta=.39(\mathrm{p}<.01)$ between the two parameters, supporting Hypothesis 3 . The effect drops from $\beta_{3}=.44(\mathrm{p}<.01)$ at $\mathrm{t}_{3}$ to $\beta_{2}=$ $.10(\mathrm{p}<.24)$ at $\mathrm{t}_{2}$, resulting in a significant positive difference of $\beta=.34(\mathrm{p}<.01)$. Contrary to the hypothesis, we find that the parameter increases between $\mathrm{t}_{3}$ and $\mathrm{t}_{1}: \beta_{3}=.44$ at $\mathrm{t}_{3}$ versus $\beta_{1}=.49$ at $\mathrm{t}_{1}$. We therefore find support for Hypothesis 3 for the comparison between high or extreme natural resource scarcity and low natural resource scarcity, but not between high and extremely high natural resource scarcity. 


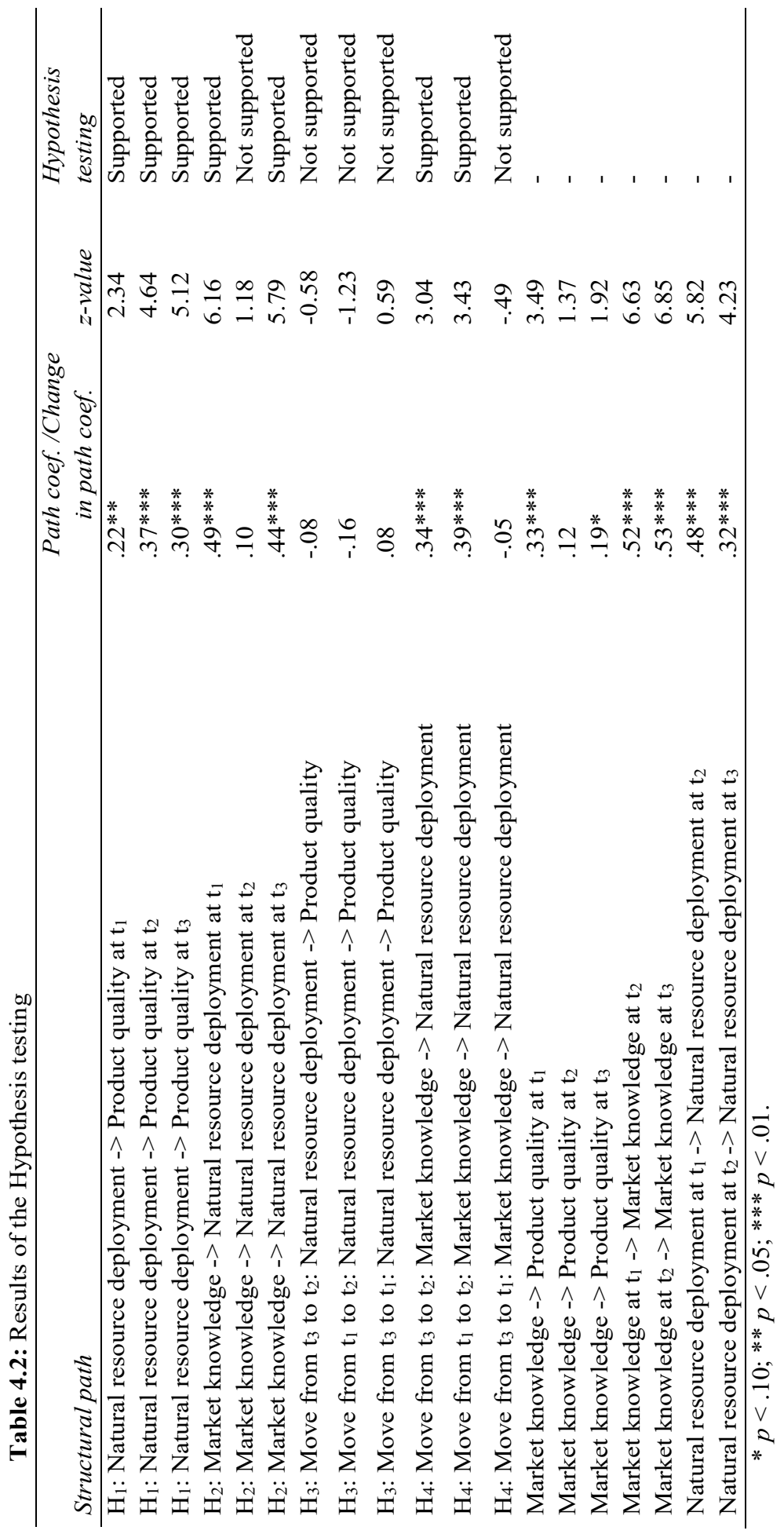


Because the marketing training was immediately after $t_{1}$, it may have affected our results in that it increased the level of market knowledge in the experimental group at $t_{2}$ and $t_{3}$, but not in the control group. To test whether this research design feature affected the results, we compared the standardized path coefficients between the control and experimental groups of the marketing training using a multigroup analysis. We found no significant differences in the standardized path coefficients for the effect of market knowledge on natural resource deployment between the two groups across $t_{1}, t_{2}$, and $t_{3}$. Furthermore, we also compared whether the average level of product quality for the two group differs across $t_{1}, t_{2}$, and $t_{3}$ using post-hoc tests. The Bonferroni, Scheffe, and Sidak post-hoc tests showed no statistically significant differences in the average product quality across time for both the control and experimental groups. This result implies that pastoralists manage to keep product quality relatively stable across high and low resource-scarce times.

\subsection{Discussion and Implications}

The results of this study show that pastoralists in resource-scarce times prevent a decrease in product quality through natural resource deployment that is rooted in market knowledge. There are three unexpected effects that need further discussion. First, we didn't find a moderating effect of resource scarcity on the relation between natural resource deployment and product quality $\left(\mathrm{H}_{3}\right)$. Therefore, the moderation of resource scarcity is entirely based on the effect of market knowledge on natural resource deployment. Second, we didn't find an effect of market knowledge on natural resource deployment under low resource scarcity. This finding suggests that market knowledge only strengthens resource deployment when resources are scarce. When resources become more abundant, the level of market knowledge apparently makes no difference, suggesting that more production-oriented ways of resource deployment lead to desired results. Together, these results 
suggest that businesses can be more innovative when faced with resource scarcity (Berrone et al., 2013), but only if they can rely on a sufficient understanding of the market (De Luca \& AtuaheneGima, 2018). Third, we found no significant differences in the effect of market knowledge between high and extremely high resource-scarce times. This finding suggests that the behavioral patterns of coping with resource scarcity do not change as a matter of degree but are rather either present or absent. More specifically, the pastoralists use their deployment capabilities that are rooted in market knowledge in resource-scarce times, but don't increase this behavior if the resource scarcity increases further.

This study's findings extend the literature in several ways. First, the study shows that the role of resource scarcity in triggering not only product innovations (e.g., Cunha et al., 2014; Gibbert, Hoegl, \& Valikangas, 2014) but also process innovations, specifically, the assembling and integrating of resources as captured in our natural resource deployment concept. Second, prior research has examined resource deployment as a functional capability that enables businesses to make efficient and effective use of marketing resources to achieve marketing mix objects in a product group or submarket (Kor \& Mahoney, 2005; Slotegraaf et al., 2003). This study extends the research by investigating natural resource deployment as an organizational capability that enables businesses to make effective and flexible use of resources in business processes and is anteceded by market knowledge as an organizational asset. As such, natural resource deployment capability can help businesses to attain and sustain competitive advantages in resource-scarce environments.

The results imply that to minimize quality loss and maintain competitive advantage during resource-scarce times, businesses should carefully consider how they create customer value through the way they manage the deployment of scarcely available resources. The managers should 
be aware that the effective and flexible deployment of resources considerably contributes to customer value creation and competitive advantage at times of resource scarcity. If managers anticipate resource scarcity, developing their resource deployment competence will help them to better manage such scarcity in the future. Businesses that are strong in market knowledge will have an advantage because resource deployment is developed from a sharp understanding of the market.

Another implication from our study relates to the importance of market knowledge during resourcescare times. Lack of market insights can create a discord between resource deployment and customer preferences, which may lead businesses to unnecessarily use more resources. For that reason, market intelligence managers should work very closely with operational managers who make decisions regarding the appropriation and utilization of resources, especially when those resources are acutely in short supply.

\subsection{Limitations and Directions for Further Research}

Our study has limitations that offer directions for future research. First, the study used three waves of panel data. Data collected over a longer period can provide additional insights into the relationship between market knowledge and natural resource deployment. Second, to measure the level of natural resource scarcity, we used a proxy variable, resulting in unequal time intervals across the moments of data collection. Instead of using proxy measures, future research may use direct measures, such as satellite-generated data on vegetation coverage and water availability. Third, we measured product quality through self-assessment. In our data the level of scarcity for natural pasture decreased from $t_{1}$ to $t_{2}$ and then increased from $t_{2}$ to $t_{3}$. The nonlinear nature of the changes in the levels of scarcity for natural pasture suggests that the results can't be caused by over- or understatements. Furthermore, we didn't find evidence for single method bias. Since 
product quality is primarily based on customers' perception (Kroll et al., 1999), future research may use customer ratings of product quality.

Finally, our study context, Ethiopian pastoralists, also differs in many ways from the corporate high-income market contexts, which is the traditional focus of management literature. To obtain a broader understanding of how the lessons learnt in this study translate to other contexts, we encourage more research in different high-income market contexts where businesses deal with temporal fluctuations in the availability of critical resources, for instance, in the agribusiness where the availability of underground or irrigation water is seasonally variable or any type of business for which financial resources, credit availability, or input supplies are variable depending market conditions.

\subsection{Conclusion}

To minimize the drop in quality for their customers, businesses with market knowledge are more likely to develop in resource deployment capability, which minimizes their resource use and reduces waste. As our empirical findings suggest, with the increased scarcity of natural resources, businesses should have a sharp understanding of the market to minimize the quality loss and maintain competitive advantage through natural resource deployment. The findings also suggest that more attention should be given to the moderating effects of the natural resource environment when studying the effects of business resources on performance. 


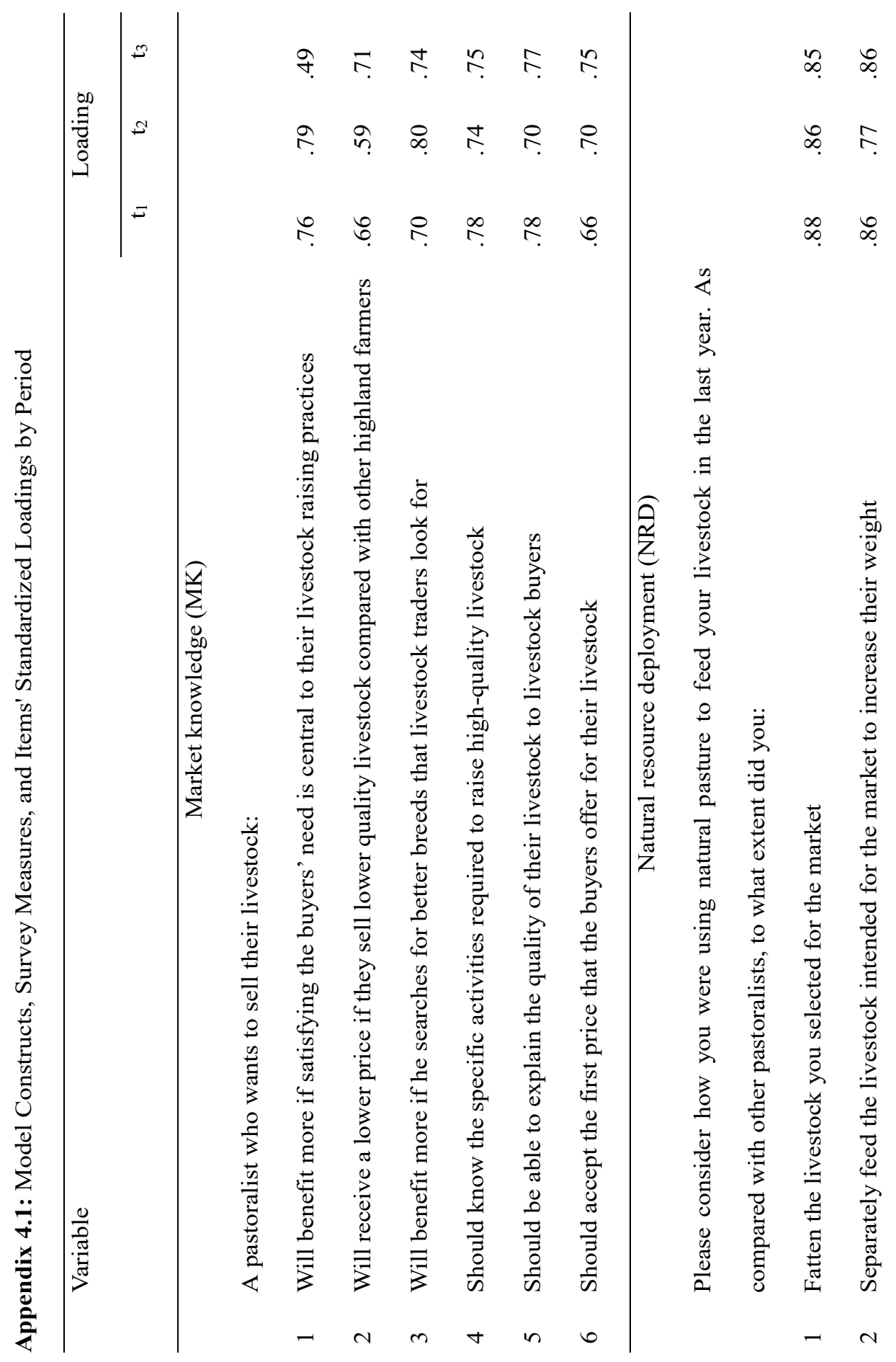




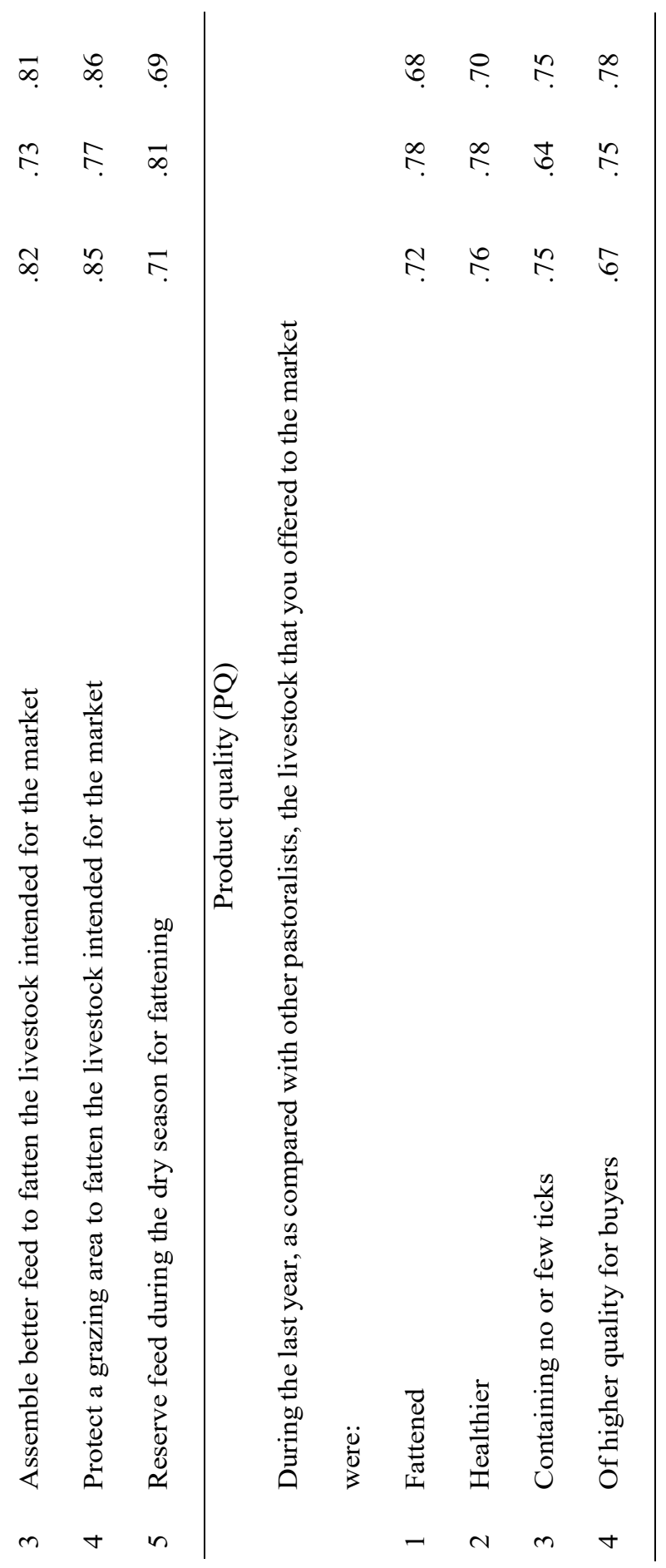





\section{Chapter 5}

\section{Market knowledge as a driver of sustainable use of common-pool resources in communities that are integrated with the global market system}

This chapter is submitted for publication as Desalegn A. Gugissa, Paul T.M. Igenbleek, \& Hans van Trijp. Market knowledge as a driver of sustainable use of common-pool resources in communities that are integrated with the global market system 


\begin{abstract}
Rural communities that depend on common-pool resources for their livelihoods are being increasingly affected by the expanding global market system. Because such market integration is still relatively thin, communities vary in terms of market comprehension. Using a common-pool resource dilemma experiment, this study examines the effect of market knowledge on decisions concerning the use of common-pool resources among Borana pastoralists. Participants chose to use shared grazing rangelands at low or high levels of grazing intensity. Depending on the resourceuse decisions in previous rounds, the participants encountered different resource-availability conditions that required them to make trade-offs between their short-term interests and the longterm sustainability of the shared rangelands. The results indicate that, when resource conditions were good, resource users with more market knowledge are more likely to choose lower grazing intensity. During scarcity, this effect is weaker. The results further show that within-group variance in market knowledge has a negative effect on decisions relating to sustainable-resource use in times of resource scarcity. The results imply that providing an understanding of market functioning is of vital importance to protecting shared natural resources from depletion in communities experiencing increasing impact from the global market economy.
\end{abstract}

Keywords: Market knowledge, market integration, sustainability, common-pool resources, rural communities 


\subsection{Introduction}

The ongoing process of globalization is increasingly moving the global market system into remote parts of the globe, including to communities whose subsistence depends on commonly shared natural resources (e.g., grazing lands, forests, fishing areas, and irrigation systems). As markets expand, such resources are increasingly used to supply demands from external markets (Agrawal \& Yadama, 1997). While market integration has positive effects on the livelihood of these communities (Keller \& Shiue, 2007), it also provides incentives for the overexploitation of resources, given that the influence of cash returns on decision-making in the commons dilemma Hardin (1968). In commons dilemma, individual short-term interests to exploit a scarce shared resource are at odds with the long-term interests of the larger community (Cass \& Edney, 1978; Hardin, 1968). To ensure the sustainable management of common-pool resources, communities may develop trust-based relationships and institutions that steer decisions toward long-term interests (Ostrom, 1990). The incentives that market integration provides to overexploit resources in the short-term places such relations and institutions under pressure (Agrawal \& Yadama, 1997; Pendleton \& Howe, 2002).

Several studies on the impact of markets on common-pool resources support these assertions (Mutenje et al., 2011). In southern Africa, an increase in market integration among forest-fringe dwellers has exacerbated the degradation of forest resources (Mutenje et al., 2011). Common institutions also appear unable to attenuate the effect of market forces on forest degradation in Ecuadorian indigenous communities (R. Godoy, Reyes-Garcia, Byron, Leonard, \& Vadez, 2005). According to other studies, however, market integration fosters the sustainable usage of commonpool resources by influencing the perceptions of gains and losses associated with resource overexploitation (Oldekop et al., 2013; Vaccaro et al., 2009). In the Gulf of California in 
northwestern Mexico, small-scale fishers were able to generate stable incomes sustainably by using ecological indicators of the fishing system to guide their fishing decisions (Basurto, 2008). In a review of experimental studies, Andersson and Agrawal (2011) report evidence that resource users adjust their common institutions in response to threats from market forces.

In this study, we test a potential explanation for why communities may adopt different approaches to the sustainable use of common-pool resources when integrating with markets. We argue that the understandings that resource users have concerning the functioning and dynamics of markets (market knowledge) affect their decisions concerning the use of common-pool resources (Cecchi \& Bulte, 2013). Specifically, we test the hypothesis that market knowledge promotes individual resource users to make sustainable use of common-pool resources. Market knowledge is defined as the organized and structured information about customers, competitors, and dynamics in the market environment (De Luca \& Atuahene-Gima, 2018). The concept builds on a tradition in the economic literature that relaxed the original assumption of rationality. This tradition includes theories on bounded rationality (e.g., Argote \& Greve, 2007) and studies on the effects of market experience on choice behavior (e.g., Cecchi \& Bulte, 2013). We treat market knowledge as one of the "individual differences" that help to explain whether decision-makers will or will not cooperate in a common-pool resource dilemma (Weber, Kopelman, \& Messick, 2004). Users with higher levels of market knowledge better understand (1) how they can benefit from market incentives in the long term, and are thus more likely to make sustainable choices; and (2) the influence of resource degradation on the quality of the products they sell, and thus understand how the overuse of common-pool resources threatens their source of income.

This study tests the above theory by examining market knowledge as an individual-difference variable within the context of a dilemma experiment involving common-pool resources. Such 
experiments have been used to investigate how the decisions of resource users are sensitive to subtle changes in the context or incentive structure (Anderies et al., 2011). Many of these experiments focus primarily on contextual factors (e.g., payoff structure, resource dynamics, group heterogeneity), as well as on stable individual characteristics (e.g., social motives, gender). Unstable personal characteristics (e.g., market experience, market knowledge) have been largely ignored, however, or used only as contextual features (Anderies et al., 2011).

The grazing experiment used in this study was initially developed by Cardenas, Janssen, and Bousquet (2013) as an experiment in common-pool fishery. Prediger et al. (2011) use a comparable experimental design to explain the impact of cultural and ecological differences on cooperative behaviors among communal farmers. Building on their work, we use the experiment as a "withinculture" design to examine the impact of individuals' understanding of markets on the likelihood that they will make sustainable decisions concerning the use of common-pool resources. In the experiment, participants were required to make decisions concerning grazing intensity, as a proxy for the amount of pasture resources that they preferred to extract from shared grazing rangelands to feed and fatten the livestock they selected for markets. Depending on resource-use decisions made in previous rounds, the rangelands would degrade when certain exploitation thresholds were exceeded. The participants therefore faced different resource-availability conditions, which lead to different outcomes (Prediger et al., 2011).

In our study, we focus on variations in individual resource-use decisions, with market knowledge as an independent variable. The grazing experiment was carried out among Borana pastoralists in Southern Ethiopia. Because all participants shared the same culture, clan origins, and ecological conditions, there were no substantial contextual differences in the experiment. Given the differences identified by prior research within this context with regard to pastoralists' 
understanding of markets and their subsequent behaviors (e.g., Ingenbleek et al., 2013; Teklehaimanot et al., 2017), we regard this context as suitable for testing our hypothesis that market knowledge promotes users to make sustainable use of common-pool resources.

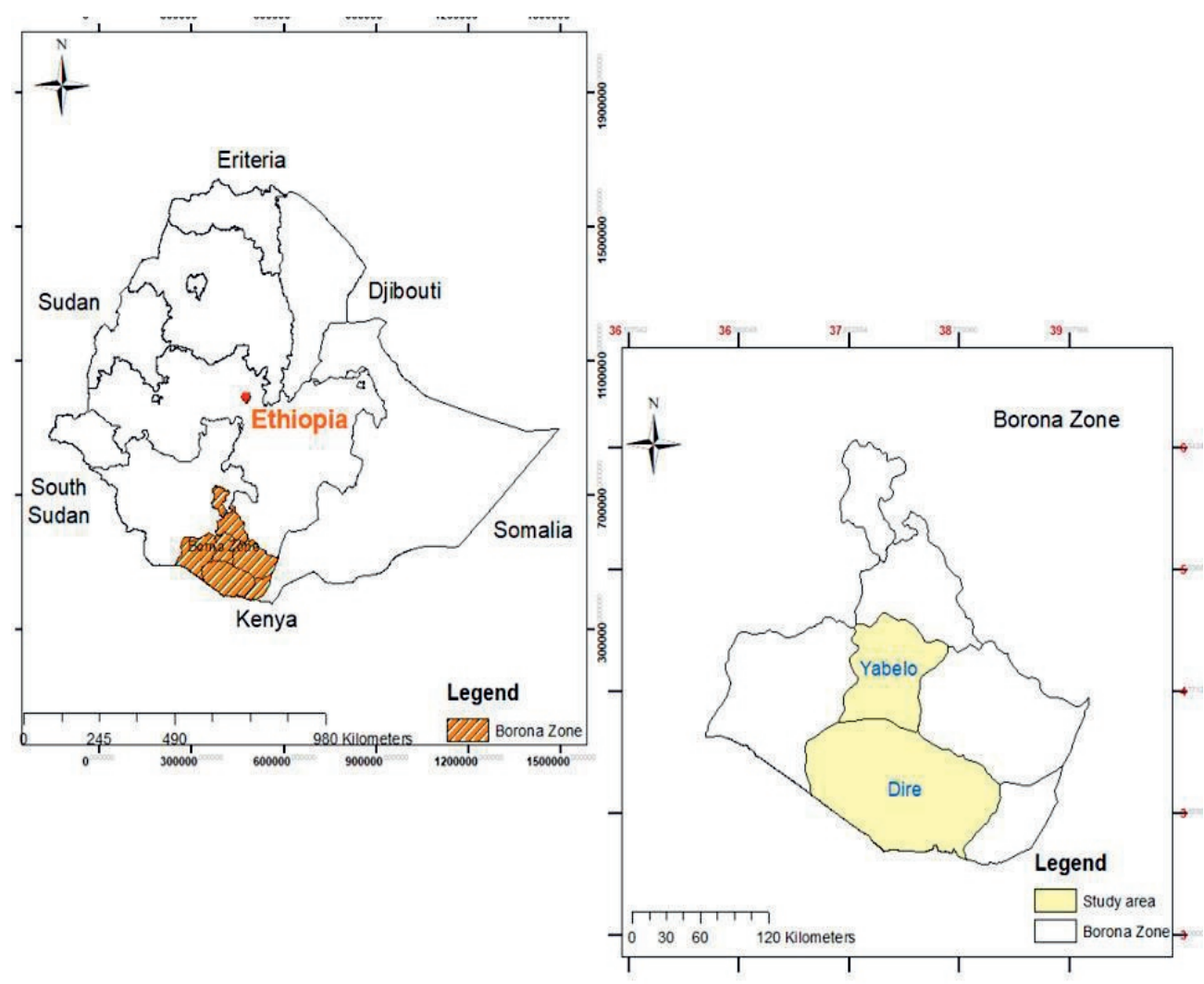

Figure 5.2: Map of the study site

\subsection{The Effect of Market Knowledge on the Sustainable Use of Common-pool Resources}

The costs and benefits that users of common-pool resources perceive in relation to cooperation in commons dilemmas are potentially affected by the information that they store and process concerning their prior experiences (Cárdenas \& Ostrom, 2004). Depending on the framing of commons dilemmas, individual resource users bring elements from their prior experiences to give 
subjective meanings to the commons dilemma (Cárdenas \& Ostrom, 2004). In our grazing experiment, we use market knowledge at the individual and group levels to explain differences in the likelihood of making sustainable use of shared grazing rangelands. The participants' market knowledge can affect cooperation in at least two ways. First, the market knowledge that participants bring into the experiment can influence their understanding of the gains and losses associated with the over-exploitation of resources. Recent studies in the area show that pastoralists who integrate into markets with a higher level of market knowledge have a better notion of which livestock they should sell, when, and to whom, thus generating higher income than do those making transactions without such knowledge (e.g., Tessema et al., 2019). Pastoralists with greater market knowledge therefore benefit more from sustaining the shared grazing rangelands, as they are able to generate more revenue from markets. The degradation of communal land would also deteriorate their potential to generate income from markets. Pastoralists with greater market knowledge should therefore perceive greater gains from sustaining communal grazing rangelands.

Second, pastoralists with greater market knowledge may have received market feedback that enhances their understanding concerning the influence of resource degradation on the quality of the livestock they sell. Pastoralists who produce livestock primarily for markets receive market feedback on the quality of the livestock they sell from their buyers and brokers or/and in the form of the price they receive for their livestock (Tessema et al., 2019). Market knowledge also guides them to produce livestock that satisfies the requirements of buyers, thus enabling stronger relationships with buyers (Tessema et al., 2019). Pastoralists with greater market knowledge are therefore likely to have had more market feedback with which to understand the effect of resource degradation on the quality of the livestock they sell. They are thus likely to understand the causal chain between resource degradation, the quality of the animals that they bring to the market, and 
the responses of potential buyers. For this reason, greater market knowledge also enhances cooperation to sustainable resource-uses.

At the group level, greater average market knowledge may persuade individual resource users to make more sustainable decisions. This is because, in a group with greater average market knowledge, a significant share of the members have higher levels of market knowledge, and are thus more likely to make sustainable grazing decisions. This increases the likelihood that individual resource users in the group will reciprocate the sustainable decisions of their group members (Ostrom, 1998). Individuals who share grazing rangelands with resource users who have higher levels of market knowledge are thus more likely to make sustainable resource-use decisions.

Within-group differences in market knowledge may reduce the collective actions of group members. Greater within-group variance in market knowledge can create differences in perceptions about the use of shared resources and distrust among group members with regard to making sustainable use of shared resources. Differences in perceptions concerning actual use and lack of trust among a group of resource users are likely to reduce the likelihood that individuals in the group will make sustainable use of common-pool resources (Varughese \& Ostrom, 2001; Vona \& Patriarca, 2011). Individuals in a group with greater within-group variance in market knowledge are thus less likely to make sustainable resource-use decisions.

In maximizing the long-term total earnings of group members (Castillo, Bousquet, Janssen, Worrapimphong, \& Cardenas, 2011), we expect better performance from groups with higher average levels of market knowledge than from those with lower average levels of market knowledge. This is because individual resource users in more knowledgeable groups are more likely to choose to cooperate in the sustainable use of common-pool resources, thus enhancing the 
group's performance in this regard. These groups will be more able to maximize the long-term total earnings of their group members. In contrast, groups with a greater within-group differences in market knowledge may be less capable of maximizing the long-term total earnings of their members, given their poorer performance in using shared resources sustainably.

\subsection{Materials and Methods}

\subsubsection{Research context}

We conducted the experiment among Borana pastoralists, who are known for their indigenous ecological knowledge system, which allows them to manage commonly held grazing rangelands sustainably (Gemedo-Dalle et al., 2006). Their indigenous self-governance institutions exercise control over the socio-economic life of the society, including the use of grazing rangelands. Classifying the communal grazing rangelands into dry-season and wet-season grazing units is the main strategy that Borana pastoralists use to ensure the sustainable management of communal rangelands (Gemedo-Dalle et al., 2006). Like other pastoralists, mobility is also part of the traditional rangeland-management strategy (Homann et al., 2008). During resource-scarce times, they move their livestock to distant rangelands, thereby taking advantage of spatial heterogeneity in pasture availability. The route of livestock mobility depends on the availability of quality pastures and the carrying capacity of rangelands (Gemedo-Dalle et al., 2006). Based on our knowledge of the study area, the pastoralists largely possess what Ostrom (2007) regards as essential components for analyzing the sustainability of common resource systems: the resource system (e.g., grazing rangeland), the resource units (e.g., pasture), the users, and the governance system (e.g., traditional institutions). Studies have nevertheless revealed significant variations among individual pastoralists in the region with regard to marketing activities and livelihood performance (e.g., Teklehaimanot et al., 2017; Tessema et al., 2019). 
Many Borana pastoralists have long led a subsistence-oriented semi-nomadic lifestyle (Aklilu \& Catley, 2013). In recent decades, however, they have been increasingly integrating into local and export markets, which has required them to raise livestock and use the shared grazing rangelands to satisfy market requirements and realize profits (Aklilu \& Catley, 2013). In their efforts to produce livestock for the market, pastoralists often encounter natural-resource scarcity due to the area's arid climate (Luseno et al., 2003). The traditional common-resource management system is being affected by both the increased market integration of pastoralists and the depletion of natural resources. For example, in contrast to long-standing tradition, pastoralists in the region have begun to build fences and establish private enclosures for fattening and farming purposes (Reda, 2016).

\subsubsection{Experimental Design}

The experiment involved a social dilemma in which individual interest in high-intensity grazing clashes with desired group-level outcomes (Cardenas et al., 2013). Two hypothetical grazing sites were involved: Rangelands A and B, which can have either high or low levels of grazing quality. The sites were held jointly by a group of five participants. An experimental session consisted of 10 rounds. In each round, every member of a group chose to graze in either Rangeland A or Rangeland B at a grazing intensity of 0 (no grazing at all), 1 (low grazing intensity), or 2 (high grazing intensity). The higher the grazing intensity, the higher the amount of pasture resource that the participant extracted from common-grazing rangelands. The decisions were private: the group members were not aware of each other's decisions. A coordinator in the experiment collected all decisions and announced the status of pasture availability for the next round. During the experiment, group members were not allowed to communicate with each other, and there were no rules governing grazing-intensity choices. 
As shown in Table 5.1, the returns on specific grazing decisions depended on the level of grazing intensity and the grazing quality status at the chosen grazing site. The table applies to both grazing sites. Based on the payoff table, a grazing intensity of 2 yielded a return of eight tokens (the currency in the game (cf. Prediger et al., 2011) if the grazing quality in the chosen rangeland was high, but only three tokens if grazing quality was low. Before the experimental game, the participants played three trial rounds, in which we briefed them on the amount they would gain depending on their individual and fellow members' grazing-intensity choices, including the possibility of rehabilitating degraded rangeland through no grazing or low grazing intensity. Participants subsequently played 10 rounds of the experimental game. In the end, participants received the sum of their earnings converted to local currency. On average, each participant earned an amount equivalent to one day of labor.

Table 5.1: Individual payoff table

\begin{tabular}{llll}
\hline \multirow{2}{*}{ Grazing quality } & \multicolumn{2}{l}{ Grazing Intensity } \\
\cline { 2 - 4 } & 0 & 1 & 2 \\
\hline High & 0 & 7 & 8 \\
Low & 0 & 2 & 3 \\
\hline
\end{tabular}

Source: Cardenas et al. (2013)

The aggregate grazing intensity in round $\mathrm{R}_{\mathrm{n}}$ in a rangeland determines the grazing quality of the rangelands in the next round $R_{n+1}$ (Prediger et al., 2011). At the beginning of the experiment, grazing quality is high in both rangelands. In subsequent rounds, however, if the sum of grazing intensity of the five group members is greater than 4, which is the carrying capacity of the rangelands, the state of grazing quality will become low for the next two rounds. A rangeland with low grazing quality can recover to high grazing quality only if the aggregate grazing intensity applied to that rangeland is 0 or 1 for two consecutive rounds. The maximum grazing intensity that 
players can choose to maximize their individual payoffs is 2 . The aggregate grazing intensity for a five-member group can therefore range from 0 to 10 in each rangeland. If all group members behave rationally to maximize their own short-term individual payoffs, all players will choose to graze at maximum intensity. As a result, the group will encounter low grazing quality in the next round. If this opportunistic behavior continues, the group will continue to face low grazing quality in both rangelands for the remaining rounds of the game. At the end of 10 rounds, this opportunistic behavior results in 200 aggregate tokens for the group. If group members refrain from applying the maximum grazing intensity, however, the aggregate payoff for the group can be as high as 382 tokens. This result requires at least two members of a group not to apply the maximum grazing intensity (Cardenas et al., 2013)

After the first round, a rangeland's grazing quality can be in a condition of high quality $(\mathrm{H})$; low quality with two more rounds needed to recover to the high-quality condition $\left(\mathrm{L}_{2}\right)$; or low quality with only one more round needed to recover to the high-quality condition $\left(\mathrm{L}_{1}\right)$. A group with two rangelands might therefore face six possible combinations of grazing quality status: $\mathrm{HH}$ (both rangelands in high-quality condition), $\mathrm{HL}_{1}$ (one rangeland in high quality and the other in low quality, with one round required to recover), $\mathrm{HL}_{2}$ (one rangeland in high quality and the other in low quality, with two rounds required to recover), $\mathrm{L}_{1} \mathrm{~L}_{1}$ (both rangelands in low quality, with one round required to recover), $\mathrm{L}_{1} \mathrm{~L}_{2}$ (both rangelands in low quality, but one requiring one round to recover and the other requiring two rounds), and $\mathrm{L}_{2} \mathrm{~L}_{2}$ (both rangelands in low quality, with two rounds required to recover). In any round of the game, if the aggregate grazing intensity in $\mathrm{L}_{1}$ is higher than 1 , its grazing quality status shifts back to $\mathrm{L}_{2}$.

In the experiment designed by Prediger and colleagues (2011, pp. 1602), participants had difficulty distinguishing between the $\mathrm{L}_{1}$ and $\mathrm{L}_{2}$ grazing conditions. We therefore used pictures to present the 
three grazing-quality statuses (Figure 5.2). At the end of each round, the coordinator showed one of the pictures in Figure 4.2 for each of the grazing sites, as an outcome of the group's grazing decisions.
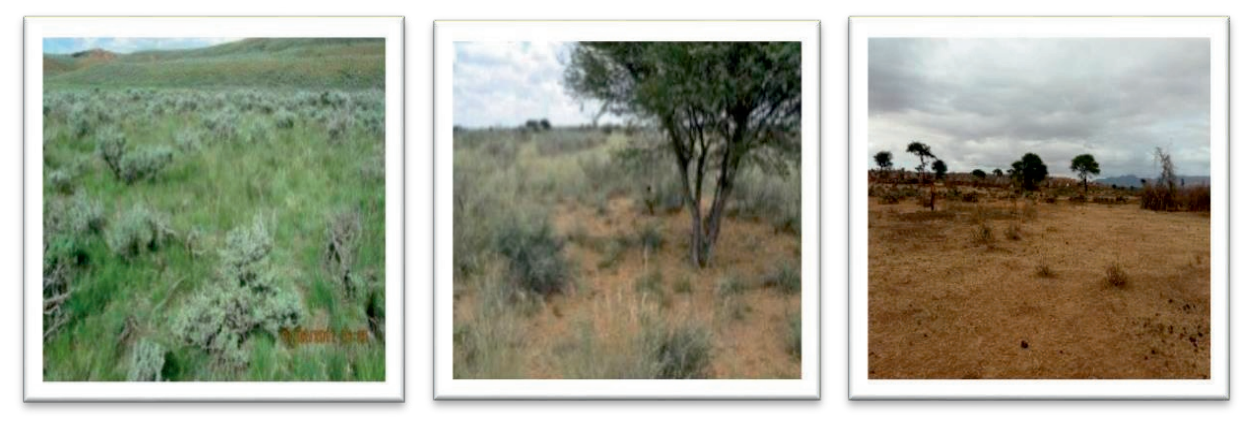

Figure 5.2: Grazing-quality status: $H, L_{1}$, and $\mathrm{L}_{2}$, respectively.

\subsubsection{Participants and measurement}

Participants were recruited from a broader project that included an experimental training program, in which 60 pastoralists were trained in market knowledge and compared to a control group of the same size (Teklehaimanot, 2017). The experimental marketing training was delivered in October 2015. The participants were selected using a multi-stage sampling procedure. Four villages from two administrative districts from the region-Yabello and Dire-were used as sampling units for selecting each of the 120 participants (Teklehaimanot, 2017). Our common grazing experiment was conducted in August 2018, using the same participants. While the sharp distinction between the two groups was unlikely to have persisted after nearly three years, the training did create more variance in individual level of market knowledge among the participants in our experiment. The sample was thus suitable for investigating individual grazing-intensity choices based on individual levels of market knowledge. After briefing, all 120 of the pastoralists were willing to take part in the experiment. Consistent with the field-experiment protocol developed by Cardenas et al. (2013), the participants in each village were randomly assigned to one of 24 five-member groups for the 
entire duration. The experiment took about two hours, including the instructions, three trial rounds, 10 rounds of the experimental game, and payments.

We used the grazing-intensity choices of individual participants in each round of the experiment to measure individual cooperation. In the experimental game, a grazing intensity of 2 is not a sustainable decision, as it often leads to the degradation of communal grazing rangelands and hinders the group's ability to maximize the aggregate payoffs. Because this grazing-intensity choice is not sustainable, we measured individual cooperation in the sustainable use of the rangelands as refraining from applying a grazing intensity of 2 (i.e., applying grazing intensity 0 or 1) (Prediger et al., 2011). Another outcome variable, individual total earnings, was measured as the aggregate token earned in 10 rounds of the experiment. To collect data on the participants' profiles, a survey was administered three days before the experiment (Anderies et al., 2011). Multiitem scales were used to measure market knowledge, along with a set of control variables including cooperation with rules for the use of common-pool resources, conformity to traditional values and norms, and collectivism. For validation purposes, the survey also included a measure of customer orientation (items provided in Appendix 5.1). All items were measured along a five-point Likert scale ranging from 5 (strongly agree) to 1 (strongly disagree). The items were developed based on a qualitative pre-study and formulated as concretely as possible to make them easily understandable to the respondents (Teklehaimanot, 2017). The measures of market knowledge tested the extent to which the pastoralists understood how markets function, customer needs, and the influence of competitors' actions. Pastoralists need such knowledge in order to produce, communicate, deliver, and exchange quality livestock in ways that satisfy the requirements of buyers and that are profitable to themselves (Teklehaimanot, 2017). After deleting items with factor loadings below 
0.7 to the common factor, the final scale used to measure market knowledge consisted of seven items.

\subsubsection{Data Analysis}

Because our dependent variable (the grazing-intensity choices of individual participants) is an ordered outcome, we used an ordered probit model to estimate the effect of market knowledge (Daykin \& Moffatt, 2002). We then report the marginal effect of market knowledge for the likelihood of applying the maximum grazing intensity (Prediger et al., 2011). We used a multiple linear regression model to analyze the effect of market knowledge on the total earnings of the participants.

The marginal effect of market knowledge on the likelihood of choosing the maximum grazing intensity was estimated across the different resource-availability conditions that groups might face in the experiment. We used four conditions, based on the level of the grazing quality in the two rangelands: resource-abundant $\left(\mathrm{HH}\right.$ and $\left.\mathrm{HL}_{1}\right)$, spatial resource availability $\left(\mathrm{HL}_{2}\right)$, short-term resource scarcity $\left(\mathrm{L}_{1} \mathrm{~L}_{1}\right.$ and $\left.\mathrm{L}_{1} \mathrm{~L}_{2}\right)$, and long-term resource scarcity $\left(\mathrm{L}_{2} \mathrm{~L}_{2}\right)$ (Prediger et al., 2011). We included control variables for age, family size, education level, and distance from the village to the market, as well as for conformity to traditional values and norms, collectivism, and respect for rules regarding the use of common-pool resources (descriptive statistics provided in Table 5.2). The last three variables function as proxies for trust, reciprocity, and reputation, respectively. We also added a one-period lag in the grazing-intensity decisions of individual participants as a control variable to account for the effect of learning from decisions in previous rounds. With regard to group composition, we controlled for average age and the average and within-group variance of market knowledge. 


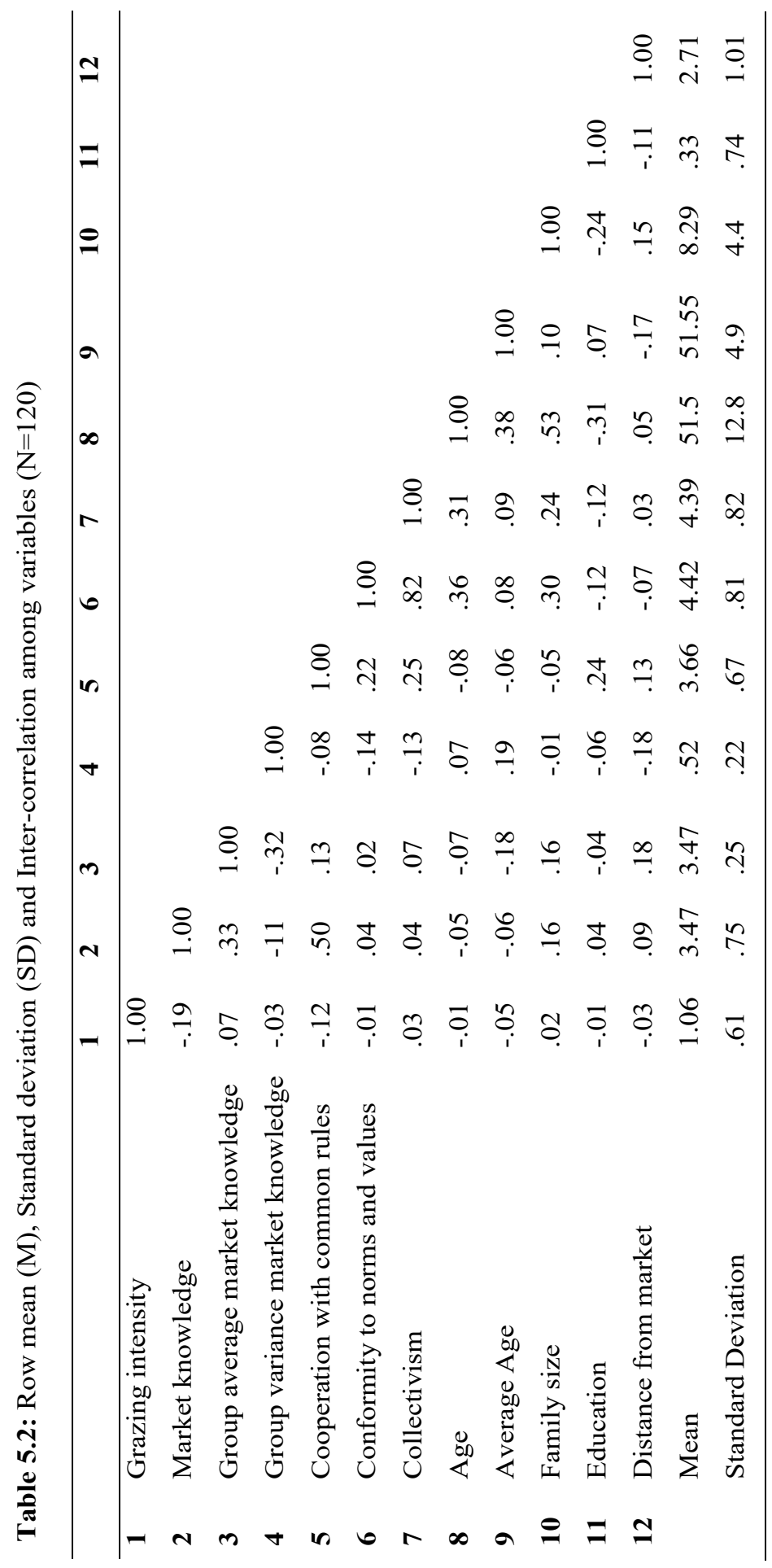




\subsection{Results}

As indicated in Table 5.3, the maximum grazing intensity of 2 was applied $21.42 \%$ of the time, whereas grazing intensities of 0 and 1 were applied $15.92 \%$ and $62.67 \%$ of the time, respectively. The participants thus decided to act sustainably $78.58 \%$ of the time by refraining from applying the maximum grazing intensity of 2 . Compared to the results from the experiment conducted by Prediger et al. (2011) among South African and Namibian pastoralists (38.5\%), the Borana pastoralists in our experiment applied the maximum grazing intensity at a lower rate $(15.92 \%)$ (see also Homann et al., 2008).

Table 5.3: Summary of resource conditions faced by the groups and grazing-intensity choices for different resource-availability conditions

\begin{tabular}{|c|c|c|c|c|c|c|}
\hline \multirow{2}{*}{$\begin{array}{l}\text { Resource-availability } \\
\text { conditions }\end{array}$} & \multirow[b]{2}{*}{ Total } & \multirow[b]{2}{*}{ Percent } & \multirow[b]{2}{*}{ Cumulative } & \multicolumn{3}{|c|}{ Grazing intensity } \\
\hline & & & & 0 & 1 & 2 \\
\hline $\mathrm{HH}$ & 42 & 17.50 & 17.50 & 0 & 117 & 93 \\
\hline $\mathrm{HL}_{1}$ & 28 & 11.67 & 29.17 & 1 & 93 & 46 \\
\hline $\mathrm{HL}_{2}$ & 84 & 35.00 & 64.17 & 1 & 315 & 104 \\
\hline $\mathrm{L}_{1} \mathrm{~L}_{1}$ & 7 & 2.92 & 67.09 & 19 & 14 & 2 \\
\hline $\mathrm{L}_{1} \mathrm{~L}_{2}$ & 68 & 28.33 & 95.42 & 142 & 186 & 12 \\
\hline $\mathrm{L}_{2} \mathrm{~L}_{2}$ & 11 & 4.58 & 100 & 28 & 27 & 0 \\
\hline Total & 240 & 100 & & 191 & 752 & 257 \\
\hline
\end{tabular}

Throughout 10 rounds, the groups maintained high grazing quality in at least one of their grazing rangelands $64.17 \%$ of the time (Table 5.3). This suggests that groups applied a "rotation strategy," in which they would have one high-quality rangeland in which to graze in each round while leaving the other rangeland to recover. Examining developments after 10 rounds, the number of goodquality rangelands and the average grazing-intensity choices per round exhibited the same patterns (see Figure 5.3). The participants had apparently adjusted the pattern of their grazing-intensity 
choices based on the availability of resources. As also demonstrated in Table 5.3, none of the participants applied the maximum grazing intensity in the worst resource-availability conditions, and they increasingly applied the lowest grazing intensity as resource scarcity increased.

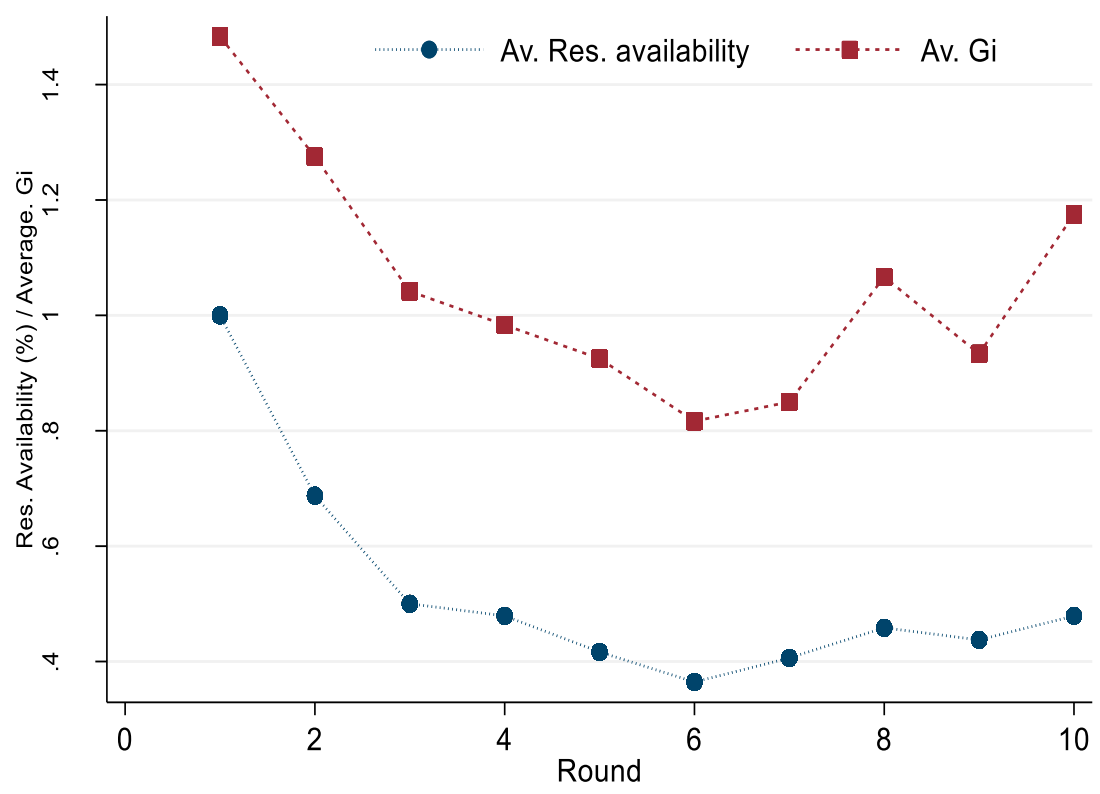

Figure 5.3: Percentage of resource availability and average grazing intensity over ten rounds

\subsubsection{The effect of market knowledge on grazing-intensity choices}

The results presented in Table 5.4 indicate the marginal effects of market knowledge on the likelihood of choosing the maximum grazing intensity across three resource-availability scenarios. The $\mathrm{L}_{2} \mathrm{~L}_{2}$ condition occurred only $4.58 \%$ of the time and was observed in only 8 of the 24 groups in the experiment. The popular rule of 10 observations per predictor variable was therefore not satisfied in the long-term resource-scarcity condition (Vittinghoff \& McCulloch, 2007). Because we included 12 predictor variables in our analysis, the 55 observations for the $\mathrm{L}_{2} \mathrm{~L}_{2}$ resource 
conditions failed to reach the minimum sample size required. We therefore excluded this resourceavailability condition from our analysis.

The results indicate that individual market knowledge was a negative predictor of the likelihood of choosing maximum grazing intensity when pasture resources were abundantly and spatially available: $\beta=-.13(p<0.01)$ and $\beta=-.12(p<0.01)$, respectively. In these conditions, individuals with more market knowledge were more likely refrain from applying maximum grazing intensity. Average market knowledge and variance in the level of market knowledge among group members were not significant. In the $\mathrm{HL}_{2}$ resource-availability condition, we further examined the rangeland choices of the participants $\left(\mathrm{H}\right.$ or $\left.\mathrm{L}_{2}\right)$. Individual market knowledge had no significant effect on grazing-site selection (Appendix 5.4). 


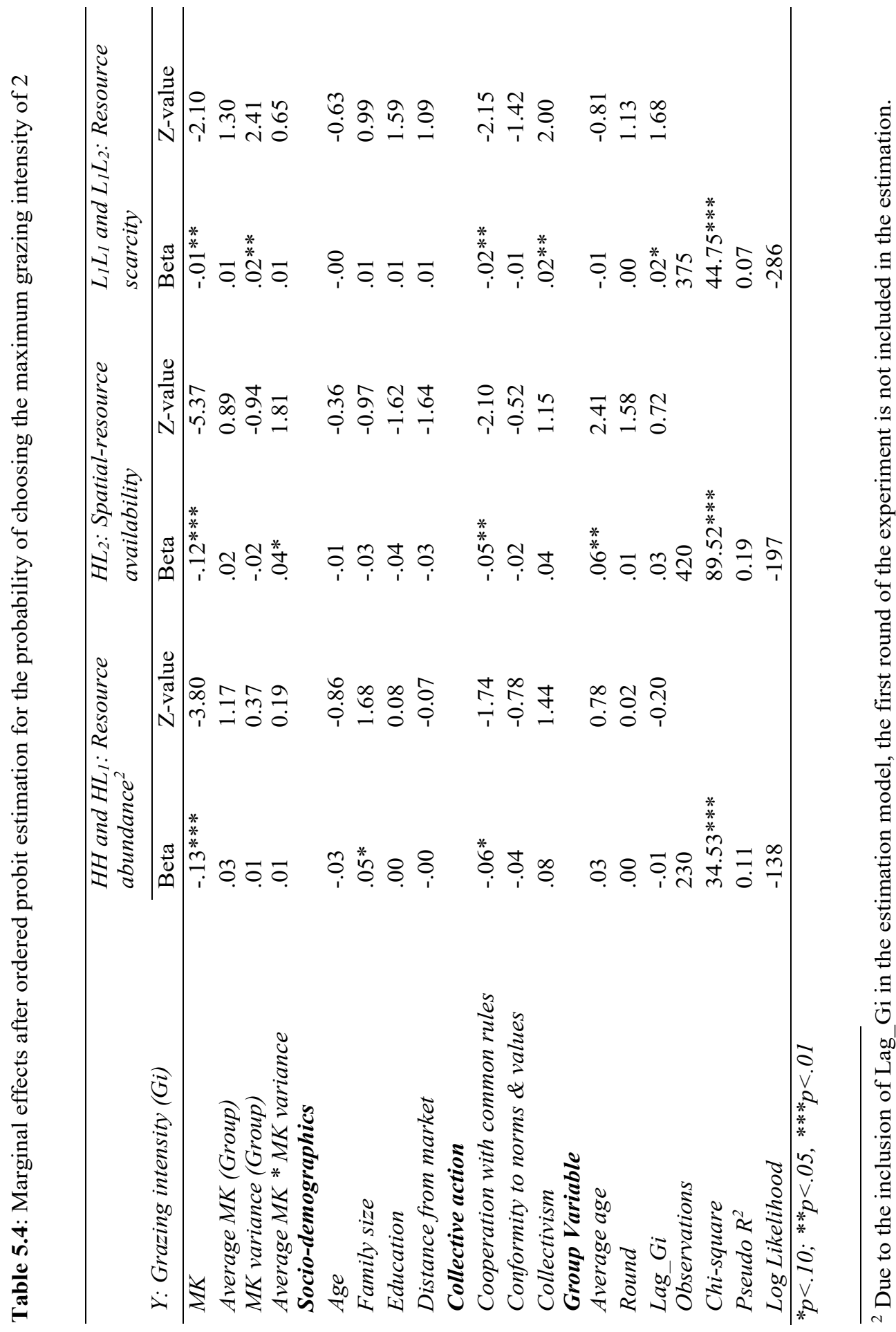


When a group is facing resource-scarce conditions, its members should choose the lowest grazing intensity to allow the degraded rangelands to recover to high grazing quality. An individual may nevertheless decide to apply the grazing intensity of 1 and hope all other group members will choose the grazing intensity of 0 . In a resource-scarcity condition $\left(\mathrm{L}_{1} \mathrm{~L}_{1}\right.$ and $\left.\mathrm{L}_{1} \mathrm{~L}_{2}\right)$, pasture resources are scarcer, however, there is a hope that the grazing quality of at least one of the rangelands will be able to recover in the next round. As indicated by the results displayed in Table 5.4, under conditions of resource scarcity, market knowledge at the individual level negatively predicts the likelihood of applying maximum grazing, with marginal effects of $\beta=-.02(p<0.05)$. The results further reveal a highly significant (1\% level) positive marginal effect of individual market knowledge on the likelihood of choosing minimum grazing intensity (see Web Appendix 1 for the marginal effects for intensities of 1 and 0 ). The marginal effect of market knowledge is weaker for these conditions than for the resource-abundant and spatial resource-availability conditions. This result is likely due to the traditional tendency of Borana pastoralists to act sustainably when resource scarcity is more acute (Davies, 2008; Kihiu, 2016). Group-level average market knowledge did not affect grazing decisions. In line with our expectations, however, variance in the level of market knowledge positively predicted the probability of choosing maximum grazing intensity, with the marginal effect of $\beta=.02(\mathrm{p}<0.05)$.

As also indicated by the results presented in Table 5.4, an individual's level of cooperation in respecting rules regarding the use of common-pool resources negatively predicted the likelihood of choosing maximum grazing intensity, with the marginal effect of $\beta=-.06(p<0.10), \beta=-.05(p$ $<0.05), \beta=-.02(\mathrm{p}<0.05)$ in the abundance, spatial, and scarce resource-availability conditions, respectively. These results highlight the importance of institutional common resource use rules in the sustainability of common-pool resources. 
We performed additional analyses to assess the robustness of our results. First, to examine whether the results were influenced by the market-knowledge measure, we replaced the market-knowledge variable with customer orientation. Rather than measuring actual market knowledge, the customerorientation scale measures a set of behaviors associated with such knowledge (Ingenbleek et al., 2013). Because we found no substantial differences between the effects of market knowledge and those of customer orientation on grazing-intensity decisions, it is unlikely that the results were affected by issues of validity with regard to the market-knowledge measure. Second, we replaced the within-group variance in market knowledge with the difference between the highest and lowest level of market knowledge in the group. The results revealed no substantial differences as compared to those using the variance measure.

\subsubsection{The effect of market knowledge on individual and group earnings}

We observed substantial variation in both individual and group-level total earnings. Individual total earnings ranged from 26 to 68 tokens, with a mean of 48.56. Group earnings ranged from 155 to 322 tokens, with a mean of 242.79. As indicated by the regression results presented in Table 5.5, individual market knowledge has a negative marginal effect on individual total earnings: $\beta=-.17$ $(\mathrm{p}<0.10)$. Group-average market knowledge had a positive effect- $\beta=.27(\mathrm{p}<0.01)$ - on individual earnings, and within-group variance in market knowledge had a negative effect: $\beta=$ $.24(\mathrm{p}<0.01)$. The most likely explanations for these findings are that groups with greater average market knowledge tend to cooperate more and that these decisions subsequently create trust in their future cooperation with the rest of the group, thereby further stimulating cooperative decisions within the group. Greater within-group variance in market knowledge has an opposite effect, given the higher level of variation in the cognitive basis of the group's members and, the members vary more in their grazing decisions, thereby reducing the trust of group members in future cooperation. 
Table 5.5: Effect of market knowledge on total earnings

\begin{tabular}{lll}
\hline \multirow{2}{*}{ Variables } & \multicolumn{2}{c}{ Total earnings (Individual) } \\
\cline { 2 - 3 } MK & Beta & t-value \\
Average MK (group) & $-.17^{*}$ & -1.76 \\
MK variance (group) & $.27^{* * *}$ & 2.98 \\
Average MK * MK variance & $-.24^{* * *}$ & -2.74 \\
Socio-demographics & $-.16^{*}$ & -1.70 \\
Age & & \\
Family size & -.02 & -0.21 \\
Education & .01 & 0.09 \\
Distance from market & .15 & 1.64 \\
Collective action & -.06 & -0.62 \\
Cooperation with common rules & & \\
Conformity to norms $\&$ values & -.05 & -0.44 \\
Collectivism & .11 & 0.73 \\
Group Variable & -.00 & -0.00 \\
Average age & & \\
Constant & $-.28^{* * *}$ & -2.92 \\
Observations & -.05 & -0.61 \\
F-statistics(df) & 120 & \\
$R^{2}$ (adj. $R^{2}$ ) & $(12,107), 4.53 * * *$ \\
\hline
\end{tabular}

${ }^{*} p<.10 ; * * p<.05, * * * p<.01$

\subsection{Discussion}

This study examines the role of market knowledge in promoting the sustainable use of commonpool resources under various conditions of resource availability within the context of Ethiopian pastoralists. The results provide empirical evidence that greater understanding of market functioning makes resource users more likely to make sustainable decisions, thereby leading to the preservation of those resources and the maximization of long-term returns for the communities. The most likely explanation for these findings is that markets enhance the extent to which users of common-pool resources understand gains and losses in association with the degradation of these 
resources (Oldekop et al., 2013). For users with market knowledge, therefore, market integration provides incentives for more making sustainable use of common-pool resources.

At the group level, the results provide no evidence that a group's average market knowledge has any significant effect on individual grazing decisions. This does not necessarily imply, however, that greater market knowledge at the group level does not affect group-level outcomes. The results for group payoffs show that groups with relatively higher levels of average market knowledge earned higher payoffs at the end of the experiment, thus indicating that groups with higher average levels of market knowledge are better at making sustainable use of grazing rangelands. Withingroup variance in market knowledge among group members reduced payoffs. This finding suggests that, although greater market knowledge could help pastoralists to maximize their long-term returns from livestock production, the learning process about the market should be inclusive. The finding that users with more market knowledge are more capable of making sustainable use of commonpool resources underscores the importance of providing marketing training to rural communities in order to enhance their level of market integration while improving their performance in the sustainable use of common-pool resources.

Our results are consistent with the theory formulated at the start of this article. In practice, however, the sustainable choices stimulated by market knowledge are unlikely to lead directly to the sustainable management of common-pool resources at the community level. The literature on commons dilemmas has drawn attention to the role of common institutions in this process (e.g., Agrawal, 2001; Andersson \& Agrawal, 2011). It is therefore likely that market knowledge will also affect the institutions developing within communities in response to the decisions, expectations, and trust that resource users develop over time. Future research should therefore explore the influence of market knowledge on the development of common institutions within communities. 
This study is intended primarily to explain individual differences in decisions concerning the sustainable use of common-pool resources. All of the participants in this study shared a common cultural background and clan origin, and there were no substantial differences between the groups. The results thus provide only limited insight into group-level of contextual differences in decisions concerning the sustainable use of common resources. Future studies should therefore test the theory further, using multiple groups with differing levels of market knowledge.

\subsection{Conclusion}

In this study, we show that the capacity to use common-pool resources sustainably depends on the understanding of what markets are and how they function within the context of rural communities and that such knowledge subsequently influences the long-term returns for individual livelihoods, which depend on the use of these resources. Our empirical findings suggest that greater understanding of the market leads to more sustainable choices at the individual level and that average market knowledge maximizes group-level earnings from the use of common-pool resources. Within-group variance in market knowledge impedes the sustainable use of commonpool resources. Our findings also suggest that resource scarcity diminishes the effects of market knowledge on individual sustainable choices. Policymakers could thus achieve multiple objectives by enhancing the market knowledge of entire communities of resource users, including livelihood improvement and the sustainable use of common-pool resources within rural communities, while promoting the production of food for the growing population and increasing the export earnings of their countries. 
Appendix 5.1: Model constructs, Survey Measures, and standardized loading for each item

Market knowledge (Teklehaimanot, 2017)

$$
\text { alpha }=.93 ; \text { eigenvalue }=4.5
$$

A pastoralist who wants to sell his livestock:

1 Should be aware of changes in the buyers' livestock preferences.

Will benefit more if his livestock-raising practices center on satisfying the needs of

2 buyers.

Will benefit more if he searches for better breeds that livestock traders are looking for.

Will receive lower prices if he sells livestock of a lower quality than that sold by highland farmers.

5 Should know the specific activities required to raise high-quality livestock.

6 Should be able to explain the quality of his livestock to livestock buyers.

7 Should accept the first price that the buyers offer for his livestock. (R)

Customer-orientation (Ingenbleek et al., 2013)

$$
\text { alpha }=.94 ; \text { eigenvalue }=4.26
$$

1 I increase the quality of the livestock that I am planning to sell.

0.88

2 I do nothing to increase the quality of the livestock that I want to sell.

3 I breed with livestock that will give me the quality traders are looking for.

4 I sell my livestock only when I cannot generate income from other sources.

5 I raise livestock that the market wants.

6 I always search for better breeds to satisfy livestock traders and exporters.

0.92

\section{Cooperation to Common Rules}

$$
\text { alpha }=.91 ; \text { eigenvalue }=4.11
$$

\footnotetext{
1 I always graze my livestock in the grazing areas distant from my village (Arda). 0.8

2 I prefer to graze my livestock near my village (Arda). (R) 0.77

3 I always fence the enclosed rangeland for calves (Kalo). 0.8

4 When I water my livestock in a pond, I always put Meerii. 0.81

5 During rainy seasons, I graze all of my livestock in Worralands. (R) 0.71

6 I always herd my dry and lactating livestock separately in both wet and dry seasons. $\quad 0.73$
} 
7

I care more about the well-being of my livestock than I do about the overgrazing of our rangeland. (R)

Conformity to Traditional Values and Norms (Teklehaimanot, 2017)

$$
\text { alpha }=.94 ; \text { eigenvalue }=3.75
$$

\begin{tabular}{llc}
\hline 1 & I strongly respect our traditions. & 0.83 \\
2 & It is important for us to stick to our traditions and experience. & 0.84 \\
3 & I am devoted to transferring our traditions to my children. & 0.91 \\
& I adhere to our norms to avoid any deeds that would endanger the preservation of & 0.9 \\
& our traditions. & 0.85 \\
5 & I conform to our norms.
\end{tabular}

\section{Collectivism (Teklehaimanot, 2017)}

alpha $=.92$; eigenvalue $=2.93$

\begin{tabular}{llc}
\hline 1 & I consider it important to contribute livestock to my clan members. & 0.85 \\
2 & I assign priority to the survival and protection of our community & 0.83 \\
3 & I am loyal to the collective well-being of my clan members. & 0.85 \\
4 & I feel pride in contributing to my clan members. & 0.9 \\
\hline
\end{tabular}




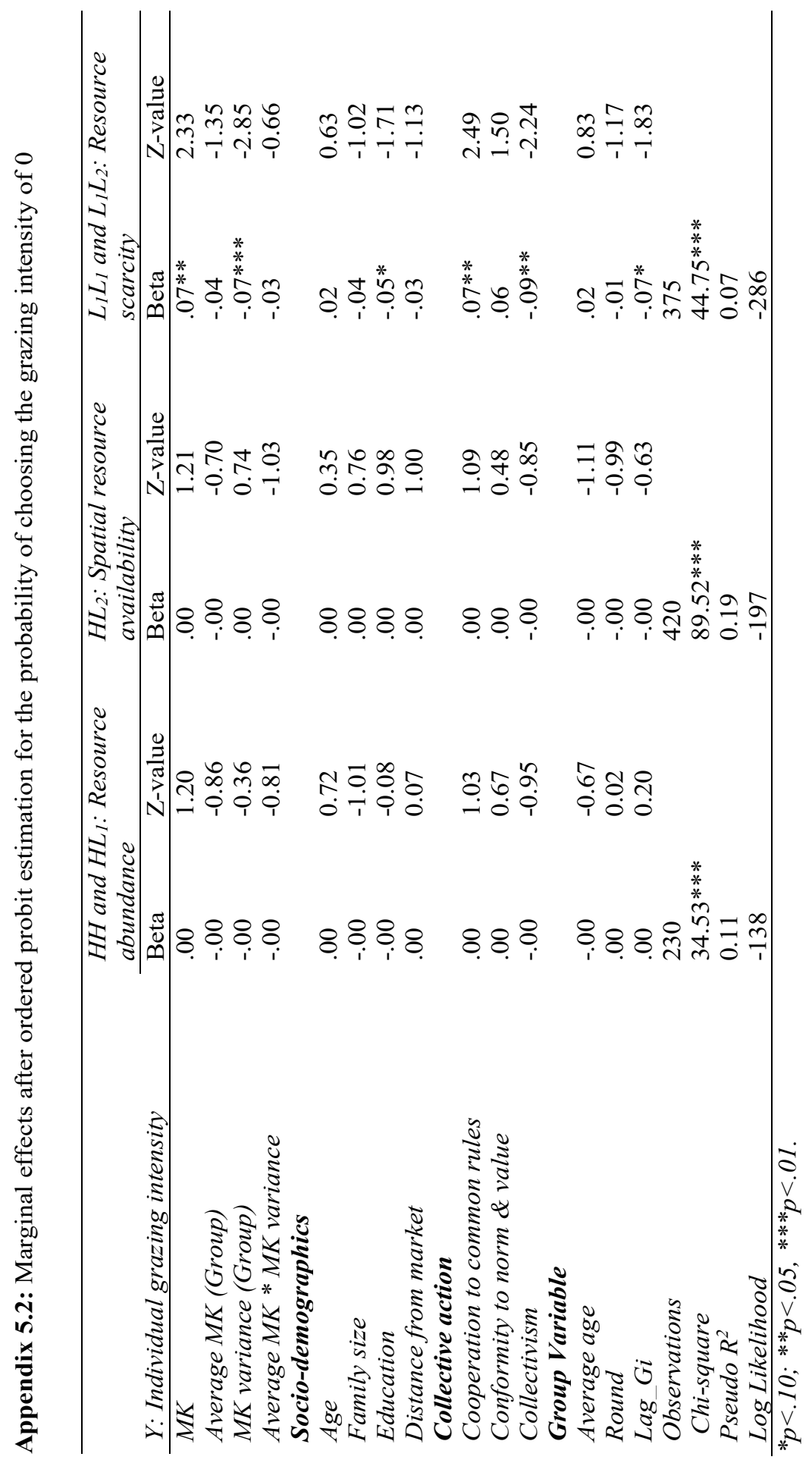




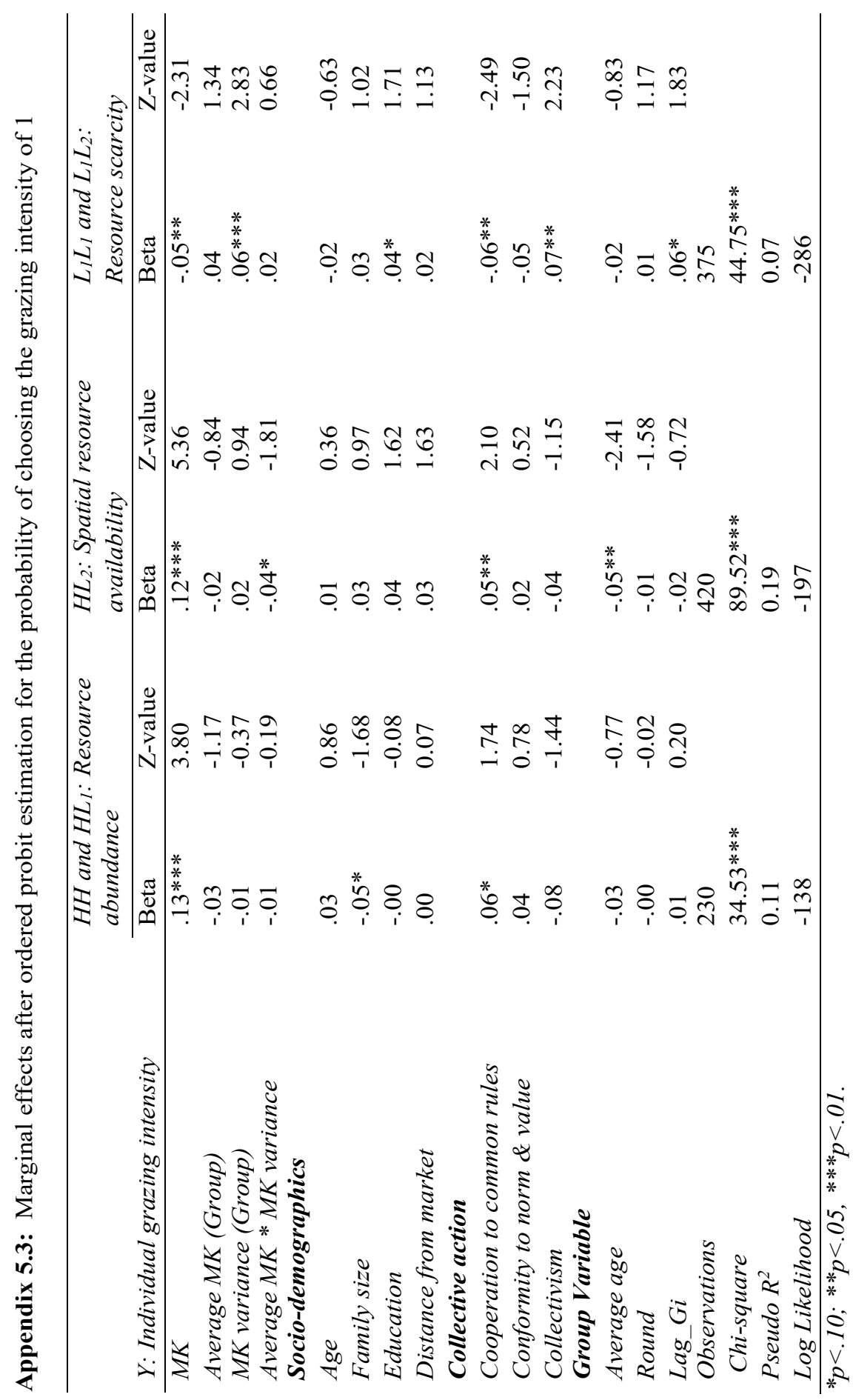


Appendix 5.4: Marginal effects after logit estimation for choosing the good grazing quality location when $\mathrm{HL}_{2}$

\begin{tabular}{lll}
\hline & $\boldsymbol{H L}_{2}$ & \\
\cline { 2 - 3 } Y: Location choice & Beta & Z-value \\
\hline MK & .02 & 1.11 \\
Average MK (Group) & -.03 & -1.49 \\
MK variance (Group) & .00 & 0.07 \\
Average MK * MK variance & .02 & 1.22 \\
Socio-demographics & & \\
Age & -.03 & -1.39 \\
Family size & -.00 & -0.05 \\
Education & .01 & 0.64 \\
Distance from market & .00 & 0.20 \\
Collective action & & \\
Cooperation to common rules & $-.06^{* *}$ & -2.53 \\
Conformity to norm \& value & $.08^{* * *}$ & 2.96 \\
Collectivism & $-.05^{*}$ & -1.83 \\
Group Variable & & \\
Average age & $.04^{* *}$ & 2.07 \\
Round & $.01^{*}$ & 1.74 \\
Lag_Gi & -.01 & -0.48 \\
Observations & 420 & \\
Chi-square & $26.58^{* *}$ & \\
Pseudo R & 0.10 & \\
Log Likelihood & -125 & \\
\hline
\end{tabular}

${ }^{*} p<.10 ; * *_{p}<.05, * * * p<.01$. 



\section{Chapter 6}

General Discussion 


\subsection{Discussion}

The overall aim of this thesis was to understand how businesses adapt their customer value creation process to natural resource scarcity. It specifically focused on the adaptation capabilities that help businesses to maintain their value creation to customers in a natural resource-scarce environment while protecting the sustainability of natural resources. To achieve its overall aim, the thesis answered the following research questions: (1) How do pastoralists adapt the customer value creation process to the scarcity of natural resources? (2) How do natural resource adaptation capabilities of pastoralists influence customer value creation in a resource-scarce environment? (3) How does the level of natural resource scarcity that pastoralists experience influences the business performance contribution of adaptation capabilities and market knowledge? (4) Does market knowledge impact the sustainable use of natural resources, and if so, how? The thesis answered these questions using a qualitative chapter that develops a conceptual framework and three quantitative chapters that test (part of) the framework and its underline assumptions.

To answer question 1, related to how businesses deal with natural resource scarcity, chapter 2 develops the understanding of how pastoralists adapt their value creation processes to the scarcity of natural resources. The chapter takes the customer value creation process as central to all marketing activities (cf., Mizik \& Jacobson, 2003; Varadarajan, 2010). The three-stage customer value creation process of Webster (2002) was used to analyse how the pastoralists' natural resource adaptation actions influence the value defining, developing, and delivering stages of the customer value creation processes. From this in-depth analysis, we showed that integrating insights about actual and predicted resource scarcities into the customer value creation process is at the heart of adapting the value creation processes to the scarcity of natural resources. This implies that lessons on how businesses adapt the value creation process to resource scarcity can be easily drawn from 
businesses that directly experience resource scarcities. The findings showed that the pastoralists deploy different adaptation actions at the value defining, developing, and delivering stages of their value creation process to deal with the actual and predicted natural resource scarcities. From these activities, we have identified and conceptualized three generic natural resource adaptation capabilities, namely matching value propositions, natural resource deployment, and managing customer expectations.

In the value-defining stage, matching value propositions capability enables businesses to adjust their value propositions to customers based on the actual and predicted natural resource scarcities. The capability enables businesses to recognize new or improved value creation opportunities that help them to better satisfy the needs of customers given the actual and predicted resource scarcities. Then, natural resource deployment capability enhances businesses' ability to make effective and efficient use of scarcely available resources in the value development stage. This capability guides businesses to allocate available resources in ways that create maximum value to customers, to build slack resources (e.g., inventories, flexible operations) as a precautionary measure for resource scarcity, to minimize unnecessary usage of resources and to create flexible access to alternative resources. Finally, in the value-delivering stage, managing customer expectations capability enables businesses to create an appropriate level of value expectations in the mind of customers. Businesses can do so by communicating with customers in advance about their intended value offerings and potential consequences of resource scarcity.

Chapter 2 further revealed that knowledge about the natural environment enables the pastoralists to develop the adaptation capabilities, whereas market knowledge fosters the deployment of the adaptation capabilities in the customer value creation process. The findings suggest that natural resource adaptation capabilities are rooted in the two knowledge bases: market knowledge and 
natural environmental knowledge about actual and predicted natural resource scarcities. The finding implies that to develop natural resource adaptation capabilities, businesses should guide their value creation processes with combined insights from the market and the natural environment. The chapter concluded by developing a conceptual model that indicates the antecedents and consequences of the adaptation capabilities.

Chapter 3 empirically tested the mediating role of the natural resource adaptation capabilities in the market knowledge and customer value creation relationship. In doing so, we used product quality and quality of life as outcomes for the pastoralists' customer value creation process. We found that market knowledge has strong positive effects on the three natural resource adaptation capabilities. Unlike managing customer expectations, the matching value propositions and natural resource deployment capabilities positively mediate the effect of market knowledge on product quality and quality of life. These results imply that adaptation capabilities that intervene at early stages in the value creation process, specifically: matching value proposition and natural resource deployment capabilities, are relatively more effective in dealing with resource scarcity. The most likely explanation is that the three adaptation capabilities indeed intervene sequentially in the value creation process and thus if the resource scarcity is already overcome in earlier stages of the process, the adaptation capabilities in the subsequent stage become less important.

Chapter 3 further observed that pastoralists who differ in market knowledge also differ in the natural resource adaptation capabilities, even though they share the same traditional ecological knowledge system. This finding provides empirical evidence for the basic premises in the previous chapter, namely that businesses have to combine insights from the two knowledge streams: market knowledge and natural environmental knowledge to develop the natural resource adaptation capabilities in the process of customer value creation. 
To answer research question 3, Chapter 4 examined the moderating effect of the natural resource scarcity on the impact of market knowledge on natural resource deployment capability and product quality. The chapter built on our unique access to the three-waves of longitudinal data collected from 120 pastoralists at relatively distinct natural resource availability conditions: dry, rainy and drought seasons. We primarily focused on the natural resource deployment capability because it relates to businesses' ability to make use of available natural resources, which vary strongly across seasons in our study area. The results showed that pastoralists minimize the decrease in product quality during natural pasture-scarce seasons through natural resource deployment capability. Market knowledge was found to have a stronger impact on natural resource deployment capability when natural resources are more constrained. This finding provides insights that market knowledge invokes businesses to make more effective and efficient use of available resources when resources are more limited than abundant. Businesses become more innovative in the use of resources when they encounter resource scarcity (Berrone et al., 2013), but our findings suggest that such innovation in the use of natural resources only improves performance when they can rely on a sufficient understanding of markets.

Chapter 5 tested the important underlying assumption of the conceptual model in chapter 2, regarding the complementarity of the traditional ecological knowledge and the market knowledge systems of the pastoralists. The chapter used a common-pool resource dilemma experiment of Cardenas et al. (2013) to test the hypothesis that higher market knowledge encourages sustainable use of common-pool natural resources. Its main argument is that pastoralists with a higher level of market knowledge are more likely to make sustainable resource use decisions in a common resource dilemma situation. This happens for at least two fundamental reasons. First, from their previous market participation experience, pastoralists with a higher level of market knowledge 
have been earning higher income from markets. Thus, they are more likely to make sustainable resource use choices since they have a relatively higher incentive to sustain the common-resource rather than overexploiting for short-term benefits. Second, they are more likely to have a better understanding of the impact of resource degradation on the quality of the product they sell since they get feedbacks from markets (in terms of customer feedback and price) about the quality of their products. Those pastoralists thus better understand how the depletion of common-pool natural resources threatens their source of income from markets. The results indicated that, when resource conditions were good, resource users with more market knowledge are more likely to apply a lower grazing intensity to sustain their shared grazing lands. During resource scarcity, this effect is weaker. The results further revealed that within-group variance in market knowledge harms group members' decisions on sustainable resource use. The results imply that (also) for communities that experience increasing pressure from the global market economy enhancing market knowledge is of vital importance to protect shared natural resources from depletion.

\subsection{Conclusions}

The thesis comes to five conclusions. First, in resource-scarce environments, customer value creation is not only a matter of understanding of the market dynamics, but it is also a matter of learning from the natural environment to build the capabilities needed to deal with resource scarcities. These capabilities are developed through learning about actual and predicted resource scarcities and then, integrating the resulting insights into the value creation process. For this to occur, the marketing function must be seen as a learning process, not only about markets but also about the natural environment.

Second, integrating insights from natural environments into the customer value creation process enables businesses to develop three generic natural resource adaptation capabilities, namely 
matching value propositions, natural resource deployment, and managing customer expectations. These capabilities intervene sequentially at the value defining, developing, and delivering stages of the customer value creation process, respectively.

Third, market knowledge is an important resource for developing natural resource adaptation capabilities in the customer value creation process. In natural resource-scarce settings, market knowledge positively impacts outcomes from the value creation process, such as product quality, by fuelling the natural resource adaptation capabilities with market insights, which guides businesses to evaluate and implement adaptation actions from the perspective of maintaining value creation to customers in resource-scarce times or predicted resource-scarce times.

Fourth, in dynamic resource environments market knowledge contributes more to the natural resource deployment capability when businesses are confronted with limited rather than abundant resources. During resource-scarce times, market knowledge has a stronger positive impact on the natural resource deployment capability of businesses. As a result, market knowledge becomes more essential to maintain business performance when resources are more acute rather than abundant.

Fifth, market knowledge contributes to the sustainability of natural resources, in at least two ways. First, by enhancing businesses' adaptation capabilities to natural resource scarcity, which helps them to develop sustainable value creation processes. Second, by fostering cooperation to the sustainable use of common-pool natural resources. Thus, market knowledge enhancing programs such as marketing training to businesses in emerging and developing countries can be an effective tool to help them to thrive in resource-scarce settings while they are doing good to the sustainability of natural resources. 


\subsection{Theoretical contributions}

This thesis makes at least seven contributions to our existing knowledge. First, the thesis provides insight into how the customer value creation process can be adapted to natural resource scarcity. It shows that knowledge about actual and predicted natural resource scarcities enables businesses to develop natural resource adaptation capabilities, and market knowledge fosters the deployment of these capabilities in the customer value creation process. Such insights extend the literature on customer value creation, which mostly focuses on knowledge about markets (Marinova, 2004; Slater et al., 2012). To show the importance of knowledge about the natural environment, the conceptual framework in Chapter 2 suggests that guiding the value creation process through combined insights from both the market and natural environment enable businesses to adjust value propositions to resource scarcities, make effective and efficient use of available resources, and manage customer expectations based on resource availability conditions. The results in Chapter 3 and 4 further show that such adaptation capabilities help businesses to create superior customer value in a resource-scarce environment.

Second, the thesis contributes to the marketing literature on knowledge-based view of the firm, indicating that market knowledge is not only instrumental to create customer value but also to cope with resource scarcities. The dominant logic in the strategic marketing and management literature on how to cope with resource scarcity is largely based on resource-dependency theory. This theory stresses the importance of strengthening relationships with stakeholders who control resources by forming alliances, joint ventures, mergers, and acquisitions to overcome dependency on scarce resources (Drees \& Heugens, 2013; Pfeffer \& Salancik, 2003). Such theorizing overlooks internal capabilities that reduce dependency on scarce resources. It also neglects the fact that competition over control of natural resources can exacerbate the scarcity of those resources. For common-pool 
natural resources (e.g., fresh water, fishing resources, and forests), such competition may lead to the depletion of those resources, as nobody owns them. The findings of this thesis, however, suggests that natural-resource adaptation capabilities could offer alternative strategies for reducing dependency on scarce resources, thereby enhancing the autonomy of organizations and complementing stakeholder-management strategies (Drees \& Heugens, 2013; Pfeffer \& Salancik, 2003).

Third, by providing insights into how market knowledge encourages sustainable use of commonpool natural resources, the thesis contributes to the literature on marketing and sustainability. The results in Chapter 5 further show that pursuing a competitive advantage through superior customer value creation may not necessarily be determinantal to the sustainability of natural resources if businesses who share the natural resources have the same understanding of markets. This is because market knowledge fosters cooperation to common-pool resource dilemmas. The existing literature has reflected a great deal of skepticism regarding the impact of markets on sustainable use of natural resources (e.g., Ricardo Godoy, Reyes-García, Byron, Leonard, \& Vadez, 2005; Mutenje et al., 2011). This thesis offers a subtle but important counter argument, suggesting that marketing behaviors can be sustainable depending on the market cognition of resource users.

Fourth, the thesis contributes to business development in emerging and developing markets by offering insights into how market knowledge enhances natural resource adaptation capabilities in impoverished settings. To date, most studies in this area have focused on improving access to productive resources and technologies as effective tools for businesses to satisfy their customers and to improve the quality of life in such settings (e.g., Rao, Brümmer, \& Qaim, 2012; Reardon, Barrett, Berdegué, \& Swinnen, 2009). The literature on business training has also shown the relevance of marketing training interventions in enabling businesses to satisfy their customers by 
overcoming market knowledge gaps needed to cater the needs of markets (Teklehaimanot et al., 2017; Viswanathan et al., 2009). This thesis further complements this literature by uncovering the less recognized role of market knowledge in enhancing adaptation capabilities in resource-scarce settings.

Fifth, the thesis also contributes to the resource management literature (e.g., Ndofor et al., 2011; Sirmon et al., 2007) by shedding light on the role of natural resource deployment capability in managing the acute scarcity of resources. The thesis shows that market knowledge has the strongest effect on natural resource deployment capability when resources are scarce rather than abundant. This provides empirical evidence that during resource-scarce times businesses with market knowledge are better equipped to effectively allocate existing resources to customer value-creating activities, to avoid unnecessary usage of resources, and to build slack resources (e.g. inventory and flexible resource access) as a precautionary measure for resource-scarce times. This helps businesses to stabilize their value creation to customers in a dynamic resource environment where the availability of key resources varies over times.

Sixth, the thesis also contributes to the sustainable use of common-pool natural resources among rural communities by highlighting how resource users' level of market knowledge influences the sustainable use of common-pool natural resources. Compared to the extant literature regarding factors influencing the sustainable use of common-pool resources (e.g., Andersson \& Agrawal, 2011; Castillo et al., 2011), this thesis focused on individual variables, rather than contextual factors such as common institutions and group size, to explain whether a resource-user will or will not cooperate in a common-pool resource dilemma. The main argument of the thesis is that depending on the level of understanding of markets rural communities may adopt different approaches to the sustainability of common-pool resources when integrating with the market. This 
thesis extends this line of literature by showing that market knowledge partly explains common resource users' decisions to cooperate with the sustainable use of natural resources. The thesis thus illustrates that providing an understanding of market functioning is an effective tool to foster the sustainability of natural resources in rural communities experiencing growing pressure from the global market. Marketing capabilities help businesses in rural areas to understand the benefits of sustaining common-pool natural resources as well as the consequences of unsustainable resource use behavior.

Finally, the thesis contributes to the marketing literature by expanding the marketing research frontier into resource-scarce settings. Marketing researchers are mostly focused on resource affluent contexts such as North America and Western Europe to draw lessons regarding sustainable marketing practices (e.g., Little et al., 2019; Scott \& Weaver, 2018). Empirical studies that target contexts where the depletion of natural resources is already directly being experienced by businesses are largely absent in the literature. The thesis shows how resource-scarce contexts such as the pastoralists' livestock raising businesses can be used to learn and draw important lessons on sustainable business practices.

\subsection{Practical implications}

The thesis makes an important first step into the development of practical marketing solutions that help businesses to maintain their value creation to customers in resource-scarce times. The thesis suggests that managers should first start to gather, interpret, and share information throughout the organization about actual and predicted resource scarcities. Then, the integration of the resulting insights into each process of customer value creation leads to the development of natural resource adaptation capabilities. Such capabilities help them to maintain their value creation to customers and business performance during resource-scarce times. 
In managing acutely scarce resources, marketing managers should work very closely with other functional managers such as production managers to give guidance on which adaptation actions are acceptable for which customers, depending on the impact of the adaptation actions on the customers' value needs.

The findings of the thesis suggest that managers should think of the marketing function as more than satisfying customers only. Rather they should include the management of resources and strategies, which requires businesses to adopt a supply chain management approach in managing resources. In resource scarcity conditions, a supply chain management approach promotes enhanced adaptation capabilities to the scarcity of resources. This is because the adaptation capabilities demand strong collaboration and integration of marketing, logistics, and operations functions. For enhanced natural resource adaptation capability, firms thus should not only integrate the activities of marketing, logistics, and operation functions, but also the strategies, resources, and investments in these functions.

Finally, the evidence from the thesis implies that enhancing market knowledge of rural communities deserves attention in the policies, programs and projects that aim to foster the sustainable use of natural resources. To date, such interventions are largely focused on encouraging the conservation of natural resources, and consider market integration as detrimental to the sustainability of natural resources (e.g., Mutenje et al., 2011; Rommel, Villamayor-Tomas, Müller, \& Werthmann, 2015). The results of this thesis, however, show that providing an understanding of markets is of vital importance to protect shared natural resources from depletion. Such evidence guides policymakers and NGOs to include market knowledge enhancing programs such as marketing training to minimize differences in the level of understanding of markets among rural 
communities who share natural resources. Homogeneity in the level of market knowledge among common resource users facilitates the sustainable use of shared resources.

\subsection{Research limitations and directions for future research}

The thesis represents an important first step in providing insights into the contributions of market knowledge in maintaining value creation to customers and strengthening sustainability in natural resource-scarce contexts. The thesis has focused on a natural resource-scarce setting of Borana pastoralists in Ethiopia. As an early contribution to this line of study, the thesis is not without its limitations. First, the qualitative study in chapter 2 that informed the framework was conducted in the Borana pastoralists context only. Borana pastoralists provide rich insights as they have a wide variety of adaptation actions to deal with natural resource scarcities. However, they also have their own unique culture and traditional self-governance and natural resource management systems (Homann et al., 2008). The adaptation actions may be influenced by their culture and traditional institutions. There is, therefore, room for extending this study in other resource-scarce settings. Future research may study how businesses in other resource-scarce settings adapt their operations to resource scarcity and capabilities that underlay the adaptation actions of those businesses. For instance, the study can be replicated in other pastoralist communities (e.g., pastoralists in Kenya), small-scale farmers in Africa and Asia, or entrepreneurs operating in urban areas of emerging and developing countries, which often operate under scarcities of different types of resources.

Second, the thesis has examined the mediating effects of natural resource adaptation capabilities in the impact of market knowledge on outcomes in the value creation process in the context of Borana pastoralists. Pastoralists share the same traditional institutions and indigenous ecological knowledge system. This allows the pastoralists to share relatively the same knowledge about their natural environment, specifically about actual and predicted natural resource scarcities (Homann 
et al., 2008). Replication of this study in other resource-scarce settings would therefore provide additional insights into the mediating effects of natural resource adaptation capabilities. Future research can extend the study to other resource-scarce contexts where businesses do not share the same natural environment knowledge system. Such studies provide insight into how knowledge about the natural environment influences natural resource adaptation capabilities. The studies, for instance, can be replicated among agribusinesses in emerging and developing countries in Africa, Latin America, and Asia.

Finally, the current thesis primarily focused on identifying natural resource adaptation capabilities with less emphasis on the mechanism through with businesses develop such capabilities. Future studies can thus explore the mechanism through which businesses develop such capabilities. Through qualitative studies in resource-scarce contexts, future studies can examine 'how' knowledge about actual and future predicted scarcity of resources leads to the development of adaptation capabilities. Such studies could provide insight into factors that facilitate or constrain the development of natural-resource adaptation capabilities. 


\section{References}

Acheson, J. M. (2006). Institutional failure in resource management. Annu. Rev. Anthropol., 35, 117-134.

Achrol, R. S., \& Kotler, P. (2012). Frontiers of the marketing paradigm in the third millennium. Journal of the Academy of Marketing Science, 40(1), 35-52. doi:10.1007/s11747-011-02554

Acock, A. C. (2013). Discovering structural equation modeling using Stata: Revised edition: Stata press.

Agrawal, A. (2001). Common property institutions and sustainable governance of resources. World Development, 29(10), 1649-1672. doi:10.1016/S0305-750x(01)00063-8

Agrawal, A., \& Yadama, G. (1997). How do Local Institutions Mediate Market and Population Pressures on Resources? Forest Panchayats in Kumaon, India. Development and Change, 28(3), 435-465. doi:10.1111/1467-7660.00050

Aklilu, Y., \& Catley, A. (2013). Moving up or moving out? Commercialization, growth and destitution in pastoralist areas. In Pastoralism And Development in Africa (pp. 108-120): Routledge.

Alavi, M., \& Leidner, D. E. (2001). Knowledge management and knowledge management systems: Conceptual foundations and research issues. MIS quarterly, 107-136.

Anderies, J. M., Janssen, M. A., Bousquet, F., Cardenas, J. C., Castillo, D., Lopez, M. C., . . . Wutich, A. (2011). The challenge of understanding decisions in experimental studies of common pool resource governance. Ecological Economics, 70(9), 1571-1579. doi:10.1016/j.ecolecon.2011.01.011

Andersson, K., \& Agrawal, A. (2011). Inequalities, institutions, and forest commons. Global Environmental Change-Human and Policy Dimensions, 21(3), 866-875. doi:10.1016/j.gloenvcha.2011.03.004

Angassa, A., \& Oba, G. (2008). Herder Perceptions on Impacts of Range Enclosures, Crop Farming, Fire Ban and Bush Encroachment on the Rangelands of Borana, Southern Ethiopia. Human Ecology, 36(2), 201-215. doi:10.1007/s10745-007-9156-Z

Argote, L., \& Greve, H. R. (2007). A Behavioral Theory of the Firm-40 Years and Counting: Introduction and Impact. Organization science, 18(3), 337-349. doi:10.1287/orsc. 1070.0280 
Atuahene-Gima, K., \& Wei, Y. H. (2011). The Vital Role of Problem-Solving Competence in New Product Success. Journal of Product Innovation Management, 28(1), 81-98. doi:10.1111/j.1540-5885.2010.00782.x

Baker, T., \& Nelson, R. E. (2005). Creating something from nothing: Resource construction through entrepreneurial bricolage. Administrative science quarterly, 50(3), 329-366. doi:10.2189/asqu.2005.50.3.329

Banerjee, S. B., Iyer, E. S., \& Kashyap, R. K. (2003). Corporate environmentalism: Antecedents and influence of industry type. Journal of Marketing, 67(2), 106-122.

Bansal, P., \& DesJardine, M. R. (2014). Business sustainability: It is about time. Strategic Organization, 12(1), 70-78. doi:10.1177/1476127013520265

Barrett, C. B. (2008). Smallholder market participation: Concepts and evidence from eastern and southern Africa. Food Policy, 33(4), 299-317. doi:10.1016/j.foodpol.2007.10.005

Barrett, C. B., \& Carter, M. R. (2010). The Power and Pitfalls of Experiments in Development Economics: Some Non-random Reflections. Applied Economic Perspectives and Policy, 32(4), 515-548. doi:10.1093/aepp/ppq023

Barrett, C. B., McPeak, J. G., Luseno, W. K., Little, P. D., Osterloh, S. M., Mahmoud, H., \& Gebru, G. (2004). Pastoralist livestock marketing behavior in northern Kenya and southern Ethiopia: an analysis of constraints limiting off-take rates. Available at SSRN 611064.

Basurto, X. (2008). Biological and Ecological Mechanisms Supporting Marine Self-Governance: the Seri Callo de Hacha Fishery in Mexico. Ecology and Society, 13(2). doi:10.5751/es02587-130220

Becker, J.-M., Ringle, C. M., \& Sarstedt, M. (2018). Estimating moderating effects in PLS-SEM and PLSc-SEM: Interaction term generation* data treatment. Journal of Applied Structural Equation Modeling, 2(2), 1-21.

Beermann, M. (2011). Linking corporate climate adaptation strategies with resilience thinking. Journal of Cleaner Production, 19(8), 836-842. doi:10.1016/j.jclepro.2010.10.017

Bell, J. E., Mollenkopf, D. A., \& Stolze, H. J. (2013). Natural resource scarcity and the closed-loop supply chain: a resource-advantage view. International Journal of Physical Distribution \& Logistics Management, 43(5-6), 351-379. doi:10.1108/Ijpdlm-03-2012-0092

Berazneva, J., \& Lee, D. R. (2013). Explaining the African food riots of 2007-2008: An empirical analysis. Food Policy, 39, 28-39. doi:doi.org/10.1016/j.foodpol.2012.12.007 
Berrone, P., Fosfuri, A., Gelabert, L., \& Gomez-Mejia, L. R. (2013). Necessity as the mother of 'green'inventions: Institutional pressures and environmental innovations. Strategic Management Journal, 34(8), 891-909. doi: 10.1002/smj.2041

Bharadwaj, N., \& Dong, Y. (2014). Toward further understanding the market-sensing capabilityvalue creation relationship. Journal of Product Innovation Management, 31(4), 799-813. doi:10.1111/jpim.12124

Bleischwitz, R. (2001). Rethinking productivity: why has productivity focussed on labour instead of natural resources? Environmental and Resource Economics, 19(1), 23-36. doi:doi.org/10.1023/A:1011106527578

Bode, C., Wagner, S. M., Petersen, K. J., \& Ellram, L. M. (2011). Understanding responses to supply chain disruptions: Insights from information processing and resource dependence perspectives. Academy of management journal, 54(4), 833-856.

Burgess, S. M., \& Steenkamp, J. B. E. M. (2006). Marketing renaissance: How research in emerging markets advances marketing science and practice. International Journal of Research in Marketing, 23(4), 337-356. doi:10.1016/j.ijresmar.2006.08.001

Buzzell, R. D., \& Gale, B. T. (1987). The PIMS principles: Linking strategy to performance: Simon and Schuster.

Campbell, A. J. (2003). Creating customer knowledge competence: managing customer relationship management programs strategically. Industrial Marketing Management, 32(5), 375-383. doi:http://dx.doi.org/10.1016/S0019-8501(03)00011-7

Cardenas, J.-C., Janssen, M., \& Bousquet, F. (2013). Dynamics of rules and resources: three new field experiments on water, forests and fisheries. In Handbook on Experimental Economics and the Environment (pp. 319-345).

Cárdenas, J.-C., \& Ostrom, E. (2004). What do people bring into the game? Experiments in the field about cooperation in the commons. Agricultural Systems, 82(3), 307-326. doi:10.1016/j.agsy.2004.07.008

Cass, R. C., \& Edney, J. J. (1978). Commons Dilemma - Simulation Testing the Effects of Resource Visibility and Territorial Division. Human Ecology, 6(4), 371-386. doi:10.1007/Bf00889415 
Castillo, D., Bousquet, F., Janssen, M. A., Worrapimphong, K., \& Cardenas, J. C. (2011). Context matters to explain field experiments: Results from Colombian and Thai fishing villages. Ecological Economics, 70(9), 1609-1620. doi:10.1016/j.ecolecon.2011.05.011

Catley, A., Lind, J., \& Scoones, I. (2013). Pastoralism and development in Africa: dynamic change at the margins: Routledge.

Cayla, J., \& Arnould, E. (2013). Ethnographic Stories for Market Learning. Journal of Marketing, 77(4), 1-16. doi:DOI 10.1509/jm.12.0471

Cecchi, F., \& Bulte, E. (2013). Does Market Experience Promote Rational Choice? Experimental Evidence from Rural Ethiopia. Economic Development and Cultural Change, 61(2), 407429. doi:10.1086/668275

Chang, T. Z., \& Chen, S. J. (1998). Market orientation, service quality and business profitability: a conceptual model and empirical evidence. Journal of services marketing, 12(4), 246-264. doi: $10.1108 / 08876049810226937$

Churchill, G. A. (1979). A paradigm for developing better measures of marketing constructs. Journal of marketing research, 64-73. doi:http://doi:10.2307/3150876.

Claudy, M. C., Peterson, M., \& Pagell, M. (2016). The Roles of Sustainability Orientation and Market Knowledge Competence in New Product Development Success. Journal of Product Innovation Management, 33(S1), 72-85. doi:10.1111/jpim.12343

Coppock, D. L., Desta, S., Gebru, G., \& Tezera, S. (2005). Linking pastoralists and exporters in a livestock marketing chain: Recent experiences from Ethiopia.

Coye, R. W. (2004). Managing customer expectations in the service encounter. International Journal of service industry management, 15(1), 54-71. doi:10.1108/09564230410523330

Cunha, M. P. e., Rego, A., Oliveira, P., Rosado, P., \& Habib, N. (2014). Product Innovation in Resource-Poor Environments: Three Research Streams. Journal of Product Innovation Management, 31(2), 202-210. doi:10.1111/jpim.12090

Danneels, E. (2016). Survey measures of first-and second-order competences. Strategic Management Journal, 37(10), 2174-2188.

Davies, J. (2008). Turning the tide: enabling sustainable development for Africa's mobile pastoralists. Paper presented at the Natural Resources Forum.

Day, G. S. (1994). The Capabilities of Market-Driven Organizations. Journal of Marketing, 58(4), 37-52. doi:Doi 10.2307/1251915 
Day, G. S. (2000). Managing market relationships. Journal of the Academy of Marketing Science, 28(1), 24-30. doi:Doi 10.1177/0092070300281003

Day, G. S. (2002). Managing the market learning process. Journal of Business \& Industrial Marketing, 17(4), 240-252. doi:10.1108/08858620210431651

Day, G. S. (2011). Closing the Marketing Capabilities Gap. Journal of Marketing, 75(4), 183-195. doi:DOI 10.1509/jmkg.75.4.183

Daykin, A. R., \& Moffatt, P. G. (2002). Analyzing ordered responses: A review of the ordered probit model. Understanding Statistics: Statistical Issues in Psychology, Education, and the Social Sciences, 1(3), 157-166. doi:https://doi.org/10.1207/S15328031US0103 02

De Luca, M., \& Atuahene-Gima, K. (2007). Market knowledge dimensions and cross-functional collaboration: Examining the different routes to product innovation performance. Journal of Marketing, 71(1), 95-112.

De Luca, M., \& Atuahene-Gima, K. (2018). Market Knowledge Dimensions and Cross-Functional Collaboration: Examining the Different Routes to Product Innovation Performance. Journal of Marketing, 71(1), 95-112. doi:10.1509/jmkg.71.1.095

Dolan, P. (2002). The sustainability of "sustainable consumption". Journal of Macromarketing, 22(2), 170-181.

Dopfer, M., Fallahi, S., Kirchberger, M., \& Gassmann, O. (2017). Adapt and strive: How ventures under resource constraints create value through business model adaptations. Creativity and Innovation Management, 26(3), 233-246. doi:10.1111/caim.12218

Drees, J. M., \& Heugens, P. P. (2013). Synthesizing and extending resource dependence theory: A meta-analysis. Journal of Management, 39(6), 1666-1698.

Duffy, S., Layton, R., \& Dwyer, L. (2017). When the Commons call "Enough”, Does Marketing Have an Answer? Journal of Macromarketing, 37(3), 268-285. doi:10.1177/0276146717710703

Dyllick, T., \& Hockerts, K. (2002). Beyond the business case for corporate sustainability. Business Strategy and the Environment, 11(2), 130-141. doi:10.1002/bse.323

Edvardsson, B., Klaus, P., Payne, A., \& Frow, P. (2014). Developing superior value propositions: a strategic marketing imperative. Journal of Service Management.

Eesley, C., \& Lenox, M. J. (2006). Firm responses to secondary stakeholder action. Strategic Management Journal, 27(8), 765-781. doi:10.1002/smj.536 
Eggert, A., Ulaga, W., Frow, P., \& Payne, A. (2018). Conceptualizing and communicating value in business markets: From value in exchange to value in use. Industrial Marketing Management, 69, 80-90.

Eisenack, K., \& Stecker, R. (2012). A framework for analyzing climate change adaptations as actions. Mitigation and Adaptation Strategies for Global Change, 17(3), 243-260. doi:10.1007/s11027-011-9323-9

Eisenhardt, K. M. (1989). Building Theories from Case-Study Research. Academy of management review, 14(4), 532-550. doi:Doi 10.2307/258557

Eisenhardt, K. M., \& Graebner, M. E. (2007). Theory building from cases: Opportunities and challenges. Academy of management journal, 50(1), 25-32. doi:Doi 10.5465/Amj.2007.24160888

FAO. (2001). Pastoralism in the new millennium, animal health and production series no. 150. FAO, Rome, Italy, 1-06. Retrieved from http://www.fao.org/3/Y2647E/y2647e00.htm\#toc

FAO. (2018). Pastoralism in Africa's drylands: Reducing risks, addressing vulnerability and enhancing resilience. FAO, Rome, Italy. Retrieved from http://www.fao.org/3/CA1312EN/ca1312en.pdf

Farmer, A., Breazeale, M., Stevens, J. L., \& Waites, S. F. (2017). Eat green, get lean: Promoting sustainability reduces consumption. Journal of Public Policy \& Marketing, 36(2), 299-312.

Fay, M. (2012). Inclusive green growth: The pathway to sustainable development: World Bank Publications.

Fernández-Giménez, M. E., \& Fillat Estaque, F. (2012). Pyrenean Pastoralists' Ecological Knowledge: Documentation and Application to Natural Resource Management and Adaptation. Human Ecology, 40(2), 287-300. doi:10.1007/s10745-012-9463-x

Field, C. B., Barros, V., Stocker, T. F., \& Dahe, Q. (2012). Managing the risks of extreme events and disasters to advance climate change adaptation: special report of the intergovernmental panel on climate change: Cambridge University Press.

Fiorino, D. J., \& Bhan, M. (2016). Supply Chain Management as Private Sector Regulation: What does it Mean for Business Strategy and Public Policy? Business Strategy and the Environment, 25(5), 310-322. doi:10.1002/bse.1871 
Fornell, C., \& Larcker, D. F. (1981). Evaluating Structural Equation Models with Unobservable Variables and Measurement Error. Journal of marketing research, 18(1), 39-50. doi: $10.2307 / 3151312$

Fratkin, E., \& Mearns, R. (2003). Sustainability and Pastoral Livelihoods: Lessons from East African Maasai and Mongolia. Human Organization, 62(2), 112-122. doi:10.17730/humo.62.2.am1qpp36eqgxh3h1

Friese, S. (2019). Qualitative data analysis with ATLAS. ti: SAGE Publications Limited.

Fuller, D. A. (1999). Sustainable marketing: Managerial-ecological issues: Sage Publications.

Galvin, K. A. (2009). Transitions: Pastoralists Living with Change. Annual Review of Anthropology, 38, 185-198. doi:10.1146/annurev-anthro-091908-164442

García-Sánchez, I. M., Gallego-Álvarez, I., \& Zafra-Gómez, J. L. (2019). Do the ecoinnovation and ecodesign strategies generate value added in munificent environments? Business Strategy and the Environment.

Garvey, A. M., \& Bolton, L. E. (2017). Eco-Product Choice Cuts Both Ways: How Proenvironmental Licensing Versus Reinforcement Is Contingent on Environmental Consciousness. Journal of Public Policy \& Marketing, 36(2), 284-298. doi:10.1509/jppm.16.096

Gebremeskel, E. N., Desta, S., \& Kassa, G. K. (2019). Pastoral Development in Ethiopia: Trends and the Way Forward.” Development Knowledge and Learning. (World Bank, Washington, DC. License: Creative Commons Attribution CC BY 3.0 IGO).

Gemedo-Dalle, Isselstein, J., \& Maass, B. L. (2006). Indigenous ecological knowledge of Borana pastoralists in southern Ethiopia and current challenges. International Journal of Sustainable Development and World Ecology, 13(2), 113-130. doi:Doi $10.1080 / 13504500609469666$

George, G., Schillebeeckx, S. J. D., \& Liak, T. L. (2015). The Management of Natural Resources: An Overview and Research Agenda. Academy of management journal, 58(6), 1595-1613. doi:10.5465/amj.2015.4006

Gibbert, M., Hoegl, M., \& Valikangas, L. (2014). Introduction to the Special Issue: Financial Resource Constraints and Innovation. Journal of Product Innovation Management, 31(2), 197-201. doi:10.1111/jpim.12089 
Glaser, G., \& Strauss, L. (1967). The discovery of grounded theory (0202300285). Retrieved from New York:

Godoy, R., Reyes-Garcia, V., Byron, E., Leonard, W. R., \& Vadez, V. (2005). The effect of market economies on the well-being of indigenous peoples and on their use of renewable natural resources. Annual Review of Anthropology, 34, 121-138. doi:10.1146/annurev.anthro.34.081804.120412

Godoy, R., Reyes-García, V., Byron, E., Leonard, W. R., \& Vadez, V. (2005). The effect of market economies on the well-being of indigenous peoples and on their use of renewable natural resources. Annu. Rev. Anthropol., 34, 121-138.

Gomes, N. (2006). Access to water, pastoral resource management and pastoralists' livelihoods: Lessons learned from water development in selected areas of Eastern Africa (Kenya, Ethiopia, Somalia). FAO LSP WP, 26.

Gonzalez, E. D., Koh, L., \& Leung, J. (2019). Towards a circular economy production system: trends and challenges for operations management. International Journal of Production Research, 57(23), 7209-7218. doi:10.1080/00207543.2019.1656844

Grant, R. M. (1996a). Prospering in dynamically-competitive environments: Organizational capability as knowledge integration. Organization science, 7(4), 375-387.

Grant, R. M. (1996b). Toward a knowledge-based theory of the firm. Strategic Management Journal, 17(S2), 109-122. doi:https://doi.org/10.1002/smj.4250171110

Grasso, V. B. (2013). Rare earth elements in national defense: Background, oversight issues, and options for Congress.

Hair, J. F., Ringle, C. M., \& Sarstedt, M. (2011). PLS-SEM: Indeed a silver bullet. Journal of marketing Theory and Practice, 19(2), 139-152. doi:10.2753/MTP1069-6679190202

Hair, J. F., Sarstedt, M., Hopkins, L., \& Kuppelwieser, V. G. (2014). Partial least squares structural equation modeling (PLS-SEM) An emerging tool in business research. European Business Review, 26(2), 106-121. doi:doi.org/10.1108/EBR-10-2013-0128

Hair, J. F., Sarstedt, M., Ringle, C. M., \& Mena, J. A. (2012). An assessment of the use of partial least squares structural equation modeling in marketing research. Journal of the Academy of Marketing Science, 40(3), 414-433. doi:10.1007/s11747-011-0261-6 
Hardin, G. (1968). The tragedy of the commons. The population problem has no technical solution; it requires a fundamental extension in morality. Science, 162(3859), 1243-1248. doi:10.1126/science.162.3859.1243

Hart, S. L. (1995). A Natural-Resource-Based View of the Firm. Academy of management review, 20(4), 986-1014. doi: 10.2307/258963

Hart, S. L., \& Dowell, G. (2011). A Natural-Resource-Based View of the Firm: Fifteen Years After. Journal of Management, 37(5), 1464-1479. doi:10.1177/0149206310390219

Hayes, A. F. (2013). Introduction to mediation, moderation, and conditional process analysis: A regression-based approach: Guilford Press.

Helfat, C. E., \& Winter, S. G. (2011). Untangling dynamic and operational capabilities: Strategy for the (N) ever-changing world. Strategic Management Journal, 32(11), 1243-1250.

Holbrook, M. B. (2005). Customer value and autoethnography: subjective personal introspection and the meanings of a photograph collection. Journal of Business Research, 58(1), 45-61.

Homann, S., Rischkowsky, B., Steinbach, J., Kirk, M., \& Mathias, E. (2008). Towards Endogenous Livestock Development: Borana Pastoralists' Responses to Environmental and Institutional Changes. Human Ecology, 36(4), 503-520. doi:10.1007/s10745-008-9180-7

Hult, G. T. M. (2011). Market-focused sustainability: market orientation plus! Journal of the Academy of Marketing Science, 39(1), 1-6. doi:10.1007/s11747-010-0223-4

Hult, G. T. M., Ketchen, J. D. J., \& Slater, S. F. (2005). Market orientation and performance: an integration of disparate approaches. Strategic Management Journal, 26(12), 1173-1181.

Im, S., \& Workman Jr, J. P. (2004). Market orientation, creativity, and new product performance in high-technology firms. Journal of Marketing, 68(2), 114-132. doi:DOI 10.1509/jmkg.68.2.114.27788

Ingenbleek, P. T. M., Tessema, W. K., \& van Trijp, H. C. M. (2013). Conducting field research in subsistence markets, with an application to market orientation in the context of Ethiopian pastoralists. International Journal of Research in Marketing, 30(1), 83-97. doi:10.1016/j.ijresmar.2012.11.003

Ingenbleek, P. T. M., \& Zhao, Y. (2018). Hutten catering : How to organize innovation for vital consumers in a sustainable food system? International Food and Agribusiness Management Review, 21(5), 583-593. doi:10.1002/ajmg.1320040409 
Joshi, A. W., \& Sharma, S. (2004). Customer Knowledge Development: Antecedents and Impact on New Product Performance. Journal of Marketing, 68(4), 47-59. doi:10.1509/jmkg.68.4.47.42722

Kamara, A. B., Swallow, B., \& Kirk, M. (2004). Policies, interventions and institutional change in pastoral resource management in Borana, Southern Ethiopia. Development Policy Review, 22(4), 381-403.

Keller, W., \& Shiue, C. H. (2007). Market Integration and Economic Development: A Long-run Comparison. Review of Development Economics, 11(1), 107-123. doi:https://doi.org/10.1111/j.1467-9361.2007.00359.x

Kenny, M., \& Fourie, R. (2015). Contrasting Classic, Straussian, and Constructivist Grounded Theory: Methodological and Philosophical Conflicts. Qualitative Report, 20(8), 12701289. Retrieved from $<$ Go to ISI $>$ ://WOS:000360497400009

Khan, O., Daddi, T., \& Iraldo, F. Microfoundations of dynamic capabilities: Insights from circular economy business cases. Business Strategy and the Environment.

Khan, O., Daddi, T., \& Iraldo, F. (2020). Microfoundations of dynamic capabilities: Insights from circular economy business cases. Business Strategy and the Environment, 29(3), 14791493.

Kihiu, E. N. (2016). Basic capability effect: Collective management of pastoral resources in southwestern $\quad$ Kenya. Ecological 23-34. doi:10.1016/j.ecolecon.2016.01.003

Kim, N., \& Atuahene-Gima, K. (2010). Using Exploratory and Exploitative Market Learning for New Product Development. Journal of Product Innovation Management, 27(4), 519-536. doi:10.1111/j.1540-5885.2010.00733.x

Kimbrough, E. O., \& Vostroknutov, A. (2015). The social and ecological determinants of common pool resource sustainability. Journal of Environmental Economics and Management, 72, 38-53. doi:10.1016/j.jeem.2015.04.004

Kirca, A. H., Jayachandran, S., \& Bearden, W. O. (2005). Market orientation: A meta-analytic review and assessment of its antecedents and impact on performance. Journal of Marketing, 69(2), 24-41. doi:10.1509/jmkg.69.2.24.60761

Kjellberg, H. (2008). Market practices and over-consumption. Consumption, Markets and Culture, $11(2), 151-167$. 
Kock, N. (2015). Common Method Bias in PLS-SEM: A Full Collinearity Assessment Approach. International Journal of E-Collaboration, 11(4), 1-10. doi:10.4018/ijec.2015100101

Kohli, A. K., \& Jaworski, B. J. (1990). Market orientation: the construct, research propositions, and managerial implications. The Journal of Marketing, 54(2), 1-18. doi:Doi $10.2307 / 1251866$

Koocheki, A., \& Gliessman, S. R. (2005). Pastoral nomadism, a sustainable system for grazing land management in arid areas. Journal of Sustainable Agriculture, 25(4), 113-131. doi:10.1300/J064v25n04_09

Kor, Y. Y., \& Mahoney, J. T. (2005). How dynamics, management, and governance of resource deployments influence firm-level performance. Strategic Management Journal, 26(5), 489496. doi:10.1002/smj.459

Kotler, P. (2011). Reinventing Marketing to Manage the Environmental Imperative. Journal of Marketing, 75(4), 132-135. doi:DOI 10.1509/jmkg.75.4.132

Kotler, P., \& Keller, K. L. (2006). Marketing management 12e. New Jersey.

Kotler, P., \& Keller, K. L. (2012). Competitive Dynamics. Marketing Management (14th ed.). Pearson Prentice Hall.

Kroll, M., Wright, P., \& Heiens, R. A. (1999). The contribution of product quality to competitive advantage: Impacts on systematic variance and unexplained variance in returns. Strategic Management Journal, 20(4), 375-384. doi:10.1002/(Sici)10970266(199904)20:4<375::Aid-Smj15>3.0.Co;2-Y

Layton, R. A. (2009). On economic growth, marketing systems, and the quality of life. Journal of Macromarketing, 29(4), 349-362.

Lee, D., Neves, B., Wiebe, K., Lipper, L., \& Zurek, M. (2009). Rural poverty and natural resources: Improving access and sustainable management. ESA Working Paper(09-03). Retrieved from http://www.fao.org/3/a-ak422e.pdf

Li, T., \& Cavusgil, S. (1999). Measuring the dimensions of market knowledge competence in new product development. European Journal of innovation management, 2(3), 129-146. doi:10.1108/14601069910289068

Little, V. J., Lee, C. K. C., \& Nair, S. (2019). Macro-demarketing: The Key to unlocking unsustainable production and consumption systems? Journal of Macromarketing, 39(2), 166-187. 
Luca, L. M. D., \& Atuahene-Gima, K. (2007). Market Knowledge Dimensions and CrossFunctional Collaboration: Examining the Different Routes to Product Innovation Performance. Journal of Marketing, 71(1), 95-112. doi:10.1509/jmkg.71.1.95

Lusch, R. F., Vargo, S. L., \& Tanniru, M. (2010). Service, value networks and learning. Journal of the Academy of Marketing Science, 38(1), 19-31.

Luseno, W. K., McPeak, J. G., Barrett, C. B., Little, P. D., \& Gebru, G. (2003). Assessing the Value of Climate Forecast Information for Pastoralists: Evidence from Southern Ethiopia and Northern Kenya. World Development, 31(9), 1477-1494. doi:http://dx.doi.org/10.1016/S0305-750X(03)00113-X

Madhavaram, S., \& Hunt, S. D. (2008). The service-dominant logic and a hierarchy of operant resources: developing masterful operant resources and implications for marketing strategy. Journal of the Academy of Marketing Science, 36(1), 67-82. doi:10.1007/s11747-007-0063Z

Maignan, I., \& Ferrell, O. C. (2004). Corporate social responsibility and marketing: An integrative framework. Journal of the Academy of Marketing Science, 32(1), 3-19. doi:10.1177/0092070303258971

Mariadoss, B. J., Tansuhaj, P. S., \& Mouri, N. (2011). Marketing capabilities and innovation-based strategies for environmental sustainability: An exploratory investigation of B2B firms. Industrial Marketing Management, $\quad$ 40(8), $\quad$ 1305-1318. doi:10.1016/j.indmarman.2011.10.006

Marinova, D. (2004). Actualizing innovation effort: the impact of market knowledge diffusion in a dynamic system of competition. Journal of Marketing, 68(3), 1-20.

McKenzie-Mohr, D., Lee, N. R., Kotler, P., \& Schultz, P. W. (2011). Social marketing to protect the environment: What works: Sage Publications.

Menguc, B., \& Auh, S. (2006). Creating a firm-level dynamic capability through capitalizing on market orientation and innovativeness. Journal of the Academy of Marketing Science, 34(1), 63. doi:10.1177/0092070305281090

Mitchell, R. K., Agle, B. R., \& Wood, D. J. (1997). Toward a theory of stakeholder identification and salience: Defining the principle of who and what really counts. Academy of management review, 22(4), 853-886. doi:10.2307/259247 
Mizik, N., \& Jacobson, R. (2003). Trading off between value creation and value appropriation: The financial implications of shifts in strategic emphasis. Journal of Marketing, 67(1), 63-76.

Moorman, C., \& Day, G. S. (2016). Organizing for Marketing Excellence. Journal of Marketing, 80(6), 6-35. doi:10.1509/jm.15.0423

Morgan, A., Feng, H., \& Whitler, K. A. (2018). Marketing capabilities in international marketing. Journal of International Marketing, 26(1), 61-95. doi:10.1509/jim.17.0056

Morgan, D. L. (1996). Focus groups as qualitative research (Vol. 16): Sage publications.

Moustaghfir, K. (2009). How knowledge assets lead to a sustainable competitive advantage: are organizational capabilities a missing link? Knowledge Management Research \& Practice, 7(4), 339-355.

Moyo, D. (2012). Winner take all: China's race for resources and what it means for the world: Basic Books (AZ).

$\mathrm{Mu}$, J. (2015). Marketing capability, organizational adaptation and new product development performance. Industrial Marketing Management, 49, 151-166. doi:10.1016/j.indmarman.2015.05.003

Mutenje, M. J., Ortmann, G. F., \& Ferrer, S. R. D. (2011). Management of non-timber forestry products extraction: Local institutions, ecological knowledge and market structure in South-Eastern Zimbabwe. Ecological Economics, 70(3), 454-461. doi:10.1016/j.ecolecon.2010.09.036

Ndofor, H. A., Sirmon, D. G., \& He, X. (2011). Firm resources, competitive actions and performance: investigating a mediated model with evidence from the in-vitro diagnostics industry. Strategic Management Journal, 32(6), 640-657. doi:10.1002/smj.901

Nelson, D. R., Adger, W. N., \& Brown, K. (2007). Adaptation to environmental change: Contributions of a resilience framework. Annual Review of Environment and Resources, 32(1), 395-419. doi:10.1146/annurev.energy.32.051807.090348

Nenonen, S., Storbacka, K., \& Windahl, C. (2019). Capabilities for market-shaping: triggering and facilitating increased value creation. Journal of the Academy of Marketing Science, 47(4), 617-639. doi:10.1007/s11747-019-00643-z

Nitzl, C., Roldan, J. L., \& Cepeda, G. (2016). Mediation analysis in partial least squares path modeling: Helping researchers discuss more sophisticated models. Industrial management \& data systems, 116(9), 1849-1864. doi:10.1108/Imds-07-2015-0302 
Nussbaum, M., Sen, A., \& Sen, M. A. (1993). The quality of life: Oxford University Press.

Nyong, A., Adesina, F., \& Osman Elasha, B. (2007). The value of indigenous knowledge in climate change mitigation and adaptation strategies in the African Sahel. Mitigation and Adaptation Strategies for Global Change, 12(5), 787-797. doi:10.1007/s11027-007-9099-0

Olavarrieta, S., \& Friedmann, R. (2008). Market orientation, knowledge-related resources and firm performance. Journal of Business Research, 61(6), 623-630. doi:10.1016/j.jbusres.2007.06.037

Oldekop, J. A., Bebbington, A. J., Hennermann, K., McMorrow, J., Springate, D. A., Torres, B., . . Preziosi, R. F. (2013). Evaluating the effects of common-pool resource institutions and market forces on species richness and forest cover in Ecuadorian indigenous Kichwa communities. Conservation letters, 6(2), 107-115. doi:https://doi.org/10.1111/j.1755$\underline{263 X .2012 .00297 . \mathrm{X}}$

Ostrom, E. (1990). Governing the Commons: The Evolution of Institutions for Collective Action. In: Cambridge University Press.

Ostrom, E. (1998). A behavioral approach to the rational choice theory of collective action: Presidential address, American Political Science Association, 1997. American political science review, 92(1), 1-22. doi:https://doi.org/10.2307/2585925

Ostrom, E. (2007). A diagnostic approach for going beyond panaceas. Proc Natl Acad Sci U S A, 104(39), 15181-15187. doi:10.1073/pnas.0702288104

Ostrom, E. (2008). The challenge of common-pool resources. Environment, 50(4), 8-20. doi:Doi 10.3200/Envt.50.4.8-21

Ostrom, E. (2009). A general framework for analyzing sustainability of social-ecological systems. Science, 325(5939), 419-422. doi:10.1126/science.1172133

Ozkaya, H. E., Droge, C., Hult, G. M., Calantone, R., \& Ozkaya, E. (2015). Market orientation, knowledge competence, and innovation. International Journal of Research in Marketing, 32(3), 309-318. doi:http://doi.org/10.1016/j.ijresmar.2014.10.004

Payne, A., Frow, P., \& Eggert, A. (2017). The customer value proposition: evolution, development, and application in marketing. Journal of the Academy of Marketing Science, 45(4), 467489. doi:10.1007/s11747-017-0523-Z

Payne, A., Storbacka, K., \& Frow, P. (2008). Managing the co-creation of value. Journal of the Academy of Marketing Science, 36(1), 83-96. doi:10.1007/s11747-007-0070-0 
Pendleton, L. H., \& Howe, E. L. (2002). Market integration, development, and smallholder forest clearance. Land Economics, 78(1), 1-19. doi:10.2307/3146919

Pfeffer, J., \& Salancik, G. R. (2003). The external control of organizations: A resource dependence perspective: Stanford University Press.

Phillips, K., Rodrigue, E., \& Yücel, M. (2013). Water scarcity a potential drain on the Texas economy. Southwest Economy(Q4), 3-7. Retrieved from https://www.dallasfed.org/ /media/documents/research/swe/2013/swe1304b.pdf

Podsakoff, P. M., MacKenzie, S. B., Lee, J. Y., \& Podsakoff, N. P. (2003). Common method biases in behavioral research: a critical review of the literature and recommended remedies. $J \mathrm{Appl}$ Psychol, 88(5), 879-903. doi:10.1037/0021-9010.88.5.879

Prediger, S., Vollan, B., \& Frolich, M. (2011). The impact of culture and ecology on cooperation in a common-pool resource experiment. Ecological Economics, 70(9), 1599-1608. doi:10.1016/j.ecolecon.2010.08.017

Radjou, N., Prabhu, J., \& Ahuja, S. (2012). Jugaad innovation: Think frugal, be flexible, generate breakthrough growth: John Wiley \& Sons.

Rao, E. J., Brümmer, B., \& Qaim, M. (2012). Farmer participation in supermarket channels, production technology, and efficiency: the case of vegetables in Kenya. American journal of agricultural economics, 94(4), 891-912.

Reardon, T., Barrett, C. B., Berdegué, J. A., \& Swinnen, J. F. (2009). Agrifood industry transformation and small farmers in developing countries. World Development, 37(11), $1717-1727$.

Reda, K. T. (2016). Dynamics in pastoral resource management and conflict in the Borana rangelands of southern Ethiopia. African Security Review, 25(1), 31-43. doi:10.1080/10246029.2015.1126526

Rommel, J., Villamayor-Tomas, S., Müller, M., \& Werthmann, C. (2015). Game participation and preservation of the commons: An experimental approach. Sustainability (Switzerland), 7(8), 10021-10035. doi:10.3390/su70810021

Sanchez, R., \& Heene, A. (1997). Reinventing strategic management: New theory and practice for competence-based competition. European Management Journal, 15(3), 303-317. doi:http://dx.doi.org/10.1016/S0263-2373(97)00010-8 
Sandvik, I. L., \& Sandvik, K. (2003). The impact of market orientation on product innovativeness and business performance. International Journal of Research in Marketing, 20(4), 355-376.

Saunders, B., Sim, J., Kingstone, T., Baker, S., Waterfield, J., Bartlam, B., . . . Jinks, C. (2018). Saturation in qualitative research: exploring its conceptualization and operationalization. Qual Quant, 52(4), 1893-1907. doi:10.1007/s11135-017-0574-8

Schilke, O. (2014). Second-order dynamic capabilities: How do they matter? Academy of Management Perspectives, 28(4), 368-380.

Schmidt, A., Boersma, K., \& Groenewegen, P. (2018). Management strategies in response to an institutional crisis: The case of earthquakes in the Netherlands. Public Administration, 96(3), 513-527. doi:DOI:10.1111/padm.12516

Schoonhoven, C. B. (1981). Problems with Contingency Theory - Testing Assumptions Hidden within the Language of Contingency Theory. Administrative science quarterly, 26(3), 349377. doi:Doi 10.2307/2392512

Scott, K. A., \& Weaver, T. S. (2018). The Intersection of Sustainable and Anti-Consumption: Repurposing to Extend Product Lifespans. Journal of Public Policy \& Marketing, 0(ja), null. doi:10.1509/jppm.17.043

Sharma, A., \& Iyer, G. R. (2012). Resource-constrained product development: Implications for green marketing and green supply chains. Industrial Marketing Management, 41(4), 599608. doi:10.1016/j.indmarman.2012.04.007

Sheth, N. (2011). Impact of Emerging Markets on Marketing: Rethinking Existing Perspectives and Practices. Journal of Marketing, 75(4), 166-182. doi:DOI 10.1509/jmkg.75.4.166

Sheth, N., \& Mittal, B. (1996). A framework for managing customer expectations. Journal of Market-Focused Management, 1(2), 137-158.

Simons, R. (2014). Choosing the right customer. Harvard business review, 92(3), 48-55. Retrieved from https://hbr.org/2014/03/choosing-the-right-customer

Sirmon, D. G., Hitt, M. A., \& Ireland, R. D. (2007). Managing firm resources in dynamic environments to create value: Looking inside the black box. Academy of management review, 32(1), 273-292. doi:10.5465/Amr.2007.23466005

Slater, S. F. (1997). Developing a customer value-based theory of the firm. Journal of the Academy of Marketing Science, 25(2), 162-167. doi:10.1007/Bf02894352 
Slater, S. F., Mohr, J. J., \& Sengupta, S. (2014). Radical product innovation capability: Literature review, synthesis, and illustrative research propositions. Journal of Product Innovation Management, 31(3), 552-566. doi:10.1111/jpim.12113

Slater, S. F., Olson, E. M., \& Eibe Sørensen, H. (2012). Creating and exploiting market knowledge $\begin{array}{lllll}\text { assets. Journal of } & \text { Business }\end{array}$ doi:doi.org/10.1108/02756661211242672

Slotegraaf, R. J., Moorman, C., \& Inman, J. (2003). The role of firm resources in returns to market deployment. Journal of marketing research, 40(3), 295-309. doi:10.1509/jmkr.40.3.295.19235

Smit, B., Burton, I., Klein, R. J., \& Wandel, J. (2000). An anatomy of adaptation to climate change and variability. In Societal adaptation to climate variability and change (pp. 223-251): Springer.

Smith, B. G. (2007). Developing sustainable food supply chains. Philosophical Transactions of the Royal Society B: Biological Sciences, 363(1492), 849-861. doi:10.1098/rstb.2007.2187

Smith, J. B., \& Colgate, M. (2007). Customer value creation: a practical framework. Journal of marketing Theory and Practice, 15(1), 7-23.

Solomon, T. B., Snyman, H. A., \& Smit, G. N. (2007). Cattle-rangeland management practices and perceptions of pastoralists towards rangeland degradation in the Borana zone of southern Ethiopia. J Environ Manage, 82(4), 481-494. doi:10.1016/j.jenvman.2006.01.008

Spiller, S. A., Fitzsimons, G. J., Lynch Jr, J. G., \& McClelland, G. H. (2013). Spotlights, floodlights, and the magic number zero: Simple effects tests in moderated regression. Journal of marketing research, 50(2), 277-288.

Tang, C., \& Tomlin, B. (2008). The power of flexibility for mitigating supply chain risks. International journal of production economics, 116(1), 12-27. doi:https://doi.org/10.1016/j.ijpe.2008.07.008

Teece, D. J. (2007). Explicating dynamic capabilities: The nature and microfoundations of (sustainable) enterprise performance. Strategic Management Journal, 28(13), 1319-1350. doi:10.1002/smj.640

Teece, D. J., Pisano, G., \& Shuen, A. (1997). Dynamic capabilities and strategic management. Strategic Management Journal, 18(7), 509-533. 
Teklehaimanot, M. L. (2017). The design and impact of a marketing training to strengthen customer value creation among Ethiopian pastoralists. (Includes bibliographical references. - With summary in English). Wageningen University, Wageningen. Retrieved from http://edepot.wur.nl/416431C1 - NN08202,6688

Teklehaimanot, M. L., Ingenbleek, P. T. M., Tessema, W. K., \& van Trijp, H. C. M. (2017). Moving Toward New Horizons for Marketing Education: Designing a Marketing Training for the Poor in Developing and Emerging Markets. Journal of Marketing Education, 39(1), 47-60. doi: $10.1177 / 0273475316688318$

Tessema, W. K., Ingenbleek, P. T. M., \& Van Trijp, H. C. M. (2014). Pastoralism, sustainability, and marketing. A review. Agronomy for Sustainable Development, 34(1), 75-92. doi:10.1007/s13593-013-0167-4

Tessema, W. K., Ingenbleek, P. T. M., \& van Trijp, H. C. M. (2019). Refining the smallholder market integration framework: A qualitative study of Ethiopian pastoralists. NjasWageningen Journal of Life Sciences, 88, 45-56. doi:10.1016/j.njas.2018.12.001

Thornberg, R. (2012). Informed Grounded Theory. Scandinavian Journal of Educational Research, 56(3), 243-259. doi:10.1080/00313831.2011.581686

Thornton, P. K., van de Steeg, J., Notenbaert, A., \& Herrero, M. (2009). The impacts of climate change on livestock and livestock systems in developing countries: A review of what we know and what we need to know. Agricultural Systems, 101(3), 113-127. doi:10.1016/j.agsy.2009.05.002

Trochim, W. M. K. (1989). Outcome Pattern-Matching and Program Theory. Evaluation and program planning, 12(4), 355-366. doi:Doi 10.1016/0149-7189(89)90052-9

Troilo, G., De Luca, L. M., \& Atuahene-Gima, K. (2014). More Innovation with Less? A Strategic Contingency View of Slack Resources, Information Search, and Radical Innovation. Journal of Product Innovation Management, 31(2), 259-277. doi:10.1111/jpim.12094

UN, D. (2010). United Nations Department of Economic and Social Affairs/Population Division (2009b): World Population Prospects: The 2008 Revision. Internet: http://esa. un. org/unpp (gelesen am 16.

Vaccaro, I., Zanotti, L. C., \& Sepez, J. (2009). Commons and markets: opportunities for development of local sustainability. Environmental Politics, 18(4), 522-538. doi:10.1080/09644010903007393 
Varadarajan, R. (2010). Strategic marketing and marketing strategy: domain, definition, fundamental issues and foundational premises. Journal of the Academy of Marketing Science, 38(2), 119-140. doi:10.1007/s11747-009-0176-7

Varadarajan, R. (2014). Toward Sustainability: Public Policy Global Social Innovations for Baseof-the-Pyramid Markets, and Demarketing for a Better World. Journal of International Marketing, 22(2), 1-20. doi:DOI 10.1509/jim.13.0158

Varadarajan, R. (2017). Innovating for sustainability: a framework for sustainable innovations and a model of sustainable innovations orientation. Journal of the Academy of Marketing Science, 45(1), 14-36. doi:10.1007/s11747-015-0461-6

Vargo, S. L., \& Lusch, R. F. (2004). Evolving to a new dominant logic for marketing. Journal of Marketing, 68(1), 1-17. doi:DOI 10.1509/jmkg.68.1.1.24036

Vargo, S. L., \& Lusch, R. F. (2008). Service-dominant logic: continuing the evolution. Journal of the Academy of Marketing Science, 36(1), 1-10. doi:10.1007/s11747-007-0069-6

Varughese, G., \& Ostrom, E. (2001). The contested role of heterogeneity in collective action: Some evidence from community forestry in Nepal. World Development, 29(5), 747-765. doi:10.1016/S0305-750x(01)00012-2

Venkatesan, R., \& Kumar, V. (2004). A customer lifetime value framework for customer selection and resource allocation strategy. Journal of Marketing, 68(4), 106-125.

Villarejo-Ramos, A. F., \& Sanchez-Franco, M. J. (2005). The impact of marketing communication and price promotion on brand equity. Journal of Brand Management, 12(6), 431-444.

Viswanathan, M., Sridharan, S., Gau, R., \& Ritchie, R. (2009). Designing marketplace literacy education in resource-constrained contexts: Implications for public policy and marketing. Journal of Public Policy and Marketing, 28(1), 85-94. doi:10.1509/jppm.28.1.85

Vittinghoff, E., \& McCulloch, C. E. (2007). Relaxing the rule of ten events per variable in logistic and Cox regression. Am J Epidemiol, 165(6), 710-718. doi:10.1093/aje/kwk052

Vona, F., \& Patriarca, F. (2011). Income inequality and the development of environmental technologies. Ecological $\quad$ Economics, 2201-2213. doi:10.1016/j.ecolecon.2011.06.027

Weber, J. M., Kopelman, S., \& Messick, D. M. (2004). A conceptual review of decision making in social dilemmas: applying a logic of appropriateness. Pers Soc Psychol Rev, 8(3), 281-307. doi:10.1207/s15327957pspr0803_4 
Webster, F. E. (2002). Market-driven management: how to define, develop, and deliver customer value (Vol. 28): John Wiley \& Sons Incorporated.

Weerawardena, J. (2003). The role of marketing capability in innovation-based competitive strategy. Journal of strategic marketing, 11(1), 15-35.

Witkowski, T. H. (2005). Antiglobal challenges to marketing in developing countries: Exploring the ideological divide. Journal of Public Policy \& Marketing, 24(1), 7-23. doi:DOI 10.1509/jppm.24.1.7.63902

Woodruff, R. B. (1997). Customer value: the next source for competitive advantage. Journal of the Academy of Marketing Science, 25(2), 139-153.

Wooliscroft, B., \& Ganglmair-Wooliscroft, A. (2018). Growth, Excess and Opportunities:Marketing Systems' Contributions to Society. Journal of Macromarketing, 38(4), 355-363. doi:10.1177/0276146718805804

World Bank. (2013). Community-Based Development: Making a Difference in Pastoral Ethiopia. Pastoral Community Development Project. The World Bank, Washington, DC. Retrieved from $\quad$ https://www.worldbank.org/en/news/feature/2013/10/01/community-baseddevelopment-making-a-difference-in-pastoral-ethiopia

Yin, R. K. (2013). Validity and generalization in future case study evaluations. Evaluation, 19(3), 321-332. doi:10.1177/1356389013497081

Zhou, K. Z., \& Li, C. B. (2012). How knowledge affects radical innovation: Knowledge base, market knowledge acquisition, and internal knowledge sharing. Strategic Management Journal, 33(9), 1090-1102. doi:10.1002/smj.1959

Zhou, K. Z., Li, J. J., Zhou, N., \& Su, C. T. (2008). Market orientation, job satisfaction, product quality, and firm performance: Evidence from China. Strategic Management Journal, 29(9), 985-1000. doi:10.1002/smj.700 


\section{Summary}

With the ongoing concern about the depletion of natural resources, companies and their marketers are increasingly interested in finding ways to adapt their business processes to the scarcity of natural resources. How companies can do so is, however, still not clear, indicating the lack of understanding of how to incorporate insights from the natural environment into the companies' primary business function which is essential to create customer value. This thesis argues that lessons on how to adapt business processes to resource scarcity can be drawn from pastoralists who for centuries have been able to maintain their livestock breeding and fattening business despite the persistent scarcity of natural resources. Pastoralists use primarily natural pasture and water resources for breeding and fattening their livestock in ways that meet the needs of their buyers. Pastoralists however see themselves faced with persistent scarcity of natural resources due to the arid and semi-arid climatic condition of their region. The aim of this thesis is therefore to draw lessons from pastoralists on how they manage to adapt their customer value creation process to the scarcity of natural resources. To achieve its aim, the thesis answers the following four research questions: (1) How do pastoralists adapt the customer value creation to the scarcity of natural resources? (2) How do natural resource adaptation capabilities of pastoralists influence customer value creation in a resource-scarce time? (3) How does the level of natural resource scarcity that pastoralists experience influences the business performance contributions of adaptation capabilities and market knowledge? (4) Does market knowledge impact the sustainable use of natural resources, and if so, how? The questions are empirically addressed in a qualitative study that develops the conceptual framework (Chapter 2) as a basis for a set of quantitative studies (Chapters 3-5) to test (parts of) the framework and challenge its underlying assumptions. 
A qualitative study identifying and conceptualizing natural resource adaptation (Chapter 2) provided the answer to the question how the process of creating customer value can be adapted to the scarcity of natural resources. When pastoralists are confronted with an actual or predicted scarcity of natural resources, they can adapt their customer value-creating processes by leveraging three types of adaptation capabilities: matching value propositions (adjusting the value proposition to customers), natural resource deployment (making efficient and effective use of available natural resources), and managing customer expectations (interacting and communicating customers to create an appropriate level of value expectations in their mind). These capabilities intervene sequentially in the customer value creation process, respectively at the value defining, developing and delivering stages. The findings indicate that natural environmental knowledge about actual and predicted resource scarcities enables pastoralists to develop these adaptation capabilities, and that the deployment of these capabilities in the customer value creation process is fostered by market knowledge. This implies that to develop and leverage these capabilities, companies need to develop their knowledge about the market as well as the natural environment. For this to happen, marketing must be seen as a learning process, not only about markets but also about the natural environment.

To examine the impact of natural resource adaptation capabilities on customer value creation, the thesis provides two empirical studies - a cross-sectional dataset from 120 Ethiopian pastoralists during a natural resource-scarce time (Chapter 3) and a three-wave panel dataset from the same pastoralists at relatively distinct resource availability conditions (Chapter 4). In Chapter 3, the findings show that market knowledge has a strong positive effect on the three natural resource adaptation capabilities: matching value propositions, natural resource deployment and managing customer expectations. The matching value propositions and natural resource deployment capabilities were found effective in minimizing the impact of natural resource scarcity on the 
outcomes of the customer value creation. Product quality and quality of life were used as relevant outcomes of the pastoralists' customer value creation process. The results imply that adaptation capabilities that intervene at early stages in the customer value creation process are more effective in dealing with resource scarcities than those at later stages. The most likely explanation is that the three adaptation capabilities indeed intervene sequentially within the value creation process. If the resource scarcity is already overcome at earlier stages in the process, the adaptation capabilities in the subsequent stage become less important.

The question how the level of scarcity for natural resources influences the business performance abilities of market knowledge and adaptation capabilities is answered in Chapter 4-a longitudinal study. The chapter builds on three movements of panel data collected at relatively distinct natural resource availability conditions. The focus is on the natural resource deployment capability because it relates to businesses' ability to make use of available natural resources, which vary strongly across seasons for Ethiopian pastoralists. The results show that market knowledge has a stronger impact on natural resource deployment capability when resources are more constrained rather than abundant. This suggests that during resource-scarce times, market knowledge helps to minimize the decrease in product quality by enabling businesses to effectively leverage natural resource deployment capability. As such market knowledge invokes pastoralists to effectively allocate existing resources, avoid unnecessary usage of resources, and build slack resources (e.g. inventory and flexible resource access) as a precautionary measure. This in turn minimizes the impact of resource scarcity on customer value creation during resource-scarce times. Hence, the results imply that natural resource deployment capabilities enable businesses to cope with natural resource scarcity more effectively if they are empowered with a strong understanding of markets. 
Chapter 5 tests an important assumption of the framework, namely that market knowledge complements the natural environmental knowledge, which enables pastoralists to sustainably use their common-pool natural resources. Common-pool natural resources are shared natural resources among a group of resource users where individuals in the group have no specific claim except the right to use. Pastoralists manage the use of key natural resources, natural pasture and water resources, through collective ownership as common-pool resources. This chapter is therefore test whether market knowledge could help pastoralists to sustainably use their common-pool natural resources. By doing so, the chapter provides answers to the question how market knowledge impacts the sustainable use of natural resources using a common-pool resource dilemma experiment. We argue that common-pool resource users' level of market knowledge influences their cooperation to the sustainable use of common-pool natural resources. This is because it influences their perceived benefits from the sustainable use of common-pool resources and the understanding of the potential consequences of resource degradation on the quality of products they produce and sell. This thesis shows that when resource conditions are good, resource users with more market knowledge are more likely to apply a lower grazing intensity to sustain their shared grazing lands. During resource scarcity, this effect is weaker. Furthermore, within-group variance in market knowledge harms group members' decisions on sustainable resource use. Hence, in communities that experience increasing pressure from the global market economy, enhancing market knowledge is of vital importance to protect shared natural resources from depletion.

Overall, this thesis shows that the customer value creation process can be adapted to natural resource scarcity by leveraging capabilities pertaining to matching value propositions, natural resource deployment and managing customer expectations at value defining, developing and 
delivering stages of the process, respectively. Market knowledge enables businesses to competitively create customer value in a resource-scarce environment by fostering the deployment of the adaptation capabilities in the value creation process. Market knowledge also encourages natural resource-users to cooperate to the sustainable use of natural resources in resource dilemma situations. By studying the role of market knowledge to the adaptation of value creation processes and sustainability, the thesis has enriched our understanding of adaptation capabilities that companies need to develop to deal with actual and predicted resource scarcities and thereby, maintain their value creation to customers while doing good to the sustainability of natural resources. In terms of lessons learned from pastoralists, companies can deal more effectively with natural resource scarcities if they guide their value-creation processes with combined insight from both markets and the natural environment. 


\section{Samenvatting}

Met de toenemende zorgen over de uitputting van natuurlijk hulpbronnen hebben bedrijven en marketers steeds meer interesse in hoe ze hun bedrijfsprocessen kunnen aanpassen aan de schaarste in natuurlijke hulpbronnen. Het is echter nog niet duidelijk hoe bedrijven dat kunnen doen. Dit geeft aan dat er een lacune bestaat in de kennis bestaat hoe inzicht in de natuurlijke omgeving geïncorporeerd wordt in de primaire bedrijfsfunctie, namelijk het creëren van klantwaarde. In dit proefschrift wordt beweerd dat inzichten in hoe bedrijfsprocessen kunnen worden aangepast aan schaarste in natuurlijke hulpbronnen, kunnen worden afgeleid van pastoralisten. Pastoralisten zijn er in geslaagd om eeuwenlang hun bedrijfsactiviteiten overeind te houden in het vermeerderen en vetmesten van vee, ondanks de schaarste aan natuurlijke hulpbronnen in het droge klimaat van hun regio. Het hoofddoel van dit proefschrift is daarom om te leren van pastoralisten hoe zij er in slagen hun klantwaarde creatie aan te passen aan de schaarste in natuurlijke hulpbronnen. Om dit doel te bereiken worden de volgende vier onderzoeksvragen beantwoordt: (1) Hoe passen pastoralisten hun klantwaarde creatie aan aan de schaarste van natuurlijke hulpbronnen? (2) Hoe beinvloeden de competenties van pastoralisten om zich aan te kunnen passen aan schaarste het klantwaarde creatie proces in tijden van schaarste? (3) Hoe beinvloedt de schaarste die pastoralisten ervaren de bijdrage van aanpassingscompetenties en marktkennis aan bedrijfsprestaties? (4) Beinvloed marktkennis het duurzaam gebruik van natuurlijke hulpbronnen, zo ja, hoe? Deze vragen worden empirisch beantwoord in een kwalitatief onderzoek dat een conceptueel raamwerk ontwikkelt (hoofdstuk 2) als basis voor kwantitatieve studies (hoofdstukken 3-5) die dit raamwerk en de onderliggende aannames (gedeeltelijk) testen.

Een kwalitatieve studie identificeert en conceptualiseert aanpassing aan natuurlijke hulpbronnen (hoofdstuk 2). Deze studie beantwoordt de vraag hoe het proces van klantwaardecreatie aangepast 
kan worden aan de beschikbaarheid van natuurlijke hulpbronnen. Wanneer pastoralisten geconfronteerd worden met een acute of verwachte schaarste aan natuurlijke hulpbronnen, kunnen ze hun klantwaarde processen aanpassen door drie soorten competenties aan te wenden: het matchen van waardeproposities (aanpassen van de waardepropositie aan klanten), deployment van natuurlijke hulpbronnen (efficiënt en effectief gebruik maken van de beschikbare natuurlijke hulpbronnen), en het managen van de verwachtingen van klanten (interactie en communicatie met klanten om het verwachtingsniveau aan te passen). Deze competenties grijpen sequentieel in in het waardecreatie proces, respectievelijk in de fases waarin waarde wordt gedefinieerd, ontwikkelt en geleverd. De bevindingen geven aan dat kennis over de natuurlijke hulpbronnen pastoralisten in staat stelt om deze competenties te ontwikkelen en dat het aanwenden van de competenties wordt geholpen door de aanwezige marktkennis. Dit betekent dat wanneer pastoralisten dergelijke aanpassingscompetenties willen ontwikkelen en aanwenden zij zowel over kennis van de natuurlijke omgeving als van de marktomgeving moeten beschikken. Dit maakt marketing tot een leerproces waarin naar beiden kanten gekeken moet worden.

Om de impact van aanpassingscompetenties op klantwaarde creatie te onderzoeken, gebruikt dit proefschrift twee empirische studies: een cross-sectionele dataset van 120 Ethiopische pastoralisten in een periode van schaarste (hoofdstuk 3) en een panel dataset met drie rondes van diezelfde pastoralisten gemeten over periodes met verschillende condities (hoofdstuk 4). De resultaten van hoofdstuk 3 tonen aan dat marktkennis een sterk positief effect heeft op de drie aanpassingscompetenties, het matchen van waardeproposities, deployment en managen van verwachtingen. De competenties met betrekking tot het matchen van waardeproposities en deployment bleken effectief in het minimaliseren van de impact van schaarste op klantwaarde creatie. Product kwaliteit en kwaliteit van leven werden wat dat betreft gebruikt als relevante 
uitkomsten van klantwaarde creatie. De resultaten geven aan dat aanpassingscompetenties die relatief vroeg in het klantwaardeproces ingrijpen, effectiever zijn in het aanpassen aan schaarste dan competenties die later op het proces ingrijpen. De meest logische verklaring is dat de drie aanpassingscompetenties inderdaad sequentieel ingrijpen op het klantwaarde proces. Wanneer er al relatief vroeg in het proces aanpassingen gemaakt zijn aan de schaarste, worden aanpassingen in latere stadia minder belangrijk.

De vraag hoe het niveau van schaarste de invloed van marketkennis en aanpassingscompetentie op bedrijfspresetaties beïnvloed, wordt beantwoord in hoofdstuk 4, een longitudinale studie. Het hoofdstuk gebruikt drie rondes van panel data die verzameld zijn in periodes met verschillende niveaus van beschikbaarheid van natuurlijke hulpbronnen. De focus ligt daarbij op deployment omdat dit relateert aan het vermogen van de onderneming om optimaal gebruik te maken van de beschikbare hulpbronnen die sterk per periode variëren in de omgeving van pastoralisten. De resultaten laten zien dat marktkennis een sterkere invloed heeft op deployment wanneer hulpbronnen schaars zijn dan wanneer ze volop aanwezig zijn. Dit betekent dat tijdens schaarste marktkennis helpt om de vermindering in productkwaliteit te minimaliseren. Het helpt pastoralisten om de beschikbare hulpbronen effectief aan doelen toe te wijzen, verspilling te voorkomen en om voorzorgsmaatregelen te nemen zoals het aanleggen van een voorraad. Dit minimaliseert vervolgens de impact van schaarste op klantwaardecreatie. De resultaten betekenen daarom dat deployment competenties ondernemingen beter helpen om met schaarste om te gaan wanneer ze gesterkt zijn met een goed begrip van hun markten.

Hoofdstuk 5 test een belangrijke aanname van het raamwerk, namelijk dat marktkennis de kennis van de natuurlijke omgeving completeert waardoor pastoralisten op een duurzame manier gebruik kunnen maken van de hulpbronnen die ze gezamenlijk gebruiken. Dit betekent dat marktkennis 
zou kunnen helpen bij duurzaam gebruik van natuurlijke hulpbronnen door pastoralisten. Het hoofdstuk beantwoordt de vraag hoe marktkennis duurzaam gebruik van natuurlijke hulpbronnen beïnvloedt met een zogenaamd common pool resource dilemma experiment. We beweren dat marktkennis de coöperatie beïnvloedt in een common pool resource dilemma omdat ze meer voordelen van duurzaam gebruik van de hulpbronnen en omdat ze de gevolgen van verval van de hulpbronnen op de kwaliteit van hun producten beter kunnen inschatten. Het proefschrift toont aan dat wanneer de condities goed zijn, pastoralisten met meer marktkennis inderdaad besluiten om de gezamenlijke graslanden minder te begrazen. Tijdens schaarste is dit effect zwakker. Verder vinden we dat de variantie in marktkennis (sommigen veel, anderen weinig marktkennis) een negatieve impact heeft op de beslissingen in de groep om de graslanden te beschermen. Vandaar dat het verbeteren van de marktkennis van vitaal belang is om gedeelde natuurlijke hulpbronnen te beschermen tegen uitputting voor gemeenschappen die steeds meer bij de markt worden betrokken.

In zijn geheel laat dit proefschrift zien dat het waardecreatie proces aangepast kan worden aan schaarsheid van natuurlijke hulpbronnen door competenties aan te wenden die betrekking hebben op het matchen van waardeproposities, deployment en het managen van verwachtingen in respectievelijk de fases van het waardecreatie proces waarin waarde wordt gedefinieerd, ontwikkelt en geleverd. Marktkennis stelt ondernemingen in staat om deze competenties op zodanige manier aan te wenden dat ze ook bij schaarste nog waarde kunnen waarde te creeren die de concurrentie kan weerstaan. Marktkennis draagt er ook toe bij dat gebruikers van de hulpbronnen deze bronnen gezamenlijk beschermen. Door de rol van marktkennis bij aanpassing van waardecreatie processen en duurzaamheid te bestuderen, heeft dit proefschrift onze kennis verrijkt van de competenties die ondernemingen nodig hebben om met acute en verwachte schaarste om te gaan en daarmee waarde voor hun klanten te blijven creëren en toch bij te dragen aan de duurzaamheid van natuurlijke 
hulpbronnen. We hebben daarom van de pastoralisten geleerd dat bedrijven effectiever met natuurlijke hulpbronnen om kunnen gaan wanneer ze in hun waarde creatie processen gebruik maken van inzichten in zowel de markt als de natuurlijke omgeving. 


\section{Acknowledgments}

Reflecting on the past four-years journey filled with many challenges and surprises, I realize that I have received a great deal of support and assistance. As a $\mathrm{PhD}$ student I might feel lonely at times, but I had never been alone rather I was accompanied by many generous and supportive people and organizations to whom I want to extend my BIG THANK YOU.

First and foremost, I am deeply thankful to my parents, sisters and brothers for their unconditional love and support throughout my education life. Without their support and encouragement, completing this doctoral dissertation would have been very difficult. My Mother Alem Gebeyehu, the completion of this thesis is the result of your sacrifices in raising me as a single mom with love, care and hard work to fulfill all that I was ask for, at times selfish ones. My Sisters Yeshiy, you are the most loving, caring and supportive sister. Your trust and believe in my capacity gage me to focus on my study to live up to your expectations and keep you proud of my success. My sister Mastia and brother Temesegen, you have been always there whenever I need your support, thanks for your love and affection. I dedicated this thesis to the memory of my father Amlaku Gugissa Mandefro, who passed away during my childhood when I was in grade eight. He was the very first person who believed in my capacity and inspired me to dream big; he used to tell me that 'I am a brilliant one and should dream and work hard to be a doctor'. His dream has been nourishing me to the very this day. Unfortunately, his fate decided not to witness the realization of his foretelling, but his believe in education and hard work has been and will always remain instrumental in my life.

I gratefully acknowledge the Netherlands Organization for International Cooperation in Higher Education and Research (NUFFIC) through its Netherlands Fellowship Program (NFP) for funding my PhD study. I am also grateful to the study leave grant from Kotebe Metropolitan University of Ethiopia. At Kotebe Metropolitan University, I would like to thank Mr. Wondie Berhane and Dr. Brehanu Negeri and other officials for their effort in facilitating my $\mathrm{PhD}$ study leaves. I would like to thank my promoters: Dr. Paul Ingenbleek and Prof. Hans van Trijp for allowing me to pursue a $\mathrm{PhD}$ study in marketing.

Dear Paul, throughout my education life no one has invested more to shape me as a better researcher than you, I owe a lot of your time and energy. As my promotor and daily supervisor, you always 
supported me during my $\mathrm{PhD}$ time, not only when I was dealing with scientific issues, but also when I feel down, you always encourage me to uplift my moral and energy. We had countless number of lively discussions on my proposal, the design of my research and draft papers, in all the times you were pushing me 'to go deeper' and 'be sharper'. If it was not for the high-level standards and expectation of yours alongside your coaching and encouragements, my thesis would have not been completed at the current level of standard. I am very much grateful to you for all the advice and constructive criticisms. I am very proud and lucky that I am your first $\mathrm{PhD}$ student as a first promotor.

Dear Hans, I will always remember how you persuasively challenged me to advance my theoretical lenses and trail connections. My thesis would not come to a successful completion without your dedication and scholarly inputs. In all our discussions, you always come up with comments and suggestions that extend my findings to more broader contexts by zooming out of the practices of 'my pastoralists'. I am deeply thankful for your support and dedication. You also provided me the opportunity to put my line of thinking first, before suggesting your comments. At times I was unreasonably 'too defensive', you were however very patient in listening my arguments and advise me to keep a delicate balance between 'defending my work' and being 'open to alternative views'. Thank you for the advises and scholarly discussions, I really enjoyed and learned a lot from your comments and suggestions. I also very much appreciate how you manage to read every single sentence of all my draft papers in deep. Regardless of how hard and cautiously I worked, you always found some flaws to correct and new ways to further improve my papers. Thank you for your generosity too; when I was struggling with visa and financial issues during the COVID-19 crisis, you instantly steeps-in to support me. If I would do my $\mathrm{PhD}$ study all over again, I would like to change a lot of things, but surely not my promotors.

I would like to thank the members of the thesis committee Prof. dr WA Dolfsma, Prof. dr. H Van Herk, Prof. dr. S Burgess and dr ir MM van den Berg for their time and dedication in reviewing my thesis and taking part in the public defence. It is a great honour for me to have you in my thesis committee.

Dr. Workneh Kassa Tessema, Addis Ababa University, College of Business and Economics, I am grateful to you for all the support and coaching you gave me throughout my academic career. Workia thank you for introducing me to Paul and coaching me to shape my academic career. I 
cannot imagine doing my $\mathrm{PhD}$ at the $\mathrm{MCB}$ group without your coaching and encouragements. Our friendly chats about your experiences at the MCB group in spired me to dream of doing my $\mathrm{PhD}$ at MCB. Dr Mebrahtu Leake Teklehaimanot, you always treat me as a brother and unreservedly helped me in every possible way throughout my $\mathrm{PhD}$ study. Mebria, your brotherly advises helped me a lot to manage all my $\mathrm{PhD}$ challenges. You also very smart in providing me happy distractions to rest my mind outside of my research by raising inspiring discussions and debates about broader political and social issues. You make my time at Wageningen more comfortable and memorable (think of 'the dinners and drinks we shared' and 'the 2017 new year eve celebration).

At Marketing and Consumer Behavior Group (MCB), I would like to thank all my fellow colleagues for your insightful feedbacks on my presentations. Your feedbacks helped me to sharpen my thinking and brought my work to a higher level. I would particularly single out Ivo for your unreserved support and feedback in solving my statistical problems and mysteries. Ellen thank you for being kind and supportive to facilitate my travel and other arrangements. Ynte thanks for your early morning greetings and jokes. Falylath and Lenka, thanks for being a nice officemate, and also your mentorship in my $\mathrm{PhD}$ journey. Emilia, we meet at the end of my final year, but you are so comforting and considerate, thank you for being warm and kind colleague. Connetie, Jane, Lisanne, Giulia, Robert, Milica, Eva, Kristina, Li, Naomi, and Xin, thanks for the inspiring conversations about our ambitions and $\mathrm{PhD}$ worries. Brigit, Liesbeth, Laura, and Marloes, thanks for your support and cooperation in handling all my financial issues so smoothly. Besides work related issues, my time at Wageningen were also so enjoyable because of different MCB events; day outs, drinks and chats. I am very much tankful to you, colleagues (former and new) and friends of the MCB.

My time at Wageningen was enjoyable in large part due to my country mates. I am grateful to Dawit, Mohammedamin, Yeshe, Samuel, Fasile, Adugna, Solomon, Sheferawu and Delelegne for the great time we spent together away from home. Shemeles and Tameru thank you for being a nice officemate and comforting friend, and also for the dinners and discussions about our $\mathrm{PhD}$, life, and politics. My special thanks to Tesfahune, Fre, Gorawu and Yared, you made me feel less stressful during the COVID-19 lockdown because of your companionship and inspiring discussions and walks. My special thanks also to Besher for handling my thesis submission process during the final stage of my $\mathrm{PhD}$ process and coffee break chats. At Wageningen, I thank my friend Ester, Niek, Bart, and Jacqueline for the lovely coffee breaks and lively discussions. 
In Ethiopia, Yohannes Mulu (PhD), thank you for your support and encouragement. I benefited a lot from the academic discussions we had about research in general and my $\mathrm{PhD}$ researchers. I deeply thank you for your reflections and comments on my experimental study. Melese Sitotawu, Mesele Tercha (PhD), Ketema Bekele (PhD), Jemal Seid, Fekadu Gelawu (PhD), Dereje Tirefissa, Asseged Mengistu (PhD), Wasihun Mohammed (PhD) and Genanew Ayaleneh, I am very much grateful to you for all the advice, follow-ups, and encouragements. I deeply thank you for giving me happy breaks throughout my $\mathrm{PhD}$ journey.

Finally, I would also like to acknowledge the enumerators who helped me in data collection. My special thanks go to Mr. Mohammed Dawe, thank you for your dedication and owning the job as yours. My sincere thanks also go to Dr. Getachewu Gebru and Dr Kidane Georgis, for your expertise and inputs during my case study. 


\begin{abstract}
About the Author
Desalegn Amlaku Gugissa was born on 30 August 1985 in Bahir Dar, Ethiopia. He completed his secondary education at Tana Haik comprehensive secondary schools, Bahir Dar in 2003. In the same year, he joined Addis Ababa University where he studied in Management and obtained Bachelor of Arts Degree (with great distinction) in Management and Public Administration in 2006. Shortly after graduation, he joined Haramaya University as a graduate assistant in the Department of Management. After two years as a graduate assistant, he joined Addis Ababa University and pursued his Master study in Business Administration. In the year 2010, he obtained his Master degree in Business administration (with great distinction). Then, he reinstated at Haramaya University as a lecturer at the Department of Management and worked till September 2015. Next to teaching various management, marketing and entrepreneurship courses, and supervising Bachelor thesis, he served as an Associate Dean to the College of Business and Economics and researcher in Marketing and Value Chain at PRIME (Pastoralists Resilience Improvement through Market Expansion) project. From September 2015 to March 2016, he attended Korean language training at Pai Chain University, Deajeon, South Korea as a KGSP (Korean Government Scholarship Program) fellow. In April 2016, he started his PhD study at Marketing and Consumer Behaviour Group, Wageningen University. His $\mathrm{PhD}$ aims to understand how businesses in natural resource-scarce settings adapt their value creation processes to the scarcity of resources to maintain performance and ensure sustainability. While attending his $\mathrm{PhD}$ study, he has joined Kotebe Metropolitan University as a lecturer at the Department of Management in September 2017. His research interests lie within marketing and sustainability in developing and emerging countries, with a specific emphasis on business development and natural resource management. He can be reached at desalegnamlaku@gmail.com.
\end{abstract}



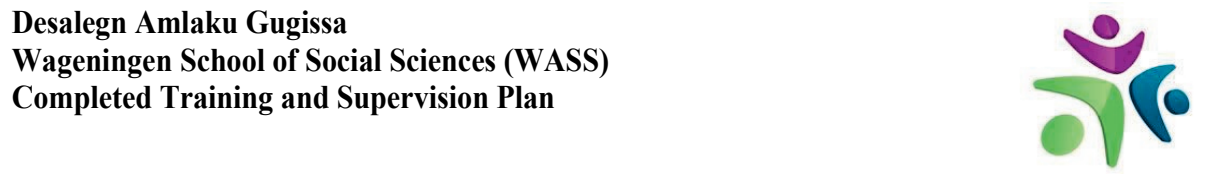

Wageningen School of Social Sciences

Name of the learning activity

A) Project related competences

Advanced statistics, MAT 20306

WUR

Year ECTS

Information literacy for $\mathrm{PhD}$ including endnote

WUR, Library

$2016 \quad 6$

introduction

Quantitative data analysis: Multivariate techniques WUR

$2018 \quad 6$

YRM60306

Writing research proposal

WUR

$2016 \quad 6$

B) General research related competences

WASS Introduction course

WASS

$2016 \quad 1$

'Market knowledge as a driver of sustainable use of common-pool natural resources'

'Market Knowledge and customer value creation using common-pool natural resources'

'How can customer value creation process be

adapted to common-pool resource constraints? A

MCB lunch club, Wageningen

2020

MCB PhD day, Rhenen

$2018 \quad 1$

case study on Ethiopian pastoralists'

Scientific Publishing

WGS

$2019 \quad 0.3$

Reviewing a Scientific Paper

WGS

$2018 \quad 0.1$

C) Career related competences/personal development

Introduction to Programming in R for social

WASS

$2020 \quad 5$

sciences

Qualitative Data Analysis with Atlas.ti: a hands-on practical

Efficient Writing Strategies

WASS

$2016 \quad 1$

Scientific Writing

Wageningen In'to Languages

$2019 \quad 1.3$

Wageningen In'to Languages

$2019 \quad 1.8$

The Essentials of Scientific Writing and Presenting

Teaching 'Entrepreneurship' and Marketing'

Wageningen In'to Languages

$2016 \quad 1.2$

Kotebe Metropolitan University,

Addis Ababa, Ethiopia

Total

*One credit according to ECTS is on average equivalent to 28 hours of study load

Abbreviations:

$\mathrm{MCB}=$ Marketing and Consumer Behaviour

WASS $=$ Wageningen School of Social Sciences

WGS = Wageningen Graduate School

WUR $=$ Wageningen University and Research Centr 

The research described in this thesis was financially supported by the Netherlands Organization for International Cooperation in Higher Education and Research (NUFFIC) through the Netherlands Fellowship Programme (NFP).

Cover design by Desalegn Amlaku Gugissa and Matias Samuel (Ms51246rr@gmail.com), Phone: +251911025648, Addis Ababa, Ethiopia

Publisher: Digiforce / Proefschriftmaken.nl, Vianen

Copyright (C) 2020 Desalegn Amlaku Gugissa 

